Portland State University

PDXScholar

Dissertations and Theses

Dissertations and Theses

Summer 7-7-2016

\title{
Frequency Multiplication in Silicon Nanowires
}

Marius Mugurel Ghita

Portland State University

Follow this and additional works at: https://pdxscholar.library.pdx.edu/open_access_etds

Part of the Nanoscience and Nanotechnology Commons Let us know how access to this document benefits you.

\section{Recommended Citation}

Ghita, Marius Mugurel, "Frequency Multiplication in Silicon Nanowires" (2016). Dissertations and Theses. Paper 3082.

https://doi.org/10.15760/etd.3077

This Dissertation is brought to you for free and open access. It has been accepted for inclusion in Dissertations and Theses by an authorized administrator of PDXScholar. Please contact us if we can make this document more accessible: pdxscholar@pdx.edu. 
Frequency Multiplication in Silicon Nanowires

by

Marius Mugurel Ghita

A dissertation submitted in partial fulfillment of the requirements for the degree of

Doctor of Philosophy

in

Applied Physics

Dissertation Committee:

Raj Solanki, Chair

James Morris

John Freeouf

Andrew Rice

Portland State University

2016 


\begin{abstract}
Frequency multiplication is an effect that arises in electronic components that exhibit a non-linear response to electromagnetic stimuli. Barriers to achieving very high frequency response from electronic devices are the device capacitance and other parasitic effects such as resistances that arise from the device geometry and are in general a function of the size of the device. In general, smaller device geometries and features lead to a faster response to electromagnetic stimuli. It was posited that the small size of the silicon nanowires (SiNWs) would lead to small device capacitance and spreading resistance, thus making the silicon nanowires useful in generating microwave and terahertz radiation by frequency multiplication. To verify this hypothesis, silicon nanowires based devices were fabricated and investigated using two experimental setups. The setups were designed to allow the investigation of the nanowire based devices at low frequencies and at high frequencies. Both setups consisted of an RF/microwave source, filters, waveguide, and a spectrum analyzer. They also allowed the characterization of the samples with a semiconductor parameter analyzer. The first step in the investigation of the SiNW devices was to install them in the waveguides and perform Current-Voltage (I-V) sweeps using the semiconductor parameter analyzer. The devices that exhibited the non-linear I-V characteristics typical of diodes were further investigated by first exposing them to $70 \mathrm{MHz}$ and $500 \mathrm{MHz}$ frequencies in the low frequency setup and then to $50 \mathrm{GHz}$ microwaves in the high frequency setup. The response of the devices was captured with a spectrum analyzer. The results
\end{abstract}


demonstrate that the non-linear effect of frequency multiplication is present in nanowire devices from DC to $100 \mathrm{GHz}$. The HF setup provides a platform that with an appropriate detector can be used to detect harmonics of the SiNWs in submillimeter/THz region of the electromagnetic spectrum. 


\section{DEDICATION}

To my wife Claudia, who encouraged and supported me on this journey.

To my daughters, Emily, Sarah, Naomi, and Hannah who know their father as working and going to school: may you always love Truth and pursue Wisdom.

To my parents, brother and sister who never stopped believing I can reach this goal. 


\section{ACKNOWLEDGMENT}

I would like to acknowledge the help and guidance of my advisor, Dr. Raj Solanki, under whose supervision this work was completed. I would also like to acknowledge the help received from Gary Goncher, PhD on the operation of the device parameter analyzer, and from Ed Godshalk, PhD for his help on RF measurements methods and waveguide design. This work was sponsored by a grant from the Army Research Laboratory obtained by Raj Solanki, Gary Goncher and Ed Godshalk. I also want to extend my gratitude to the rest of the committee overseeing my research: Drs. John Freeouf, James Morris, and Andrew Rice of Portland State University. 


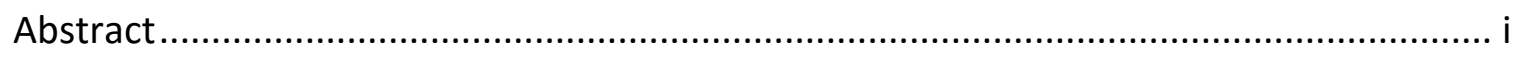

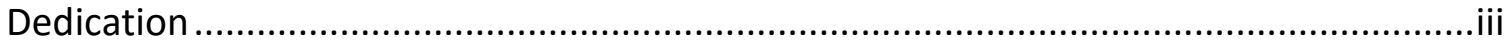

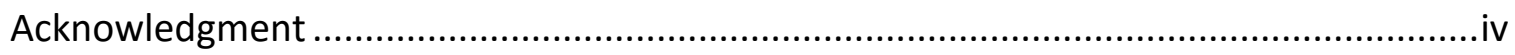

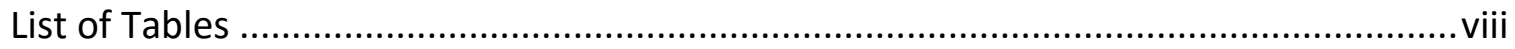

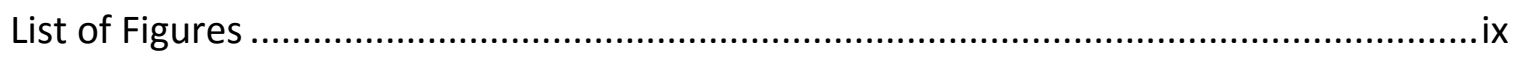

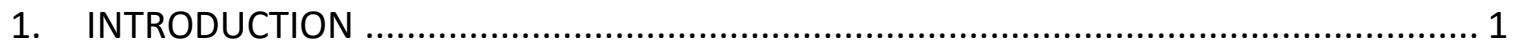

1.1 Millimeter and sub-millimeter bands ...................................................... 1

1.2 Millimeter wave applications …................................................................... 1

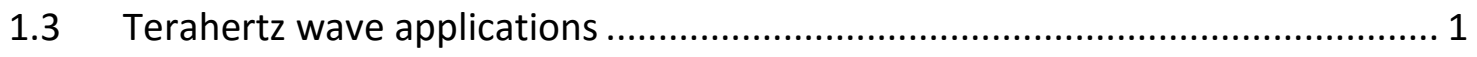

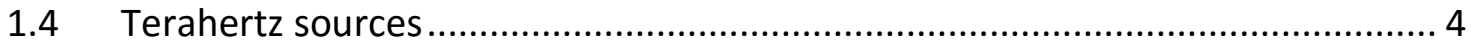

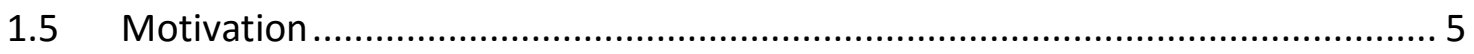

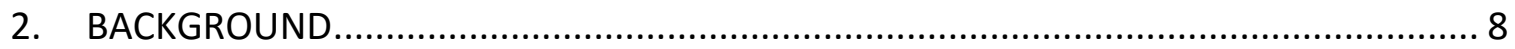

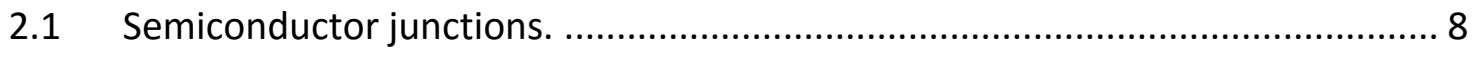

2.1.1 The semiconductor P-N junction ......................................................... 8

2.1.2 The Metal-Semiconductor (Schottky) junction...................................... 19

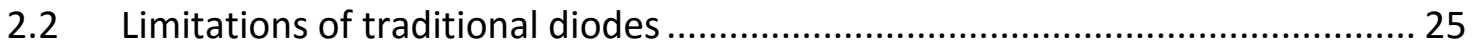

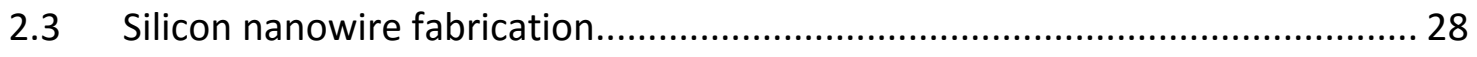

2.4 Frequency multiplication using semiconductor devices ................................ 30

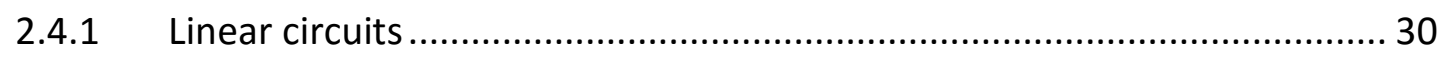

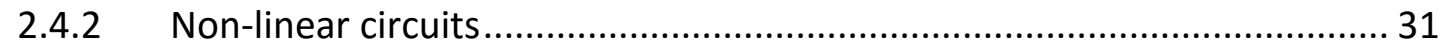

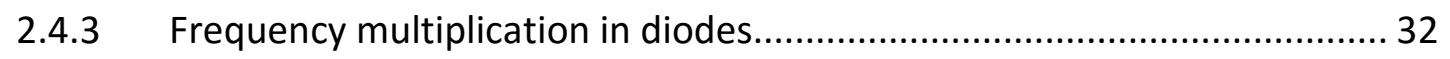

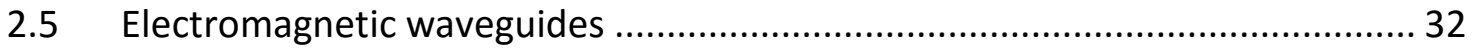

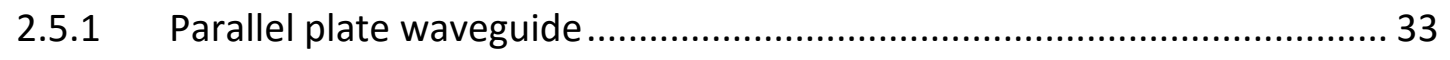

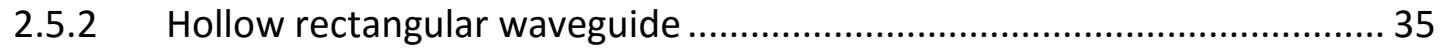

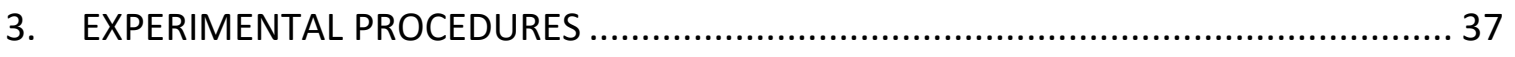

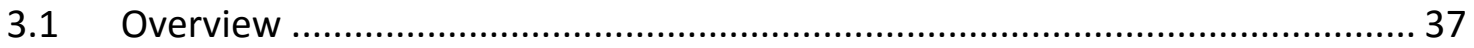

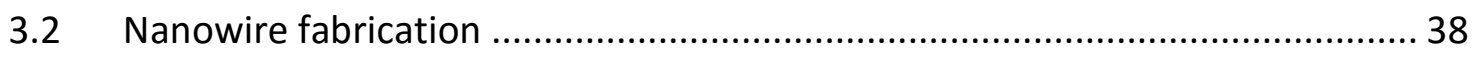




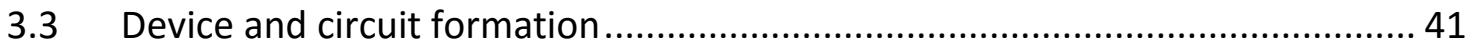

3.4 DC device characterization of silicon nanowire diodes ................................. 42

3.5 Low frequency characterization of silicon nanowire diodes .......................... 43

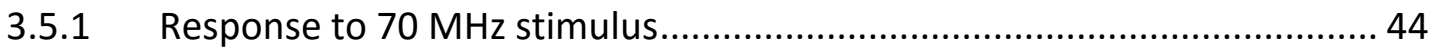

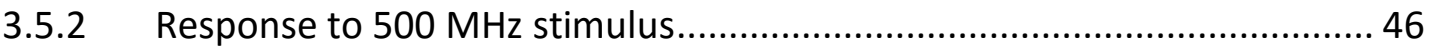

3.6 Millimeter and sub-millimeter band characterization of silicon nanowire diodes 47

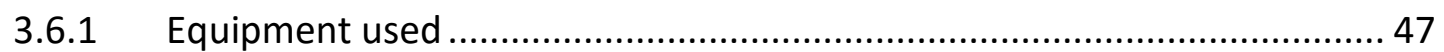

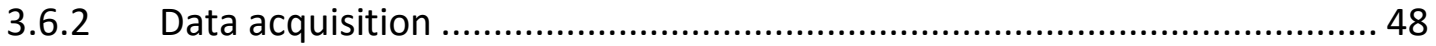

3.6.3 Microwave waveguide considerations ............................................... 49

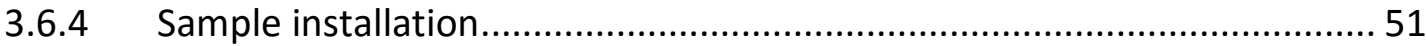

3.6.5 Harmonic search procedure ............................................................. 52

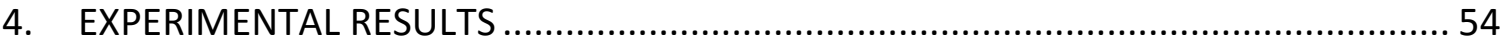

4.1 Low frequency characterization results ..................................................... 54

4.1.1 Response to $70 \mathrm{MHz}$ fundamental ...................................................... 54

4.1.2 Response to $500 \mathrm{MHz}$ fundamental .................................................... 56

4.2 Millimeter and sub-millimeter band characterization results ........................ 58

4.2.1 Sample $130(n)$ and $148(n)$ in the Microwave Waveguide probed with

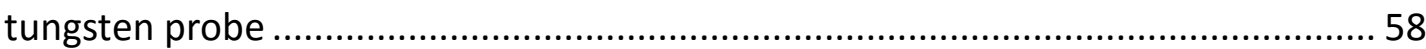

4.2.2 Sample $152(n+/ p+)$ in the Microwave Waveguide probed with tungsten probe 61

4.2.3 Sample $136(\mathrm{np}+)$ in the Microwave Waveguide probed with tungsten probe 63

4.2.4 Sample 133(n), $136(n p+), 152(n+p+)$ in the Microwave Waveguide probed with silver paint bonded copper wire 64

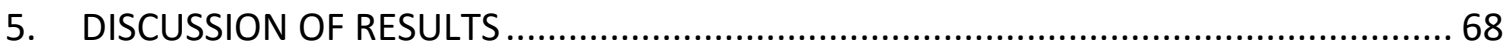

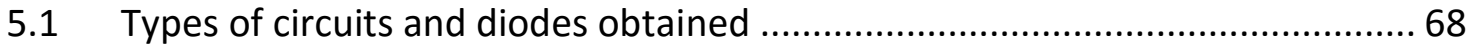

5.2 Device parameter calculations for the P-N junctions obtained........................ 70

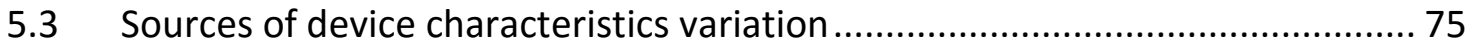


5.3.1 Variations in the current magnitude of the I-V measurements ................. 75

5.3.2 Variations in forward and reverse voltage for devices obtained from the same substrate

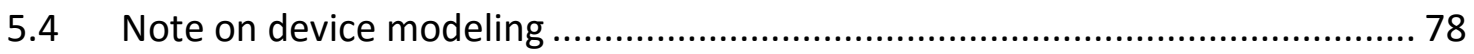

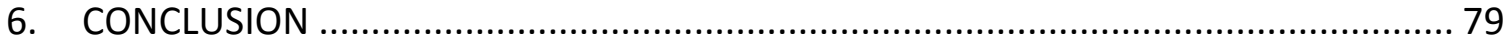

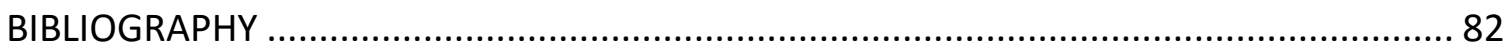

Appendix A. Commercial diode Parameters and calculated cut-off frequencies ....... 88

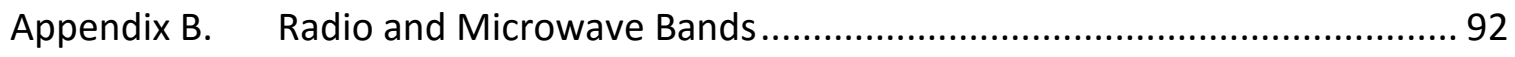

Appendix C. Standard sizes of rectangular waveguide .......................................... 93

Appendix D. Low Frequency Waveguide attenuation ............................................ 96

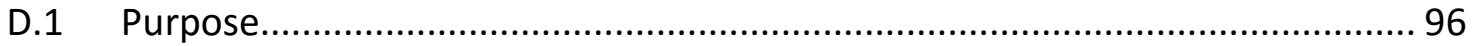

D.2 Estimation of waveguide characteristics ................................................ 96

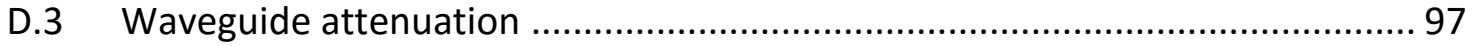

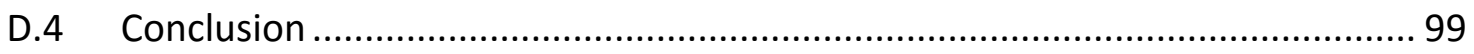

Appendix E. Modeling: Device Parameter Estimation and SPICE Simulation Effects of

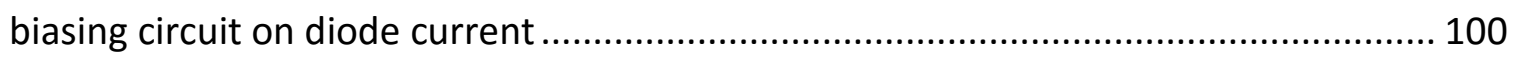

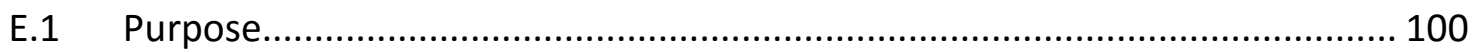

E.2 Voltage Potential Inside the microwave waveguide................................... 100

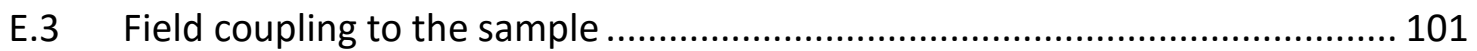

E.4 Model parameters for probe and wires................................................. 102

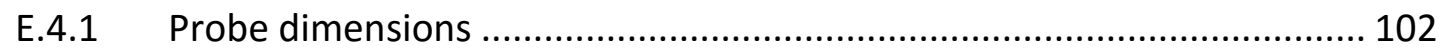

E.4.2 Circuit component parameters............................................................ 104

E.5 Investigation of the effects of circuit inductance through SPICE simulations . 104

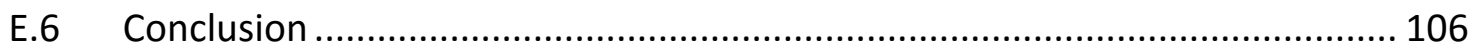

E.7 Device parameter calculators details ........................................................ 107

E.7.1 Self-Capacitance Calculator for solid cylinder .................................... 107

E.7.2 Self-Inductance calculator ................................................................. 107

Appendix F. Data Acquisition Program Source Code ........................................ 109 


\section{LIST OF TABLES}

Table 2-1. Experimental values of Metal-n-type-semiconductor barrier heights (eV) .... 15

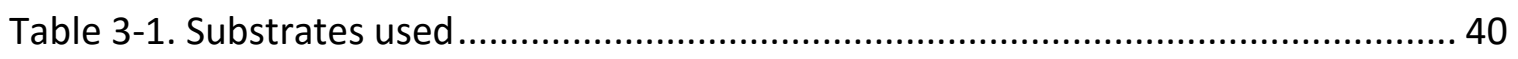

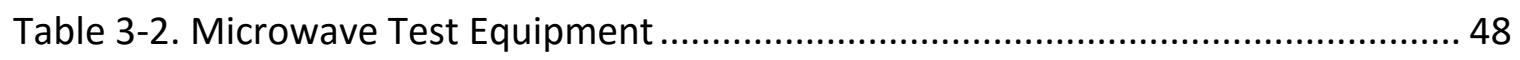

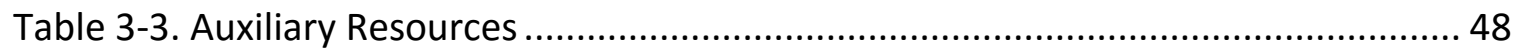

Table 4-1. Sample $130(\mathrm{n})$ and 148 (n) first harmonic search results.............................60

Table 4-2. Sample $152(n+p+)$ first harmonic response at $50 \mathrm{GHz}$ incident signal.......... 62

Table 4-3. Sample $136(\mathrm{np}+)$ first harmonic response at $50 \mathrm{GHz}$ incident signal............. 64

Table 4-4. First harmonic search result for silver paint bonded probe wire .................... 66

Table 5-1. Types of nanowire diode circuits obtained ............................................... 70

Table 5-2. Characteristics of the P-N junctions obtained ........................................... 71

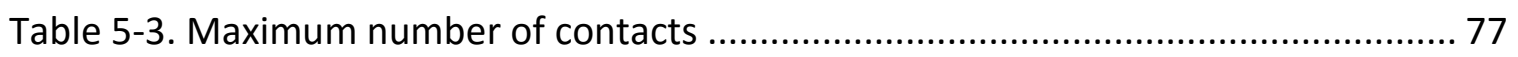




\section{LIST OF FIGURES}

Figure 1-1. THz fingerprints of explosives and clothing materials [6] ............................ 2

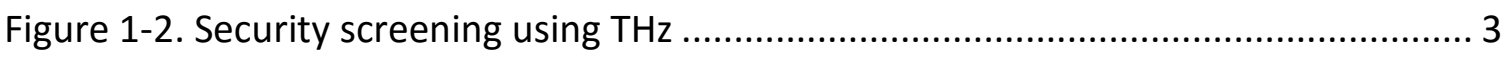

Figure 1-3. Surface and depth imaging in medical diagnosis ...................................... 3

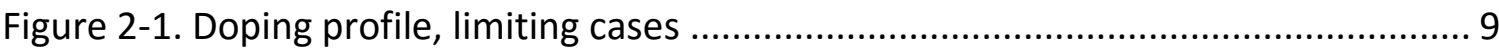

Figure 2-2. Breakdown Voltage, abrupt junctions [30] ................................................. 12

Figure 2-3. Breakdown Voltage, linearly graded junctions [30] ................................... 12

Figure 2-4. I-V characteristics of alloyed P-N junctions. The reverse voltage breakdown magnitude decreases with decreasing resistivity..................................................... 13

Figure 2-5. Metal-Semiconductor Contact Resistance ............................................ 15

Figure 2-6. Geometries for spreading resistance. (a) Disk over ground plane. (b) Disk over corresponding disk....................................................................................... 16

Figure 2-7. Metal Semiconductor interface with surface states (after [28]).................. 22

Figure 2-8. Effects of surface oxidation. Forward voltage increases with oxide thickness.

Figure 2-9. I-V curve for anti-parallel diodes (blue, solid) and single diode (green, dash) 24

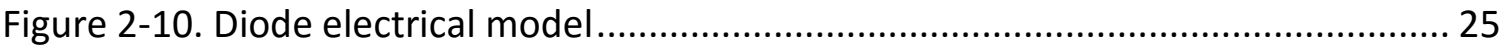

Figure 2-11. Cutoff frequency vs device radius $\mathrm{P}-\mathrm{N}$ junctions, $\mathrm{N}_{\mathrm{a}}>>\mathrm{N}_{\mathrm{d}} \ldots \ldots \ldots \ldots \ldots \ldots \ldots . . . . . . . . . . . .26$

Figure 2-12. Cutoff frequency vs contact radius Schottky Junctions ............................ 26

Figure 2-13. Device characteristics - cut-off frequency and junction capacitance.......... 27

Figure 2-14. Device characteristics - cutoff frequency (computed from published data

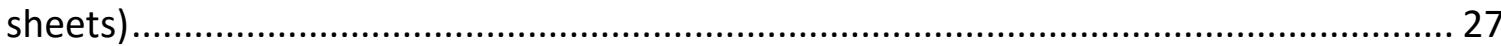

Figure 2-15. Energy band gap dependence on silicon nanowire diameter ................... 28

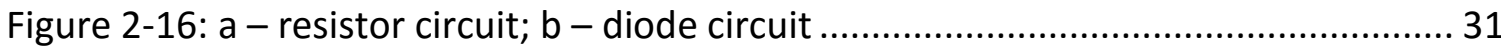

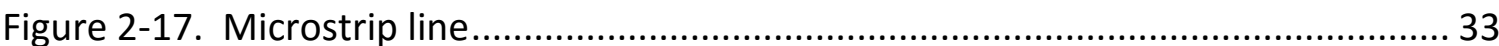

Figure 3-1. Silicon nanowires obtained by electroless etch method. Top row and lower left: progressively higher magnification of a sample; lower right: SEM image of a

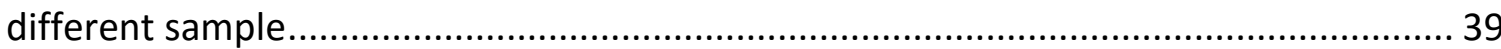

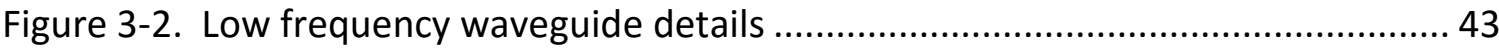

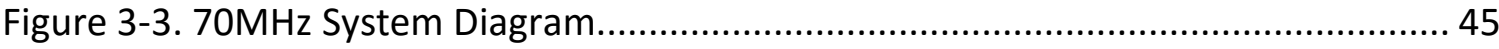

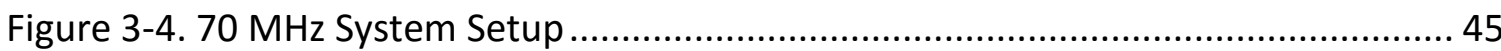

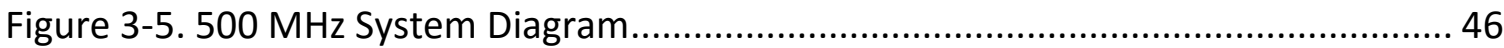

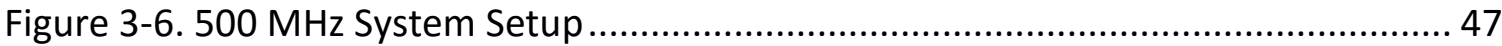

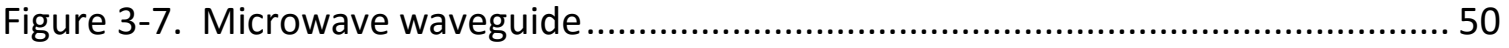


Figure 3-8. Typical Microwave Experiment Setup. Left: without low pass filter. Right:

with low pass filter.

Figure 4-1. Spectrum Analyzer trace capture. $0=$ attenuated excitation signal/fundamental, 1-8=harmonics of the fundamental generated inside sample; b, $c$,

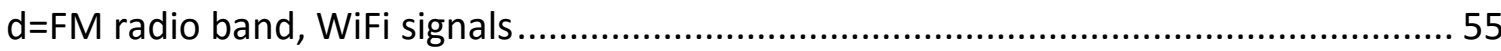

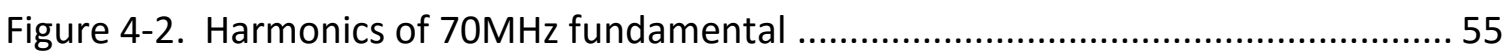

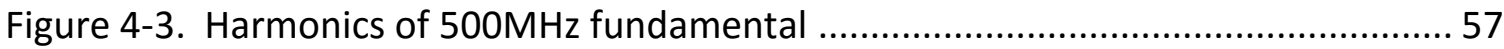

Figure 4-4. I-V response for samples probed in the high frequency waveguide............... 59 Figure 4-5. I-V response for sample $152(n+p+)$ probed in the high frequency waveguide 61

Figure 4-6. Sample136 (np+), probe contact in the high frequency waveguide. .............63

Figure 4-7. I-V curves for devices made by bonding wire to sample using silver paint ... 65

Figure 5-1. Structure of circuits obtained by probing silicon nanowire samples ............ 68

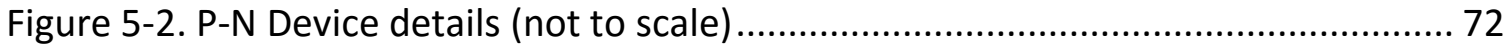

Figure 5-3. Sample $152(n+/ p+)$, Ag paint bonded probe wire, corrected for $R_{||} \ldots \ldots \ldots . . .73$

Figure 5-4. Sample 136 (n/p+), Ag paint bonded probe wire, corrected for $R_{\|} \ldots \ldots \ldots \ldots . . .74$ 


\section{INTRODUCTION}

\subsection{Millimeter and sub-millimeter bands}

The microwave band is generally considered to span the frequencies between $1 \mathrm{GHz}$ and $300 \mathrm{GHz}$. Research in this area was spurred by applications in telecommunications and defense. A list of radio frequency bands is presented in Appendix B. Spanning the frequencies between $300 \mathrm{GHz}$ and $10 \mathrm{THz}$ between the microwave and the infrared (IR) regions of the electromagnetic spectrum, lies a band known as the submillimeter or terahertz $(\mathrm{THz})$ wave band. The wavelengths corresponding to this band are between $1 \mathrm{~mm}$ and $30 \mu \mathrm{m}$, with photon energies between $1.25 \mathrm{meV}$ and $37.5 \mathrm{meV}$.

\subsection{Millimeter wave applications}

A large number of defense applications use radiation in the millimeter band. The world's first crosslink between satellites involving Milstar 1 and Milstar 2 used $60 \mathrm{GHz}$ frequencies in the $V$ band [1] . The $\mathrm{W}$ band is used for space communication (71-76 $\mathrm{GHz})$, automobile radar $(77 \mathrm{GHz})$, atmospheric radar $(94 \mathrm{GHz})$, and active denial systems (95 GHz) to name a few [2].

\subsection{Terahertz wave applications}

Many materials have properties that allow spectroscopic analysis and imaging in the $\mathrm{THz}$ region of the electromagnetic spectrum. This led to wide ranging research in spectroscopy, imaging, remote sensing and telecommunications with applications in chemistry, medical and pharmaceutical fields, pollution control, security, and radio astronomy. 
One example of using $\mathrm{THz}$ spectroscopy is in identifying concealed explosives. The lack of sharp spectral features in the materials used for clothing allows for identification of explosives obstructed from view by clothing, since explosives have easily identifiable peaks in the $\mathrm{THz}$ range. The graph in Figure 1-1 gives an example of explosive and common clothing material signatures that can be used to distinguish concealed explosives. It was also reported that $\mathrm{THz}$ radiation interacts with DNA and RNA molecules which opened up avenues of research in biology $[3,4,5][3-5]$. THz radiation is also used to identify different crystalline forms of pharmaceutical molecules (polymorphs), with implications in the study of drug absorbance.

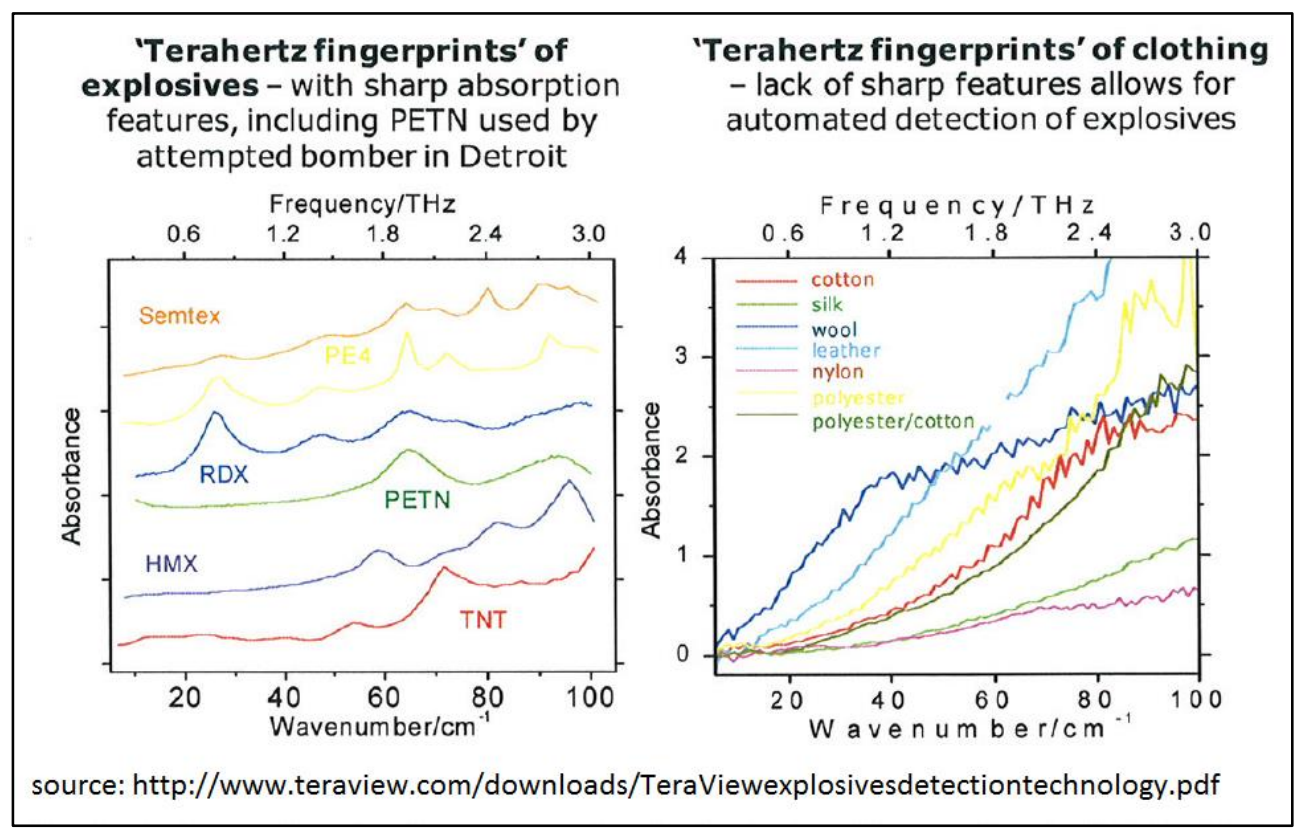

Figure 1-1. THz fingerprints of explosives and clothing materials [6]

THz imaging also has applications in security screening (Figure 1-2) and medical diagnosis (Figure 1-3). Chosen appropriately, $\mathrm{THz}$ radiation can penetrate a short distance under the skin or in teeth and provide tissue structural information. 


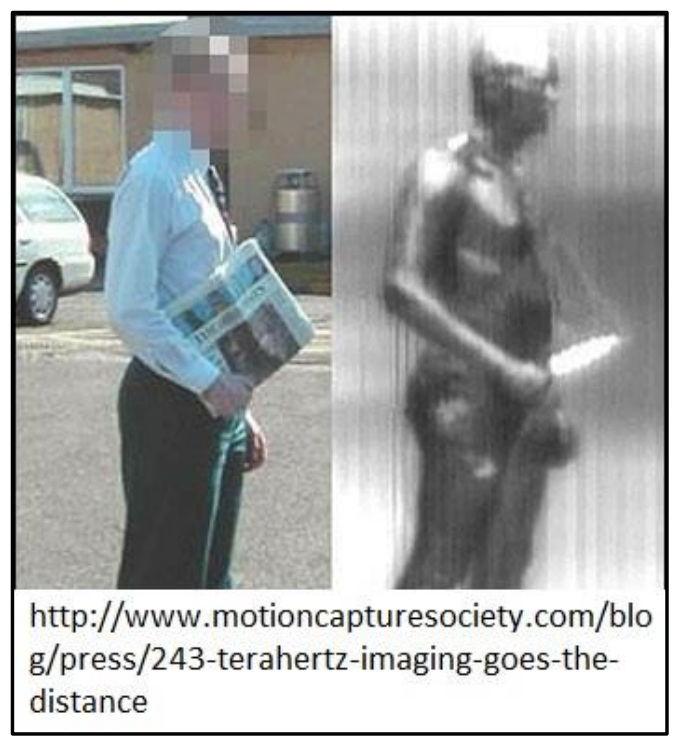

Figure 1-2. Security screening using $\mathrm{THz}$

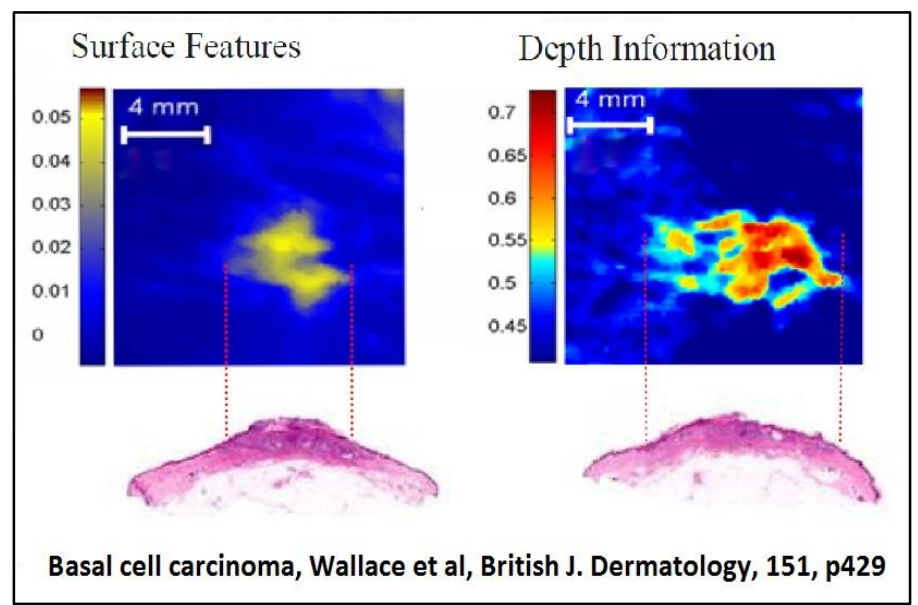

Figure 1-3. Surface and depth imaging in medical diagnosis

The specific interaction of $\mathrm{THz}$ radiation with water, aerosols and various pollutants found in the atmosphere helps in atmospheric research. Absorption of $\mathrm{THz}$ radiation by water can also be an advantage in secure communications, limiting the range of a signal and thus the possibility of it being intercepted. 


\section{$1.4 \quad$ Terahertz sources}

Microwave research and applications rely on high speed electronics, transmission lines and waveguides developed traditionally from an electrical engineering perspective. IR research and applications on the other hand are based on optics. Situated between the two regions, the $\mathrm{THz}$ band was approached with tools developed either for microwaves (electrical) or IR (optical). One of the most difficult aspects of investigating the terahertz region of the spectrum is the unavailability of inexpensive and portable radiation sources. It is difficult to fabricate devices that work above few hundred $\mathrm{GHz}$ due to short carrier transit times needed when approaching the $\mathrm{THz}$ region with microwave tools. Also, the small active areas required to minimize device capacitance which causes a high-frequency roll-off of output power are hard to manufacture. Approaching the $\mathrm{THz}$ band from the optical region is hindered by the unavailability of narrow bandgap semiconductors which would allow radiative recombination of conduction band electrons with valence band holes. The bandgap energy required has to be on the order of a few meV which is comparable with the room temperature energy of lattice phonons. Cryogenic cooling can mitigate this problem to a certain extend but it increases the cost.

One of the first sources of THz radiation was the O-Type Backward Wave Oscillator which was patented in 1952 by Rudolf Kompfner. Initially covering the millimeter bands, its range was extended beyond $1 \mathrm{THz}$ [7]. This device is used as an illumination 
source for security imaging applications due to the power produced ( $1 \mathrm{~mW}$ at $1 \mathrm{THz}$ and $50 \mathrm{~mW}$ at $200 \mathrm{GHz}$ ) and the quality of the wavefront.

Molecular gas lasers can also be made to output $\mathrm{THz}$ radiation, although their size is large and the process is not efficient $[8,9]$. Generation of microwatt levels of narrowband $\mathrm{THz}$ radiation was also demonstrated using optical mixing in non-linear crystals [10], photomixing [11], and in resonant tunneling diodes (RTDs) [12]. Optically stimulated generation of $\mathrm{THz}$ radiation was also demonstrated by focusing femtosecond Ti:sapphire laser pulses on thin slabs of II-VI and III-V semiconductors like GaP, GaSe, InTe, InN, ZnTe and $\mathrm{ZnGeP}_{2}[13,14,15,16,17,18,19][13-19]$.

Recent work by other researchers (i.e. $[20,21]$ ) demonstrated that optically pumped silicon nanowires can emit radiation in the $\mathrm{THz}$ region of the spectrum.

The most common method of obtaining continuous submillimeter/THz radiation at the present time is by frequency multiplication using Schottky diodes. Some of the work in this field was reported in [22, 23, 24][22-24]. Hesler et al. [24] for example describe an approach where the signal from a standard low frequency synthesizer $(<25 \mathrm{GHz})$ feeds a doubler/amp, which in turn provides the signal for a signal quadrupler which feeds two cascaded frequency triplers. The frequency multipliers used in this $x 72$ multiplier chain are Schottky diodes made from epitaxially grown GaAs on quartz.

\subsection{Motivation}

This research was undertaken to investigate the use of Silicon nanowires for generating millimeter and sub-millimeter electromagnetic radiation by means of frequency 
multiplication. Frequency multiplication is an effect that arises in electronic components that exhibit a non-linear response to electrical signals and electromagnetic stimulus. Barriers to achieving very high frequency response from electronic devices are the device capacitance and other parasitic effects, including contact resistance that arise from the device geometry. These parameters are in general a function of the size of the device, so that smaller device geometry and features lead to a faster response to electromagnetic stimuli. It was posited that the small size of the silicon nanowires would lead to small device capacitance, thus making the silicon nanowires useful in generating terahertz radiation. This research demonstrated the nonlinear behavior of nanowires at progressively higher frequencies. The response of nanowires to $70 \mathrm{MHz}$, $500 \mathrm{MHz}$, and $50 \mathrm{GHz}$ was investigated in order to demonstrate an approach that could lead to the production of harmonics in the terahertz band.

This research draws upon topics from two main fields: (1) semiconductor device physics and (2) radio frequency/microwave engineering. The material covered in Chapter 2 contains the necessary background to understand (1) the semiconductor phenomena that lead to the effects investigated, (2) the sample preparation method, and (3) the experimental methods used to perform the investigation. Chapter 3 describes the experimental procedure, beginning with the device fabrication, and continuing with the procedures which led to the characterization of the non-linear behavior of the nanowires starting from $D C$ up to $100 \mathrm{GHz}$. The experimental results are presented in 
Chapter 4, and a discussion of the results in Chapter 5. The final conclusions are presented in Chapter 6. 


\section{BACKGROUND}

\subsection{Semiconductor junctions.}

While the photonic and conductive properties of uniformly doped semiconductors maybe used in some applications (ex. Photoelectric effect for light detection), the junctions between semiconductors with different doping levels and between semiconductors and metals have proved to be extremely useful in developing electronic components. The non-linear effects investigated in this work arise from the properties of the P-N junctions and of the Metal-Semiconductor (MS) junctions. However, while the non-linear behavior of the junction makes the frequency multiplication effect possible, the resistance and capacitance of the junctions limit their frequency of operation. A basic review of the properties most relevant to the operation of the devices used in this research is presented in this chapter.

\subsubsection{The semiconductor P-N junction}

The basics of the current-voltage characteristics of a P-N junction were established mid last century by Shockley [25], Sah, Noyce and Shockley [26], and Moll [27], as noted in reference [28]. The electrical behavior of the $\mathrm{P}-\mathrm{N}$ junction depends on its physical characteristics, which in turn arise from the manufacturing methods employed to produce it. Some of the methods by which P-N junctions are created are: alloyed junction, diffused mesa junction, diffuse planar junction on epitaxial substrate, and ion implantation [28]. These methods can be used to produce junctions with various doping 
profiles. Most of the doping profiles however can be approximated by two cases:

linearly graded junction and the abrupt junction shown in Figure 2-1.

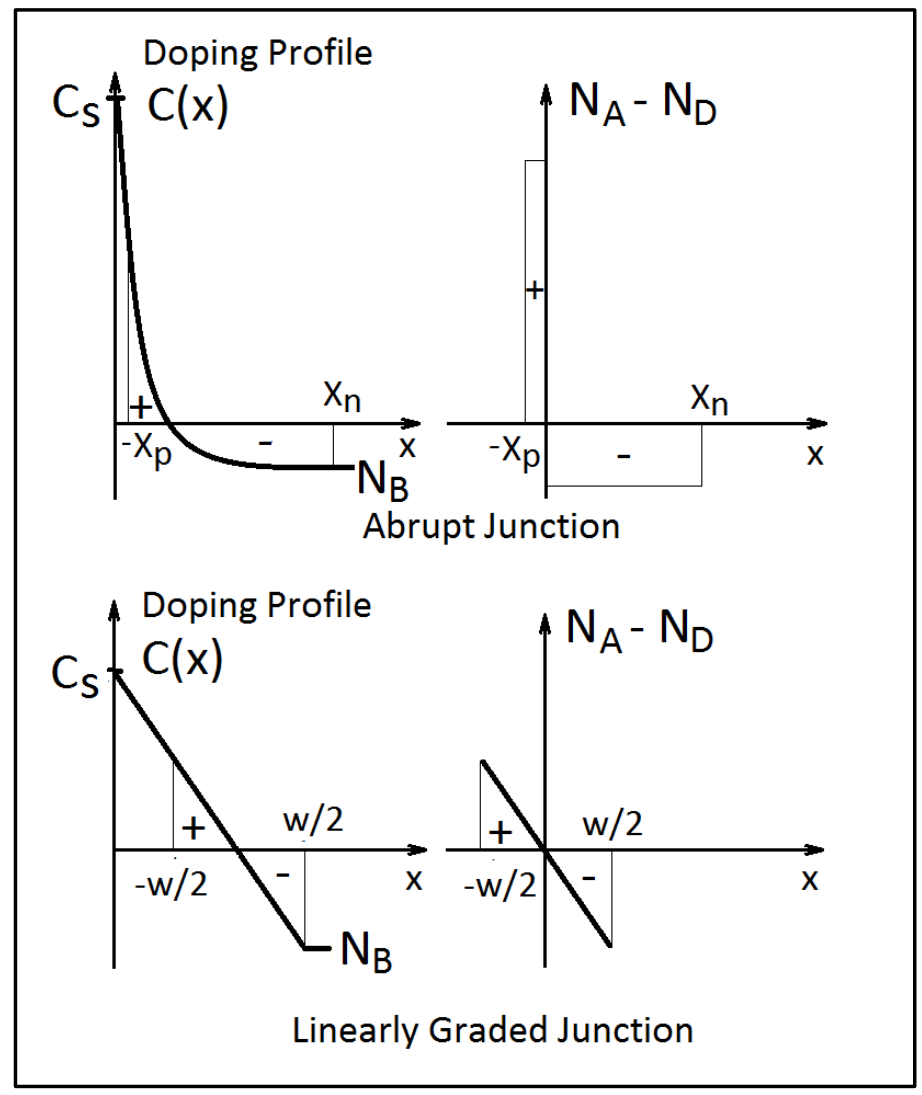

Figure 2-1. Doping profile, limiting cases

$C_{S}$ is the dopant concentration at the surface of the wafer, $N_{B}$ is the wafer background dopant concentration. The region where the number of donor atoms and number of acceptor atoms is equal is called metallurgical junction. Around this region, electrons from the $\mathrm{n}$ side of the junction diffuse into the $\mathrm{p}$ side region, leaving behind a volume of fixed positive charge. Similarly, on the $p$-side, the holes diffuse to the $n$-side and leave behind a volume of fixed negative charge. This charge separation around the metallurgical junction leads to a built-in potential, $\mathrm{V}_{\mathrm{bi}}$. To simplify the electrostatic 
analysis of the junction, the depletion approximation is employed. This approximation has two components: (1) the carrier concentration is much smaller than the net doping concentration in a region $-x_{p} \leq x \leq x_{n}$, and (2) charge density outside the depletion region is assumed to be zero. The total width of the depletion region is defined as $W \equiv x_{p}+x_{n}$

\subsubsection{Diode equation for the P-N junction}

Solving the diffusion equation for minority carriers and using the depletion approximation, the ideal diode equation can be obtained [29]:

$$
\begin{gathered}
\mathrm{I}=I_{0}\left(e^{\frac{q V_{A}}{k T}}-1\right) \\
\mathrm{I}_{0}=q A\left(\frac{D_{N}}{L_{N}} \frac{n_{i}^{2}}{N_{A}}+\frac{D_{P}}{L_{P}} \frac{n_{i}^{2}}{N_{D}}\right)
\end{gathered}
$$

where $V_{A}=$ applied voltage, $D_{N}=$ electron diffusion coefficient $\left[\mathrm{cm}^{2} / \mathrm{s}\right], L_{N}=$ electron diffusion length, $\mathrm{N}_{\mathrm{A}}=$ total number of acceptors $\left[/ \mathrm{cm}^{3}\right], \mathrm{D}_{\mathrm{P}}=$ hole diffusion coefficient $\left[\mathrm{cm}^{2} / \mathrm{s}\right], L_{p}=$ hole diffusion length, $N_{D}=$ total number of donors $\left[/ \mathrm{cm}^{3}\right]$, and $n_{i}=$ intrinsic carrier concentration given by:

$$
\begin{gathered}
n_{i}=\sqrt{N_{C} N_{V}} e^{-E_{G} / 2 k T} \\
\text { where } N_{C}=2\left[\frac{m_{n}^{*} k T}{2 \pi \hbar^{2}}\right]^{3 / 2} \text { and } N_{V}=2\left[\frac{m_{p}^{*} k T}{2 \pi \hbar^{2}}\right]^{3 / 2}
\end{gathered}
$$

$N_{C}, N_{V}=$ effective density of states in the conduction and valence bands, $E_{G}=$ band gap energy, $m_{n}{ }^{*}$ and $m_{p}{ }^{*}=$ electron and hole effective masses. 
It is observed however that in real devices the I-V relationship of (2.1) is not found. Instead avalanching and tunneling (Zener) effects are manifested if the reverse bias voltage is increased, and a recombination-generation (R-G) current is also superimposed in both forward and reverse bias cases.

For forward bias voltage larger than a few $\mathrm{mV}$ diodes can be modeled using (2.3) below:

$$
I=I_{01} e^{q V_{A} / n_{1} k T}+I_{02} e^{q V_{A} / n_{2} k T}
$$

where the first term on the RHS is due to diffusion, and the second term is due to the RG. By adjusting the parameters of (2.3), this equation can be used to model a variety of diode types (i.e. PN, PIN, Schottky, etc.).

\subsubsection{Breakdown Voltage}

When a diode is reverse biased to a large enough voltage, the $\mathrm{P}-\mathrm{N}$ junction will start to conduct current. There are two phenomena that contribute to the reverse voltage:

\section{Avalanche Breakdown}

This typically occurs when the reverse voltage is larger in magnitude than $6 \mathrm{E}_{g} / q$ [29]. In this case, the energy imparted to the semiconductor lattice by an electron accelerated by the external electric field is large enough to ionize the semiconductor atoms. The newly dislodged electrons are in turn accelerated to high energy, causing a cascade or avalanche effect $[29,30]$. Figure 2-2 and Figure 2-3 show the relationship between avalanche breakdown voltage and doping level for several semiconductors: 


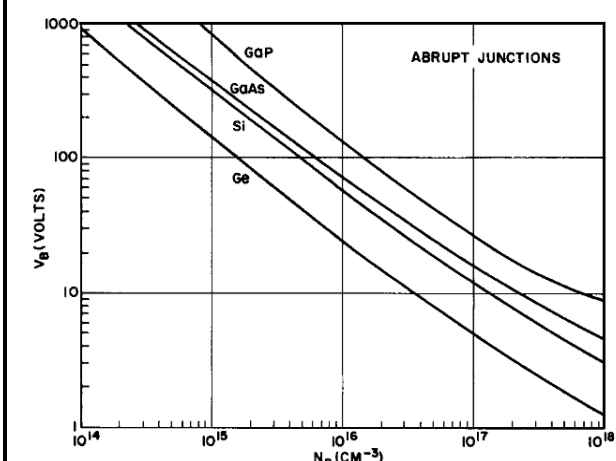

Sze \& Gibbons, 1966, Appl. Phys. Lett.

Fig. 1. Breakdown voltages vs background doping for abrupt $p-n$ junctions in $\mathrm{Ge}, \mathrm{Si}, \mathrm{GaAs}$, and $\mathrm{GaP}$.

Figure 2-2. Breakdown Voltage, abrupt junctions [30]

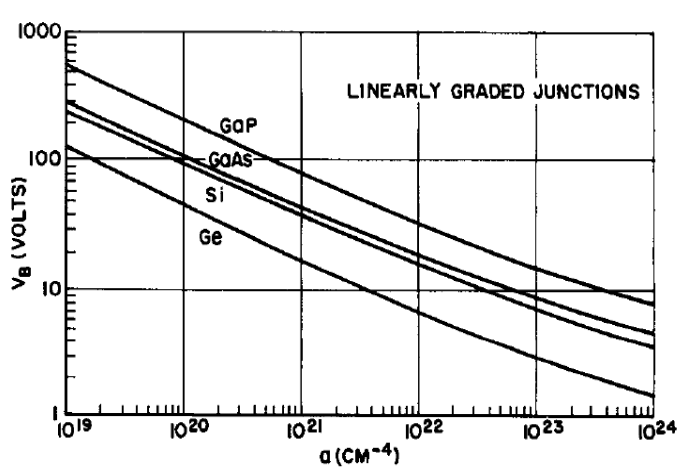

Sze \& Gibbons, 1966, Appl. Phys. Lett

Fig. 2. Breakdown voltage vs impurity gradient for linearly graded $p$-n junctions in $\mathrm{Ge}, \mathrm{Si}, \mathrm{GaAs}$, and $\mathrm{GaP}$.

Figure 2-3. Breakdown Voltage, linearly graded junctions [30]

\section{Zener Effect}

For narrow junctions, (typically less than $10^{-6} \mathrm{~cm}$ ) and for voltages smaller in magnitude than approximately $6 E_{g} / q$ of reverse bias [29], the current flows due to tunneling or field emission. This phenomenon is known as the Zener effect. The silicon band gap at room temperature is about $1.12 \mathrm{eV}$, giving a threshold between avalanche and Zener effect of about $6 \times 1.12 \mathrm{eV} / \mathrm{q}=6.72 \mathrm{~V}$. Compared to the avalanche breakdown, the increase in current due to the Zener effect is "softer" [29]. Early work investigating the Zener effect can be found in [31, 32]. Figure 2-4 from [32] reproduced below shows the general trend of decreasing breakdown voltage magnitude with decreasing resistivity/increasing doping concentration. 


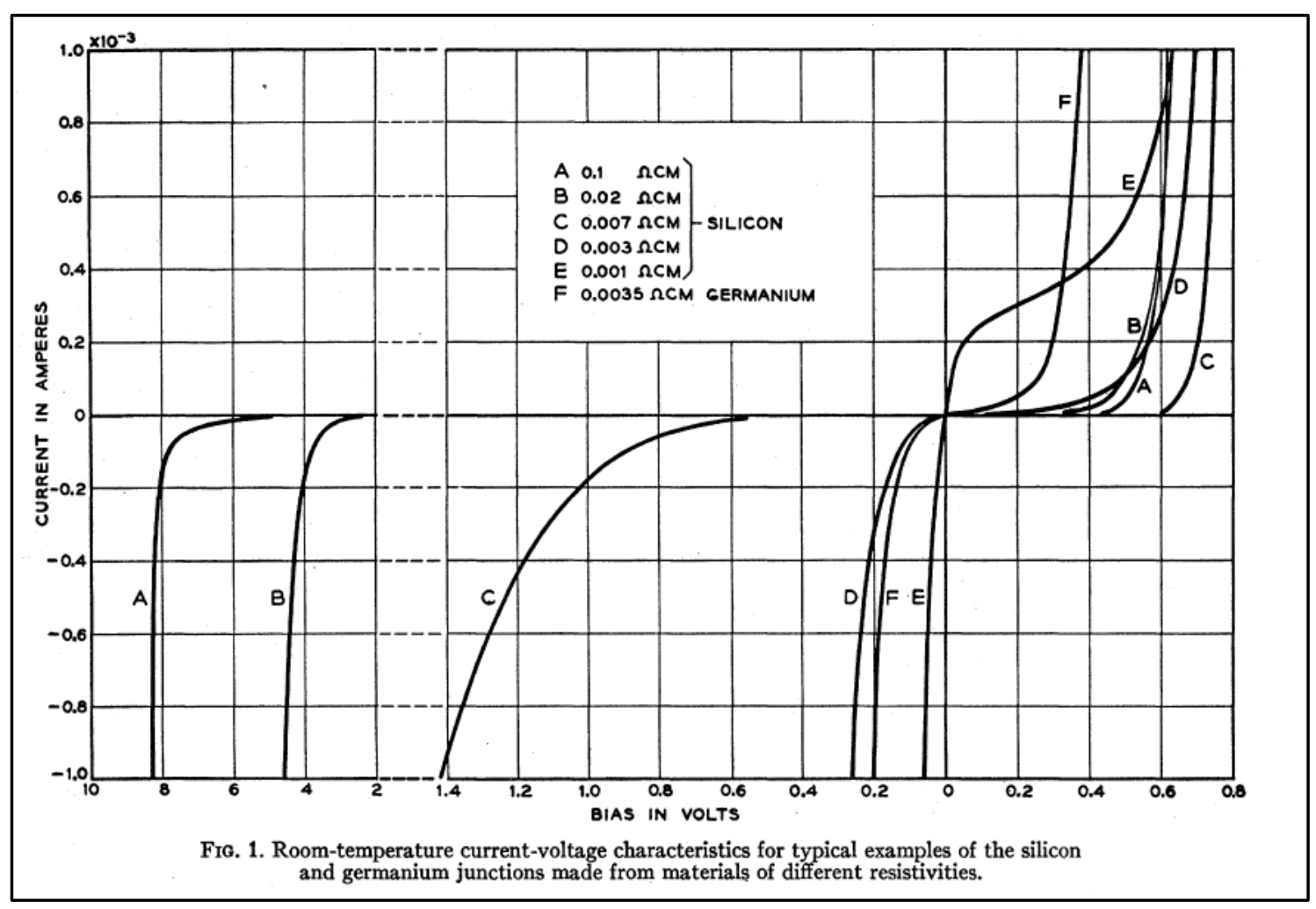

Figure 2-4. I-V characteristics of alloyed P-N junctions. The reverse voltage breakdown magnitude decreases with decreasing resistivity.

\subsubsection{Series Resistance of the P-N junction}

Besides the non-linear effects mentioned above, one must also account for the resistance of the contacts, the resistance of the quasi-neutral regions, and the spreading resistance.

\section{Contact Resistance}

The connection between the P-N junction and any external circuit where the device may be used is typically accomplished through metal contacts. In order for this contact to be non-rectifying, the semiconductor contacting the metal must be heavily doped. In such cases, the electrons can easily move between the metal and semiconductor via 
tunneling, and the contact is called an ohmic contact. Experimental and theoretical data on ohmic contacts can be found in literature. Two such examples are [33] and [34]. The contact resistance is defined as

$$
R_{C} \equiv\left(\frac{d V}{d J}\right)_{V \rightarrow 0}
$$

where $\mathrm{J}$ is the current through the contact.

For a contact to low doped silicon the contact resistance is given in (2.5) and for higher doped $\mathrm{Si}$ is given in (2.6):

$$
\begin{gathered}
\mathrm{R}_{C}=\frac{k}{q \cdot \mathcal{A} * \cdot T} e^{\frac{q \phi_{B n}}{k T}} \\
\mathrm{R}_{C} \sim e^{\frac{2 \sqrt{\epsilon_{S} \cdot m *}}{\hbar}}\left(\frac{\phi_{B n}}{\sqrt{N_{D}}}\right)
\end{gathered}
$$

Where $\phi_{\mathrm{Bn}}$ is the potential barrier between the metal and semiconductor and $\mathcal{A} *$ is the effective Richardson constant. The dependence of the contact resistance on the donor density found in [34] is reproduced in the figure below: 


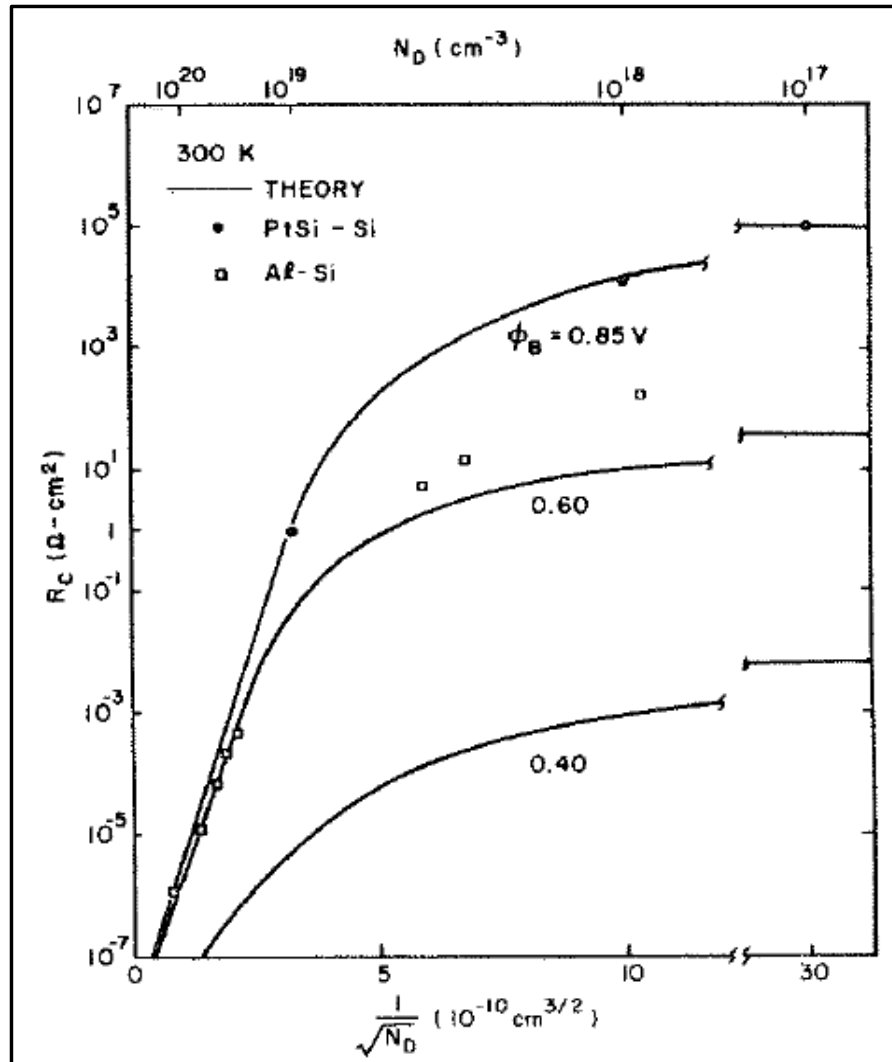

Theoretical and experimental values of specific contact resistance. (After Fang, and Sze, Ref. 67; Yu, Reł. 68.)

From Sze, Physics of Semiconductor Devices, Second Edition, page 305

Figure 2-5. Metal-Semiconductor Contact Resistance

A list of barrier heights of the metal to n-type semiconductor interfaces taken from [35]

is reproduced in Table 2-1 below:

Table 2-1. Experimental values of Metal-n-type-semiconductor barrier heights (eV)

\begin{tabular}{|c|c|c|c|c|c|}
\hline Metal & $\mathrm{Si}$ & $\mathrm{GaP}$ & $\mathrm{GaAs}$ & $\mathrm{CdS}$ & $\mathrm{Ge}$ \\
\hline $\mathrm{Au}$ & 0.81 & 1.28 & 0.90 & 0.78 & 0.45 \\
\hline $\mathrm{Ag}$ & 0.69 & 1.20 & 0.88 & 0.56 & - \\
\hline $\mathrm{Al}$ & 0.67 & 1.05 & 0.80 & - & 0.48 \\
\hline $\mathrm{Cu}$ & 0.71 & 1.20 & 0.82 & 0.36 & - \\
\hline $\mathrm{Pt}$ & 0.85 & 1.45 & 0.86 & 0.85 & - \\
\hline $\mathrm{Ni}$ & 0.66 & - & - & - & - \\
\hline $\mathrm{W}$ & 0.69 & - & 0.80 & - & 0.50 \\
\hline
\end{tabular}


From Figure 2-5 and Table 2-1, the contact resistance of the tungsten- silicon contact is estimated to be close to that of aluminum - silicon, and fall between the lines for Pt and Al. Using equation (2.5), the contact resistance of Tungsten on $n$-Silicon for low $N_{D}$ case is computed to be $415.7 \Omega-\mathrm{cm}^{2}$.

\section{Spreading Resistance}

The spreading resistance can arise in different regions of the diode, depending on the device design. The effects of the quasi-neutral region geometry on the resistance was studied theoretically by [36, 37]. Brooks and Mattes [37], give analytical forms for the spreading resistance for two cases: (1) spreading resistance between a disk and a ground plane (Figure 2-6 (a), (2.7)) and (2) spreading resistance between two parallel disks (Figure 2-6 (b), (2.8)).

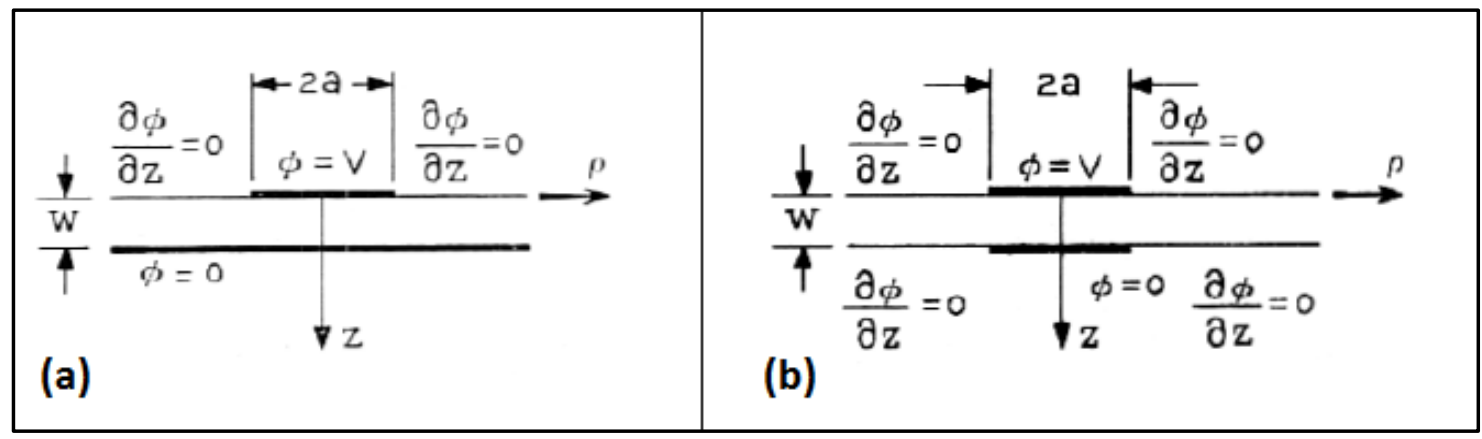

Figure 2-6. Geometries for spreading resistance. (a) Disk over ground plane. (b) Disk over corresponding disk.

$$
R_{1} \sigma a=\frac{1}{4 \int_{0}^{\infty}\left(\frac{\sin (x)}{x} J_{1}(x) \cdot \operatorname{coth}\left(\frac{w \cdot x}{a}\right)\right) d x} \stackrel{\stackrel{a}{w} \rightarrow 0}{\longrightarrow} \frac{1}{4}
$$




$$
R_{2} \sigma a=\frac{1}{2 \int_{0}^{\infty}\left(\frac{\sin (x)}{x} J_{1}(x) \cdot \operatorname{coth}\left(\frac{w \cdot x}{2 \cdot a}\right)\right) d x} \stackrel{\frac{a}{w} \rightarrow 0}{\longrightarrow} \frac{1}{2}
$$

In the equations above, $\mathrm{w}$ is the distance between the contacts, $\mathrm{a}$ is the radius of the disk forming the top contact, and $\sigma$ is conductivity.

Estimation of series resistance

In diode modeling, the resistance terms mentioned above are lumped in $\mathrm{R}_{\mathrm{s}}$, the series resistance. On a semi-log I-V plot, the series resistance appears as a departure from the expected exponential behavior with increased current.

Bringing the contact and spreading resistance together, and also accounting for the resistance of the quasi-neutral regions, one arrives at (2.9) ( [28]).

$$
R_{S}=\frac{1}{A_{j}} \int_{x_{1}}^{x_{2}} \rho(x) d x+\frac{\rho_{B}}{4 r}+R_{C}
$$

where the first term is the resistance of the quasi-neutral region(s), the second term is the limiting case of the spreading resistance in (2.7), and the third term is the contact resistance. It should be noted here that there is some inconsistency in the published literature with regards to the naming convention of the resistance, and the term $R_{S}$ is used to denote the overall resistance of a diode or just the spreading resistance.

\subsubsection{Capacitance of the P-N Junction}

The spatially distributed charge distribution and therefore the depletion width can vary in size depending on the voltage applied across the junction. The capacitance 
associated with the oscillation in the depletion width is called junction or depletionlayer capacitance. By analogy with parallel plate capacitors, the depletion layer capacitance is assumed to be

$$
C_{j}=\frac{K_{S} \varepsilon_{0} A}{W}
$$

where $\mathrm{W}$ is the depletion width, $\mathrm{A}$ is the area of the device, and $\mathrm{K}_{\mathrm{s}} \varepsilon_{0}$ is dielectric permittivity of the semiconductor. With OV bias applied to the junction, the depletion width $W_{0}$ is [35]:

$$
\begin{aligned}
& W_{0, a}=\left[\frac{2 K_{S} \varepsilon_{0} V_{b i}}{q}\left(\frac{1}{N_{A}}+\frac{1}{N_{D}}\right)\right]^{\frac{1}{2}} \text { for abrupt junctions } \\
& W_{0, g}=\left[\frac{12 K_{S} \varepsilon_{0} V_{b i}}{q g}\right]^{\frac{1}{3}} \text { for graded junctions }
\end{aligned}
$$

where $g$ is the impurity gradient of the space-charge region, related to resistivity by

$$
\rho=e \cdot g \cdot x
$$

And the built-in voltage for the abrupt junction is

$$
V_{b i}=\frac{k T}{q} \ln \left(\frac{N_{A} N_{D}}{n_{i}^{2}}\right)
$$

Varying the voltage applied across a P-N junction has the effect of changing the width of the depletion region. Under small signals, this variation can be viewed as adding or subtracting a small amount of charge at the ends of the depletion region. For the two 
types of junctions mentioned above, the depletion width variations are given by the equation below (from [35]):

$$
\begin{aligned}
& W=W_{0, a}\left(1-\frac{V}{V_{b i}}\right)^{\frac{1}{2}} \text { for abrupt junctions } \\
& W=W_{0, g}\left(1-\frac{V}{V_{b i}}\right)^{\frac{1}{3}} \text { for graded junctions }
\end{aligned}
$$

which lead to [35]

$$
\begin{aligned}
& C=\frac{C_{0}}{\left(1-\frac{V}{V_{b i}}\right)^{1 / 2}}, C_{0}=A\left(\frac{q K_{S} \varepsilon_{0}}{2 V_{b i}} \frac{N_{A} N_{D}}{N_{A}+N_{D}}\right)^{1 / 2} \text { for abrupt junctions } \\
& C=\frac{C_{0}}{\left(1-\frac{V}{V_{b i}}\right)^{1 / 3}}, C_{0}=A\left(\frac{q\left(K_{S} \varepsilon_{0}\right)^{2} g}{12 V_{b i}}\right)^{1 / 3} \text { for graded junctions }
\end{aligned}
$$

The capacitance associated variations in the depletion width exists during forward and reverse biasing of the junction. During forward bias however, an additional capacitance due to minority carriers also exists [29]. This capacitance is called diffusion capacitance and denoted with $C_{D}$. When the applied signal has a frequency smaller than the inverse minority carrier lifetimes, the minority carriers can follow the applied field. However, when the applied frequency approaches the inverse of the minority carrier lifetime, the motion of minority carriers starts to lag, leading to a decrease in diffusion capacitance.

\subsubsection{The Metal-Semiconductor (Schottky) junction}

The rectifying junction between metals and semiconductors has been studied for over a century. The first rectifying semiconductor devices created and used in applications 
were point contact diodes. Even though the metal-semiconductor (MS) junctions are easy to create, obtaining repeatable junction characteristics was difficult in the beginning. Substantial effort was invested in understanding the rectification of metalsemiconductor junctions, with a number of models being developed [38, 39, 40, 41, 42][38-42]. Advances in semiconductor device manufacturing led to repeatable manufacturing outcomes, but the properties of the junctions are still highly dependent of the processes being used. A generally applicable model for the metal-semiconductor junction has proved elusive.

\subsubsection{Diode equation for the metal-semiconductor junction}

While I-V characteristics of the Schottky diode look similar to those of P-N junctions, the phenomena underlying the junction properties are different. In contrast with the P-N junction where minority carriers play a predominant role, the MS junction properties are dominated by the majority carriers. Equation (2.15) shows the I-V characteristics for an ideal MS junction diode [29].

$$
\mathrm{I}=I_{S}\left(e^{\frac{q V_{A}}{k T}}-1\right)
$$

where: $\mathrm{I}_{S} \equiv A \cdot \mathcal{A} * T^{2} e^{-\Phi_{B} / k T}$,

$\mathcal{A} * \equiv\left(\frac{m_{n}^{*}}{m_{0}}\right) \mathcal{A}$, is the effective Richardson constant

and $\mathcal{A} \equiv \frac{4 \pi q m_{0} k^{2}}{h^{3}}=120 \frac{a m p s}{c m^{2}-K^{2}}$ is the Richardson constant 


\subsubsection{Surface Layer and Surface States}

Inside the bulk of crystalline semiconductor the atoms are arranged in a well ordered lattice, each atom or group of atoms being acted upon the same way by its neighbors. At the semiconductor boundary however, the periodicity of the bulk lattice is interrupted, and the atoms settle into positions of equilibrium different than those in the bulk. If the surface layer maintains the symmetry of the bulk, the surface is said to be relaxed, while if the symmetry is different than the bulk, the surface is said to be reconstructed. This break in the bulk symmetry leads to the appearance of surface states with energy levels that are between the valence and conduction bands of the semiconductor. The surface states have the effect of making the barrier height $\left(\phi_{\mathrm{b}}\right)$ less dependent on the choice of metal [43]. Also, if the creation of the semiconductor surface did not happened in high vacuum, the atoms on the surface react with the atoms from the atmosphere or from the vacuum chamber and an impurity layer develops on the semiconductor surface that affects its properties [44]. An energy diagram for the case when an interfacial layer and surface states exist is depicted below: 


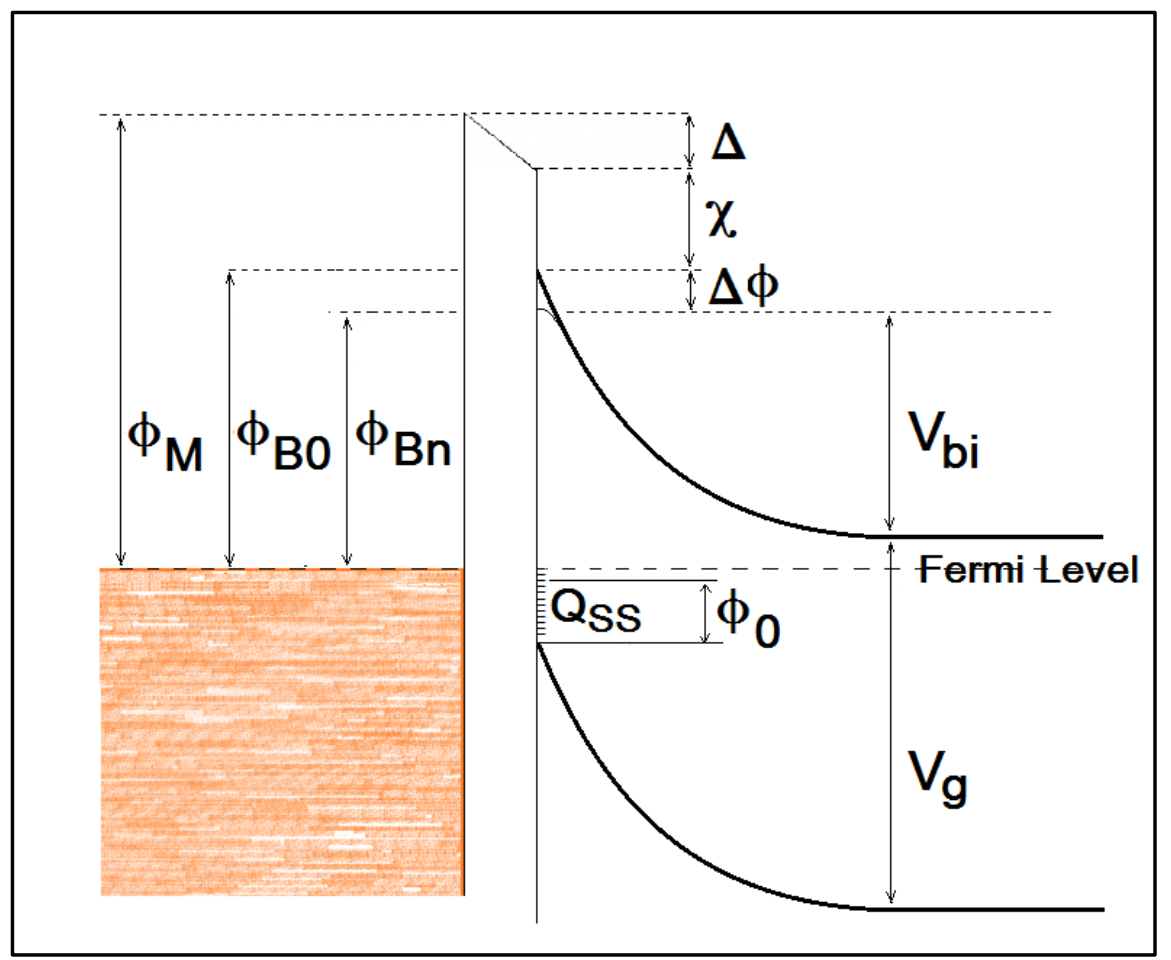

Figure 2-7. Metal Semiconductor interface with surface states (after [28]).

$\phi_{\mathrm{M}}=$ work function of metal, $\phi_{\mathrm{B} n}=$ barrier height of metal-semiconductor barrier, $\phi_{\mathrm{B} 0}=$ asymptotic value of $\phi_{\mathrm{Bn}}$ at zero electric field, $\phi_{0}=$ energy level at surface, $\Delta=$ potential across interfacial layer, $\chi=$ =electron affinity of semiconductor, $\mathrm{V}_{\mathrm{bi}}=$ built-in potential, Qss=surface state density on semiconductor. In the extreme limit where the number of surface states is high, the barrier height $\phi_{\mathrm{b}} \approx \mathrm{E}_{\mathrm{g}}-\phi_{0}$ is independent of the metal work function. This is called the Bardeen limit, and it is said that the barrier height is pinned (Fermi-level pinning).

The thickness of the interface layer must be taken into account when investigating the frequency response of the devices obtained. If the oxide layer is thin (less than $10 \AA$ ), the charge carriers can easily tunnel through the barrier, and the junction has the 
customary I-V characteristics. A thicker oxide layer has a more appreciable effect on the junction properties, as it was shown by Card and Rhoderick [45, 46], and by Williams and Rhoderick [47]. Figure 2-8 is reproduced below from [46] to demonstrate the effect of increasing oxide layer on the I-V relationship. It can be seen from the figure that the forward voltage of the diode increases with the oxide thickness.

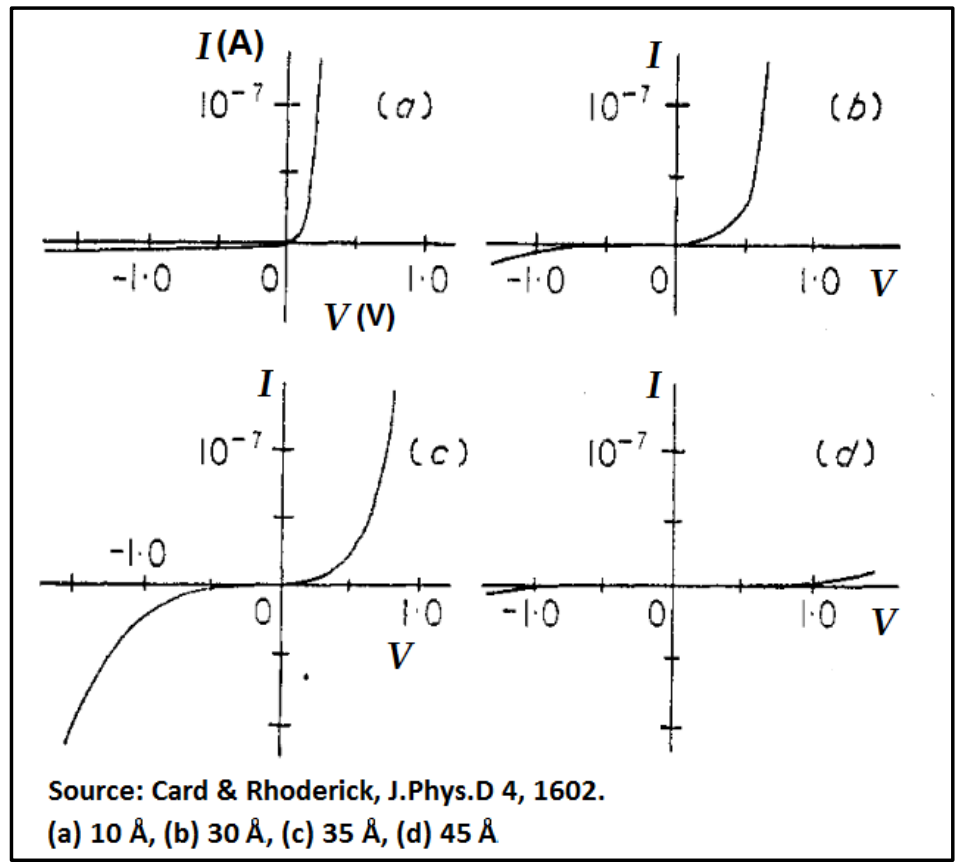

Figure 2-8. Effects of surface oxidation. Forward voltage increases with oxide thickness.

As a note, we can see that Figure 2-8 (c) looks similar with the I-V curve of anti-parallel diodes (e.g., Figure 2-9, blue curve). However, the positive and negative portions of the traces in Figure 2-8 (c) are not symmetrical, as it is the case with the anti-parallel diodes of the same type. 


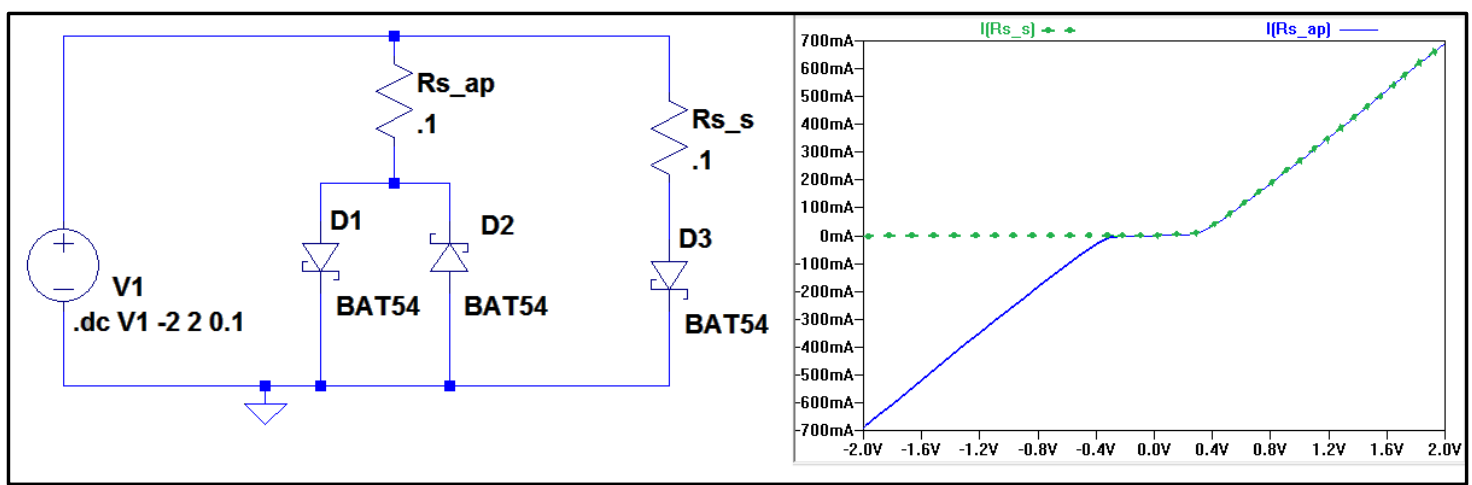

Figure 2-9. I-V curve for anti-parallel diodes (blue, solid) and single diode (green, dash)

In terms of equivalent circuits, a number of configurations were proposed to account for the thickness of the interfacial layer and the frequency response. The existing theoretical models are not general enough to cover the wide variety of interface properties [47].

\subsubsection{Capacitance of the Schottky junction}

Because Schottky diodes have very little minority carrier injection, the diffusion capacitance they exhibit is lower than that of $\mathrm{P}-\mathrm{N}$ junctions (section 2.1.1.4). For this reason, the total capacitance of a Schottky junction is typically smaller than the capacitance of a P-N junction of similar dimensions, a plus when working at high frequencies.

\subsubsection{Resistance of the Schottky junction}

The resistance of MS junction diodes arises the same way and can be analyzed similarly to the resistance of the P-N junction diodes (see 2.1.1.2). 


\subsection{Limitations of traditional diodes}

A common diode model used in circuit simulations is given in Figure 2-10. Here the series resistance $R_{S}$ lumps together all the sources of resistance (contact resistance, spreading resistance, etc.).

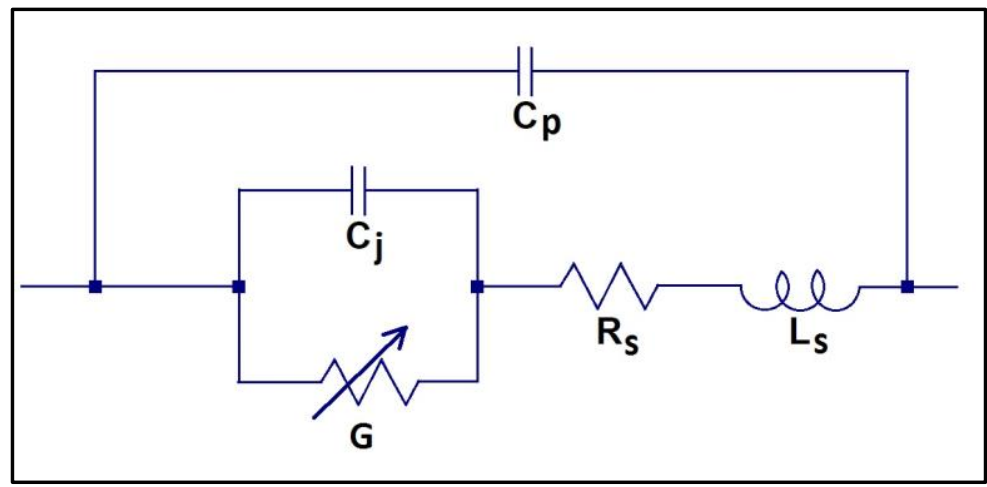

Figure 2-10. Diode electrical model

The parameters of the diode model given above are:

$$
\begin{aligned}
& C_{p}=\text { package capacitance } \\
& C_{j}=\text { junction capacitance } \\
& R_{S}=\text { series resistance (includes spreading resistance, contact resistance) } \\
& L_{s}=\text { series inductance } \\
& G=\text { the non-linear junction conductance }
\end{aligned}
$$

A figure of merit for the cut-off frequency of a diode is given by equation below:

$$
f_{c}=\frac{1}{2 \pi R_{S} C_{j}}
$$


For decreasing junction area, the increase in resistance may or may not compensate for the decrease in junction capacitance. Equation (2.16) shows that if (1) $C_{j}$ is proportional to the area $((2.10)),(2)$ the series resistance is inversely proportional to the device area, and (3) other parasitic resistances and capacitances are negligible, the cutoff frequency of a device may be independent of the device area [35]. However, this is not always the case as shown in Figure 2-11 [35] and in Figure 2-12 [48]:

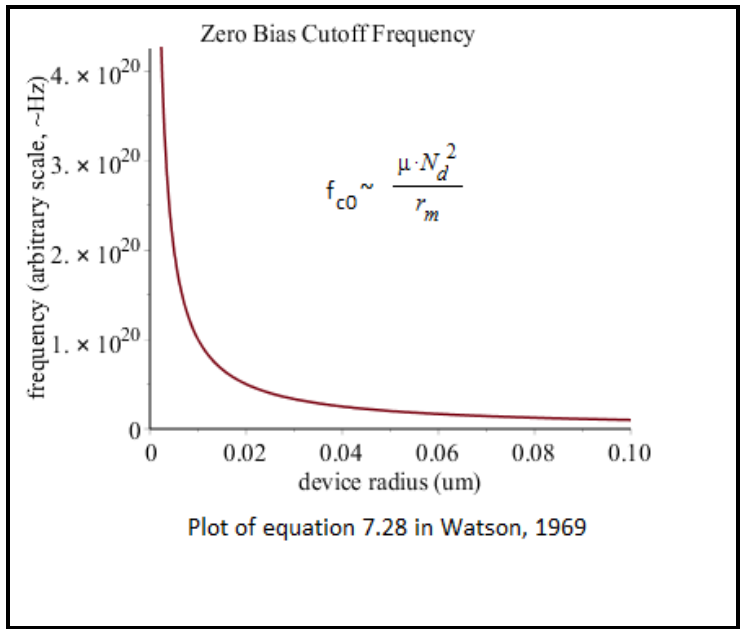

Figure 2-11. Cutoff frequency vs device radius $\mathrm{P}-\mathrm{N}$ junctions, $\mathrm{N}_{\mathrm{a}}>>\mathrm{N}_{\mathrm{d}}$

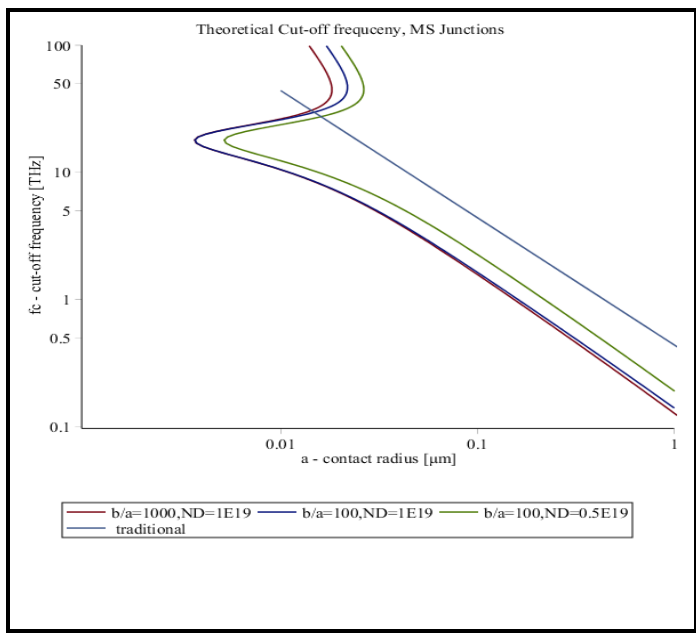

Figure 2-12. Cutoff frequency vs contact radius Schottky Junctions

The conclusion that can be drawn from the trends in the two figures above is that in general, devices with smaller geometries have a higher cut-off frequency. This trend is supported by a survey of available diodes recorded in Appendix A, and summarized in Figure 2-13 and Figure 2-14. In some cases recorded in the appendix, the cut-off frequency was not available and was computed from available parameters using (2.16). 


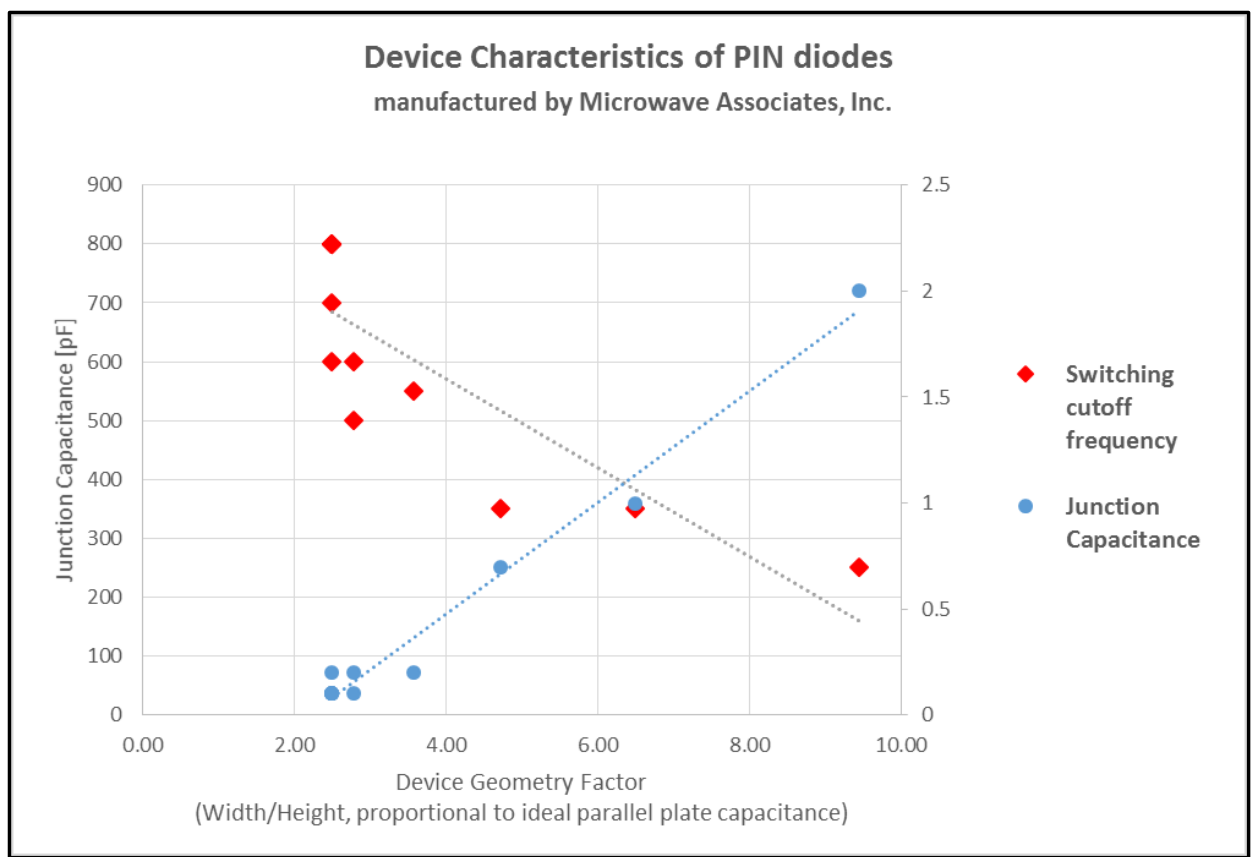

Figure 2-13. Device characteristics - cut-off frequency and junction capacitance (using data from [49])

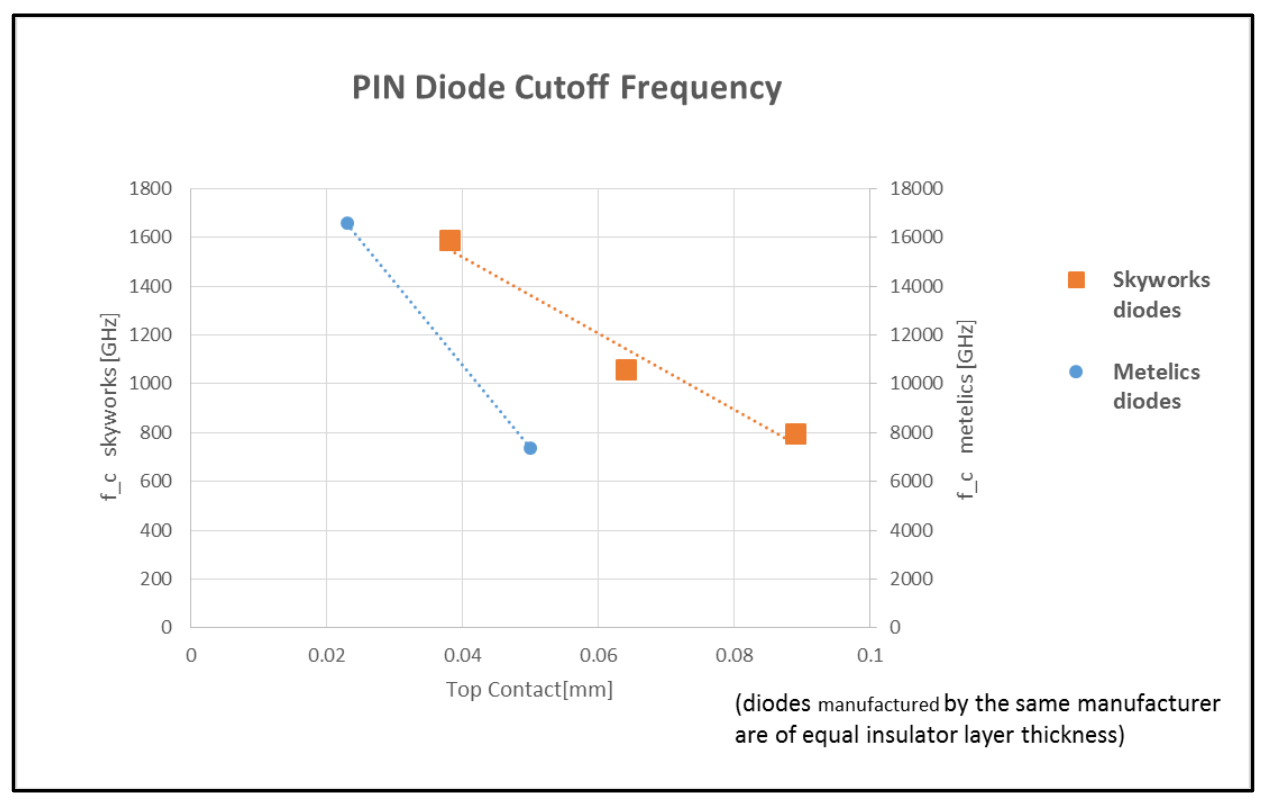

Figure 2-14. Device characteristics - cutoff frequency (computed from published data sheets) 
As their name suggest, silicon nanowires have dimensions in the nanometer range, thus leading to devices of very small geometrical size. This in turn will lead to reduced capacitance and therefore to an increase in the frequency of operation of the nanowire based devices. SiNW fabrication details are provided in the following section.

It is worth noting that experimental work by other authors showed that highly porous silicon can emit red light under photoexcitation [50]. This led others to show a dependence between the band gap energy and the diameter of silicon nanowires [51, 52]:

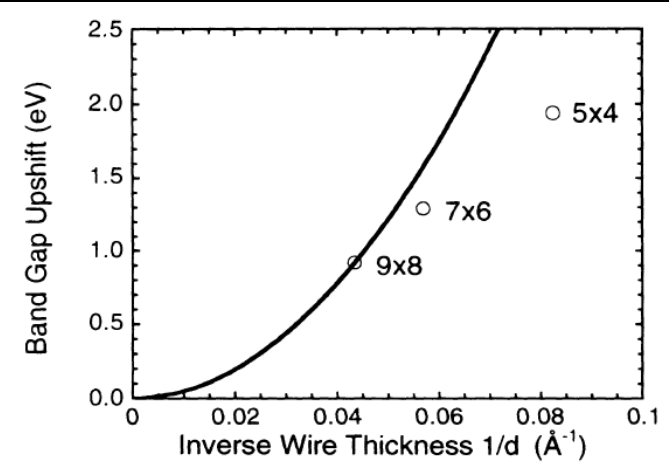

FIG. 2. The band-gap upshift of the wire structures with respect to bulk $\mathrm{Si}$ plotted against the inverse of the wire thickness (circles). The EMT upshift of Eq. (2) with $C=0.900$ is also plotted (continuous line). The wire thickness $d$ is defined by Eq. (1).

Read et al, Physical Review Letters, 1992

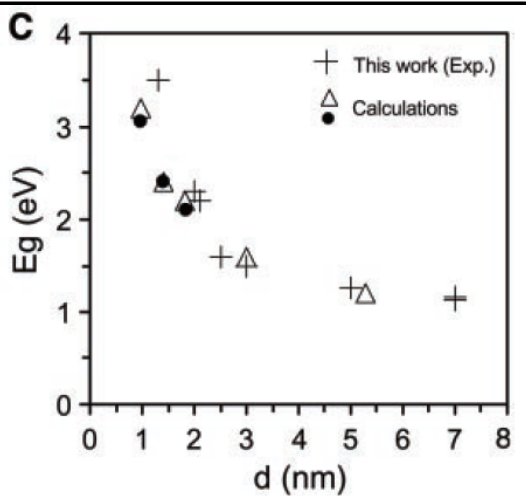

... (C) Experimental band gap versus diameter for SiNWs of wires 1 to $6 \ldots$

Ma et al, Science, 2003

Figure 2-15. Energy band gap dependence on silicon nanowire diameter

As Figure 2-15 above shows, the SiNW band gap variation is significantly different from the band gap of bulk silicon for nanowire diameters less than $10 \mathrm{~nm}$.

\subsection{Silicon nanowire fabrication}

Silicon nanowires can be obtained using several methods, the two most common being (1) growth using the vapor liquid solid (VLS) method [53] and (2) electroless etching into 
the surface of a silicon wafer [54]. Both of these methods are less complex to implement when compared with typical semiconductor device manufacturing methods employed in the industry. However, while relatively easy to implement, the geometrical alignment of the nanowires obtained is less precise. The devices used in this research were obtained using the second method - electroless etching into the surface of a silicon wafer. When used on wafers with an epitaxial silicon layer doped differently than the substrate, this method allowed us to obtain free standing nanowires that had P-N junctions inside the nanowires.

\section{Electroless Etching of a Silicon Surface}

This method of obtaining nanowires was developed by Peng, Yan, Gao and Zhu [54], and is based on the widely used Electroless Metal Deposition (EMD) method of making ohmic contacts to semiconductors. The method consists on applying a hydrofluoric acid (HF) and silver nitrite $\left(\mathrm{AgNO}_{3}\right)$ solution to the surface of a wafer. It was proposed in [54] that the HF causes the metal ions in the solution to form solid clusters on the silicon surface providing a cathodic reaction center surrounded by anodic Si reaction centers. For certain concentration of $\mathrm{AgNO}_{3}$, the deposition of $\mathrm{Ag}$ proceeds in a dendritic fashion and the uniformly distributed Ag clusters do not coalesce to form a film on the Si surface as is the case for other metals. Etching of the Si around the Ag clusters leads to the formation of high-density, free-standing Si nanowires. The high density of the nanowires obtained by this method increase trapping of light by the silicon wafer surface, making the surface appear black. This effect led to the name "Black Silicon". It 
was shown in [54] that varying the Si doping does not have a significant effect on the nanowire formation. The precise details of this method as used to obtain the nanowires used in this research can be found in section 3.2.

\subsection{Frequency multiplication using semiconductor devices}

As stated in the introductory chapter, the goal of this research is to investigate frequency multiplication in silicon nanowires. This section presents a brief mathematical introduction to the topic of frequency multiplication. Frequency multiplication is an effect that can arise in systems that exhibit a non-linear response to electromagnetic stimuli. For completeness, a description of linear electric circuits is also given here.

\subsubsection{Linear circuits}

In a linear system the superposition principle is satisfied. Therefore, the output of a linear system contains only frequency components found in the input stimulus. In electronics, the simplest form of a linear system is a system composed of a single resistor and a power supply (Figure 2-16 a). Mathematically, this system is described by the well-known Ohm's law:

$$
I_{R}=\frac{V}{R}
$$

When a periodic signal of form $V=V_{0} \cos (\omega \cdot t)$ is applied to the circuit in Figure 2-16 a, the current through the resistor will have the form

$$
I_{R}=\left(V_{0} / R\right) \cos (\omega \cdot t)
$$


One can see that the only frequencies present in the output are those found in the input. For this reason linear systems cannot be used for frequency multiplication.

\subsubsection{Non-linear circuits}

A non-linear system is a system which does not satisfy the superposition principle, or whose output is not directly proportional to its input. The simplest form of a non-linear system that can be implemented in electronics is a circuit consisting of one diode (Figure 2-16 b). Either the C-V or the I-V nonlinear relationship found in diodes can be used to generate higher harmonics. Diodes designed to exploit the non-linearity of the Capacitance-Voltage (C-V) relationship are called varactors (variable capacitors), while those designed to exploit the Current-Voltage (I-V) non-linearity to obtain a variable resistance are called varistors. The non-linear I-V relationship for an ideal diode is given in (2.1).

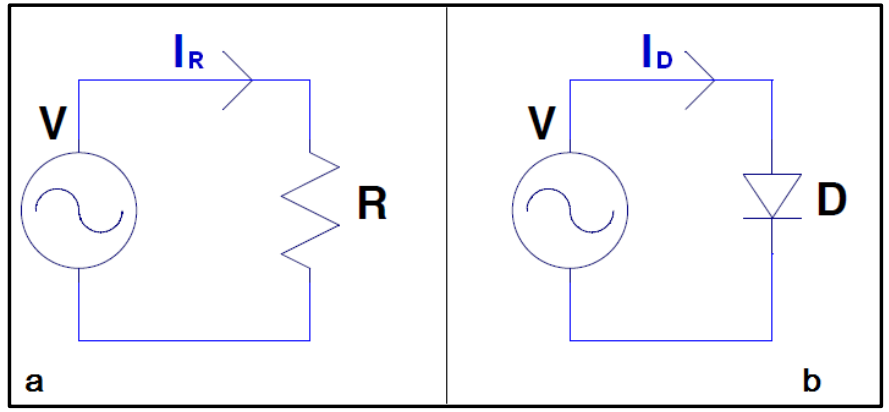

Figure 2-16: a - resistor circuit; $b$ - diode circuit

Letting $V_{\text {th }}=k T / q,(2.1)$ is rewritten:

$$
I_{D}=I_{0}\left(e^{\frac{V}{V_{t h}}}-1\right)
$$


where $\mathrm{V}_{\mathrm{th}}=\mathrm{kT} / \mathrm{q} \approx 0.026 \mathrm{~V}$ at room temperature.

A Taylor series expansion of (2.18) will produce:

$$
I_{D}=I_{0}\left(\frac{V}{V_{t h}}+\frac{1}{2}\left(\frac{V}{V_{t h}}\right)^{2}+\frac{1}{6}\left(\frac{V}{V_{t h}}\right)^{3}+\cdots\right)
$$

Substituting $V$ with $V=V_{0} \cos (\omega \cdot t)$ in the Taylor series expansion, it can be shown that

$$
I_{D} \approx I_{d c}+I_{1} \cos (\omega \cdot t)+I_{2} \cos (2 \omega \cdot t)+I_{3} \cos (3 \omega \cdot t)+\cdots
$$

(2.20) shows that the output of a non-linear system characterized by (2.18) and stimulated by a sinusoidal input will contain harmonics of that input signal. This is the basic principle used by frequency multipliers that exploit the non-linearity of the I-V relationship of a diode.

\subsubsection{Frequency multiplication in diodes}

For frequency multiplication, the useful response of the diodes is in the non-linear part of the forward bias regime. To maximize the non-linear response of the device, an external bias is often applied with the AC/RF signal in order to move the operational point of the diode into or closer to the non-linear response region of the device.

\subsection{Electromagnetic waveguides}

When electronic devices are operated at frequencies above a few $\mathrm{KHz}$, particular attention must be paid to minimize losses as signals propagate through transmission lines and interconnects. Because the main goal of this research is to show that the 
devices obtained generate harmonics of the high frequency signals they are exposed to, particular attention had to be accorded to the transmission lines and interconnects used between various components of the test system. This section will present some of the relationships employed in designing the waveguides used in this research. A detailed derivation of the relationships starting with Maxwell's equations can be obtained from works by Jackson [55] and Balanis [56].

\subsubsection{Parallel plate waveguide}

The initial avenue for investigating harmonic generation was to expose the samples to frequencies in the $\mathrm{MHz}$ range. For this, a waveguide consisting of a metal strip parallel to a metal plane was employed. This configuration is a much larger version of the microstrip configuration commonly used in high frequency electronic circuits.

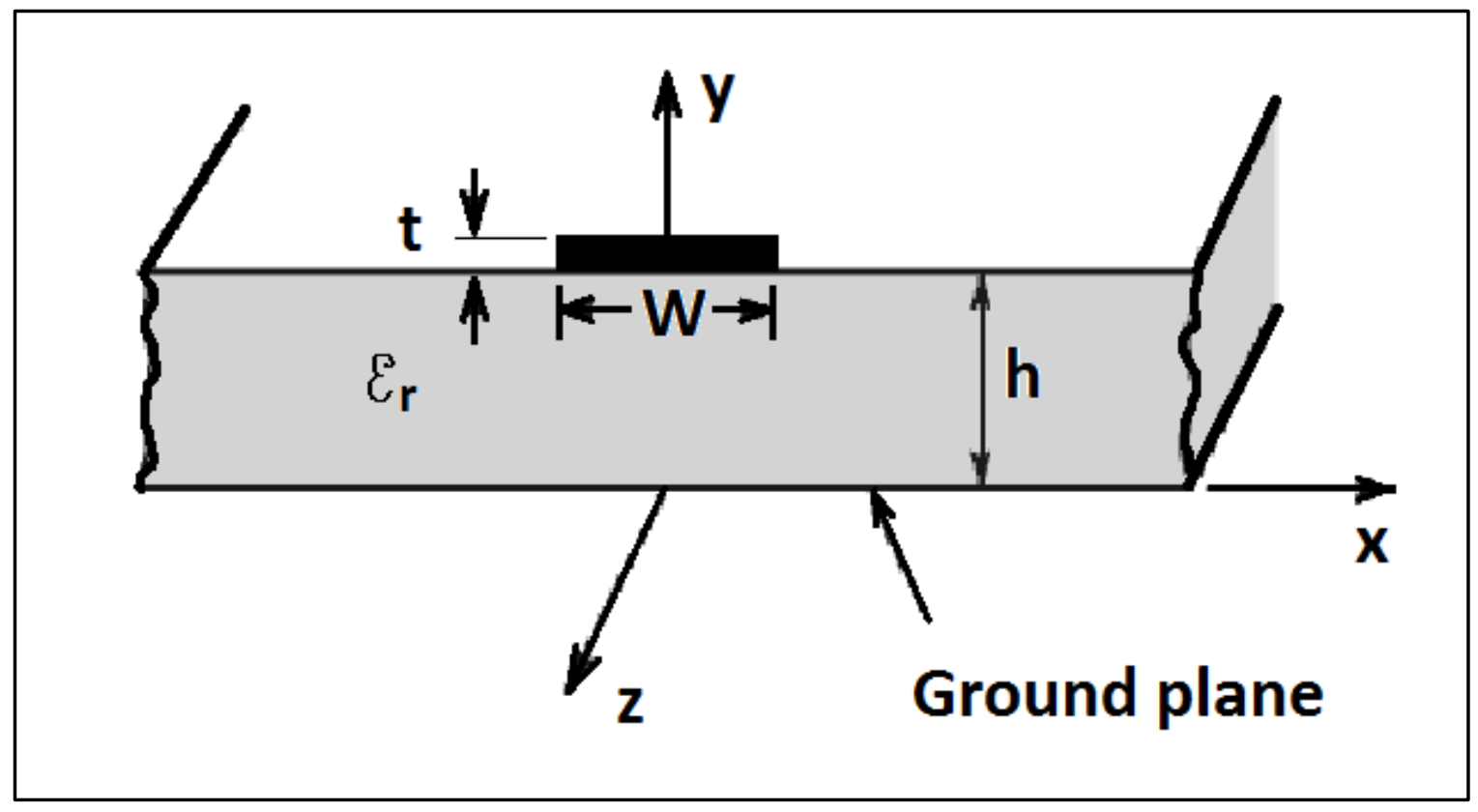

Figure 2-17. Microstrip line 
The equations characterizing the microstrip waveguide taken from [56] are given below:

$$
Z_{C}(0)=\frac{\frac{120 \pi}{\sqrt{\varepsilon_{r, e f f}(0)}}}{\frac{W_{e f f}(0)}{h}+1.393+0.667 \ln \left[\frac{W_{e f f}(0)}{h}+1.444\right]}
$$

$Z_{C}$ is the waveguide $D C(0 \mathrm{~Hz})$ characteristic impedance for the case

$$
\frac{W_{e f f}(0)}{h} \geq \frac{1}{2 \pi}
$$

where:

$$
\begin{gathered}
\varepsilon_{r, e f f}(0)=\frac{\varepsilon_{r}+1}{2}+\frac{\varepsilon_{r}-1}{2}\left[1+12 \frac{h}{W_{e f f}(0)}\right]^{-1 / 2} \\
\frac{W_{e f f}(0)}{h}=\frac{w}{h}+\frac{1.25}{\pi} \frac{t}{h}\left[1+\ln \left(\frac{2 h}{t}\right)\right] \text { for the case } \frac{w}{h} \geq \frac{1}{2 \pi}
\end{gathered}
$$

$\varepsilon_{r, \text { eff }}$ and $w_{\text {eff }}$ represent the effective dielectric constant and width of the line, $\varepsilon_{\mathrm{r}}$ is the relative dielectric constant of the medium, $\mathrm{w}$ and $\mathrm{t}$ are the strip width and thickness, and $h$ is the height of the strip above the ground plane.

The microstrip waveguide becomes dispersive at or above a frequency $f_{c}$ given below:

$$
f_{C} \geq 0.3 \sqrt{\frac{z_{C}(0)}{h} \frac{1}{\sqrt{\varepsilon_{r}-1}}} \times 10^{9} \quad(\mathrm{~h} \text { in } \mathrm{cm})
$$

The above relationships can be used to estimate the characteristics of the low frequency waveguide and to evaluate the attenuation effects on the electromagnetic signals of interest. 


\subsubsection{Hollow rectangular waveguide}

Signals in the millimeter/submillimeter bands are typically guided through rectangular hollow metal waveguides. In order to characterize the SiNW samples in this region of the spectrum, a hollow rectangular waveguide that allows mounting of the samples had to be designed and fabricated.

\section{Cutoff frequency}

The most critical parameter in the design of the microwave waveguide we used in the experiments is the cutoff frequency. The cutoff frequency of a rectangular waveguide is a value which indicates the lowest traveling wave frequency supported by the waveguide. The cutoff frequency for a rectangular hollow metal waveguide taken from [56] is given by (2.23).

$$
\left(f_{c}\right)_{m n}=\frac{1}{2 \pi \sqrt{\mu \varepsilon}} \beta_{c}
$$

where $\beta_{c}$ is the wavenumber corresponding to the mode $(m, n)$ defined as

$$
\beta_{c}^{2} \equiv\left(\frac{2 \pi}{\lambda_{c}}\right)^{2}=\left(\frac{m \pi}{a}\right)^{2}+\left(\frac{n \pi}{b}\right)^{2}
$$

$a$ and $b$ are the cross-sectional dimensions of the wave guide, $m=0,1,2, . ., n=0,1,2, \ldots$ and $\mathrm{m}, \mathrm{n}$ cannot be zero at the same time.

\section{Waveguide mode power}

Another important relationship for microwave waveguides is the relationship between the power in the traveling wave and the potential in the waveguide. Following [56] 
again, the power contained in a rectangular waveguide can be expressed with the following equation:

$$
\begin{aligned}
& P_{m n}^{T E}=\left|A_{m n}\right|^{2} \frac{\beta_{c}^{2}}{2 \eta \varepsilon^{2}}\left(\frac{a}{\varepsilon_{0 m}}\right)\left(\frac{b}{\varepsilon_{0 n}}\right) \sqrt{1-\left(\frac{f_{c, m n}}{f}\right)^{2}} \\
& \text { where } \varepsilon_{0 q}=\left\{\begin{array}{l}
1, q=0 \\
2, q \neq 0
\end{array}\right.
\end{aligned}
$$

and the relationship between the wave amplitude and the electrical field is given by:

$$
E_{y}^{+}=-\frac{A_{10}}{\varepsilon} \frac{\pi}{a} \sin \left(\frac{\pi}{a} x\right) e^{-j \beta_{z} z}, \quad\left|E_{y}^{+}\right|_{\max }=\frac{\left|A_{10}\right|}{\varepsilon_{0}} \frac{\pi}{a}
$$

It is customary for power to be given in $\mathrm{dBm}$ units (logarithmic scale, relative to $1 \mathrm{~mW}$ ). The relationship between the power in $\mathrm{dBm}$ and Watts is given by the following equations:

$$
\begin{gathered}
P_{d B m} \equiv 10 \log \frac{P_{W}}{1 m W}=30+10 \log \frac{P_{W}}{1 W} \\
P_{W}=1 W 10^{\frac{P_{d B m}-30}{10}}
\end{gathered}
$$

The power relationships above will be used to estimate the voltage potential across the samples investigated.

The topics covered in this chapter provide the background necessary to understand the setup of the experiments performed and the phenomena inside the nanowire diodes obtained. Simulation tools exist that can be used to evaluate more precisely all parameters presented so far. However, these tools were not available for this research. 


\section{EXPERIMENTAL PROCEDURES}

\subsection{Overview}

SiNW samples fabricated in our laboratory were mounted in two experimental setups.

The first setup allowed for the characterization of the samples at low frequencies using a parallel plate waveguide. The frequencies chosen for investigation using the low frequency waveguide were $70 \mathrm{MHz}$ and $500 \mathrm{MHz}$. The second setup allowed us to investigate the samples in the millimeter/submillimeter region of the spectrum. Using the microwave waveguide, the samples were exposed to a $50 \mathrm{GHz}$ signal. The setups for both the low frequency and the microwave experiments have three main components:

- $\mathrm{RF} /$ microwave source. The source produced the fundamental frequency the samples were exposed to. Filters were used to minimize the higher harmonics generated by the signal sources from reaching the samples.

- Waveguide. The waveguide (1) allowed electrical connections to the sample, (2) allowed the samples to be exposed to the excitation signal, and (3) provided a path for the harmonics generated in the sample to reach the detector.

- Spectrum analyzer (SA). The spectrum analyzer was used to detect the harmonics originating in the sample.

The general experimental procedure consisted in the following steps:

- Nanowire fabrication

- Device/circuit creation

- DC Characterization 
- LF Characterization

- Microwave Characterization

The I-V traces and spectrum sweeps acquired during sample characterization were captured using a computer and stored for later analysis. The following subsections provide a detailed description of the experimental method.

\subsection{Nanowire fabrication}

We chose to make our devices consisting of free standing SiNW by electroless etching of a silicon wafer using a solution composed of hydrofluoric acid (HF) and silver nitrite $\left(\mathrm{AgNO}_{3}\right)$ following the method described in [54] and summarized in section 2.3. The parameters of the process of obtaining the nanowires had to be optimized. The diameter of the wires can be controlled by adjusting the concentration of silver nitrite in the HF solution. The nanowires used in the experiments presented here were obtained using a concentration of $\mathrm{AgNO}_{3}$ in $\mathrm{HF}$ of 0.103 molar. Etch times between 15 minutes and 2 hours were tried. The optimum etch time for obtaining silicon nanowires used in the experiment was of about 20 minutes. The etch process was also tried at room temperature and at $50^{\circ} \mathrm{C}$.

Figure 3-1 shows SEM images of silicon nanowires obtained by the method described above. The top row and lower left show progressively higher magnifications of a SiNW sample, and the lower right shows an SEM image of a different sample. 

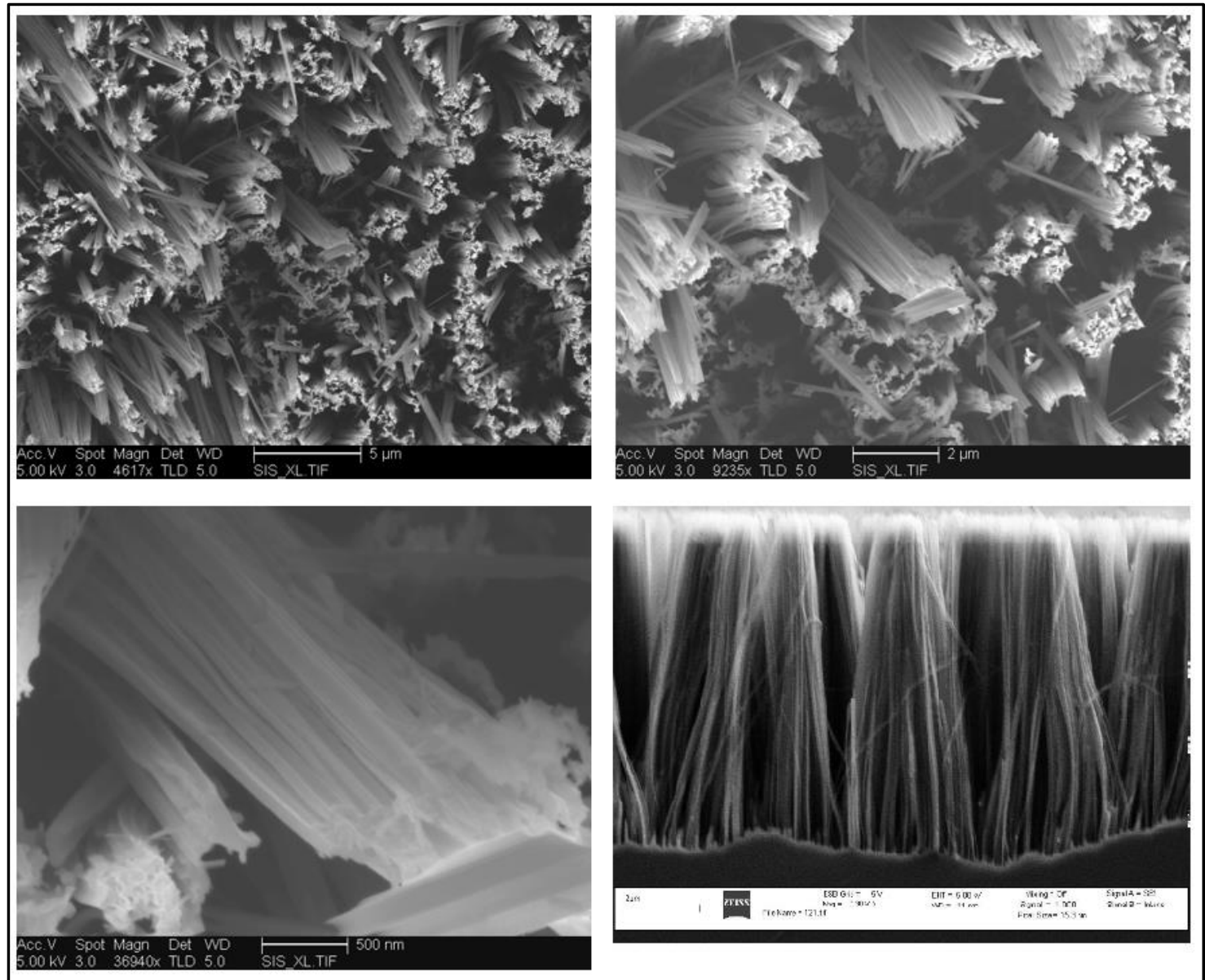

Figure 3-1. Silicon nanowires obtained by electroless etch method. Top row and lower left: progressively higher magnification of a sample; lower right: SEM image of a different sample

The length of the nanowires obtained by the method above were in the $20-25 \mu \mathrm{m}$ range and their diameter was in the range $20-60 \mathrm{~nm}$. Subsequent device parameter calculations assumed a nanowire diameter of $35 \mathrm{~nm}$.

Table 3-1 below lists the type of silicon substrates used to make the nanowires. The resistivity of the substrate was known, and the dopant concentration was computed from the resistivity values. 
Table 3-1. Substrates used

\begin{tabular}{|c|c|c|c|c|c|}
\hline $\begin{array}{l}\text { Sample } \\
\#\end{array}$ & Type & $\begin{array}{l}\text { Resistivity } \\
(\Omega-\mathrm{cm})\end{array}$ & $\begin{array}{l}\text { Dopant } \\
\text { Concentration }\end{array}$ & $\begin{array}{l}\text { Mobility } \\
\left(\mathrm{cm}^{2} / \mathrm{V}-\mathrm{cm}\right)\end{array}$ & Notes \\
\hline $\begin{array}{l}4, \\
152\end{array}$ & $\begin{array}{l}n+/ \\
p+\end{array}$ & $\begin{array}{l}\mathrm{N}+(\text { epi): } \\
0.340 \\
\mathrm{P}+ \\
\text { substrate: } \\
0.01-0.02 \\
\end{array}$ & $\begin{array}{l}\mathrm{N}_{\mathrm{D}}: \\
1.658 \times 10^{16} \\
\mathrm{~N}_{\mathrm{A}}: \\
8.4 \times 10^{18}- \\
3.1 \times 10^{18} \\
\end{array}$ & $\begin{array}{l}1106.92 \\
74.07-100.64\end{array}$ & $\begin{array}{l}n+: \text { Phosphorus } \\
W_{\text {epi }}=5.5 \mu m \\
p+: \text { Boron. }\end{array}$ \\
\hline 6 & $n$ & $1-10$ & $\begin{array}{l}N_{D}: \\
8.05 \times 10^{16}- \\
4.51 \times 10^{14}\end{array}$ & $\begin{array}{l}773.16- \\
1384.01\end{array}$ & Phosphorus \\
\hline 83 & $p+$ & 0.002 & $\begin{array}{l}\mathrm{N}_{\mathrm{A}}: \\
5.95 \times 10^{19}\end{array}$ & 52.43 & Boron \\
\hline 84 & $\mathrm{p}$ & $13-23$ & $\begin{array}{l}\mathrm{N}_{\mathrm{A}}: \\
1.0398 \times 10^{15} \\
5.84 \times 10^{14}\end{array}$ & $\begin{array}{l}461.72- \\
464.66\end{array}$ & Boron \\
\hline 86 & $p / n$ & N/A & N/A & $\mathrm{N} / \mathrm{A}$ & Plated with $100 \AA ̊ P t$ \\
\hline 89 & $\mathrm{p} / \mathrm{n}$ & $\mathrm{N} / \mathrm{A}$ & N/A & N/A & \\
\hline 87 & $n+$ & $0.001-0.003$ & $\begin{array}{l}N_{D}: \\
7.85 \times 10^{19}-\end{array}$ & 79.498- 95.607 & Phosphorus \\
\hline $\mathrm{n} / \mathrm{a}$ & $\begin{array}{l}p+/ \\
p++\end{array}$ & $\begin{array}{l}P+(\text { epi): } \\
0.01-0.02 \\
P++ \\
\text { substrate: } \\
0.003-0.007\end{array}$ & $\begin{array}{l}\mathrm{N}_{\mathrm{A}-\mathrm{epi}}: \\
8.4 \times 10^{18}- \\
3.1 \times 10^{18} \\
\mathrm{~N}_{\mathrm{A} \_} \mathrm{s}: 3.76 \times 10^{19} \\
-1.35 \times 10^{19}\end{array}$ & $\begin{array}{l}74.07-100.64 \\
55.30-66.063\end{array}$ & Boron \\
\hline $\mathrm{n} / \mathrm{a}$ & $n / p+$ & $\begin{array}{l}\mathrm{N}(\text { epi): } \\
5.30 \\
\mathrm{P}+ \\
\text { substrate: } \\
0.01-0.02\end{array}$ & $\begin{array}{l}\mathrm{N}_{\mathrm{D}}: \\
8.61 \times 10^{14} \\
\mathrm{~N}_{\mathrm{A}}: \\
8.4 \times 10^{18}- \\
3.1 \times 10^{18} \\
\end{array}$ & $\begin{array}{l}1367.117 \\
74.07-100.64\end{array}$ & $\begin{array}{l}\text { N:Phosphorus } \\
W_{\text {epi }}=27.4 \mu \mathrm{m} \\
\text { P: Boron }\end{array}$ \\
\hline $\mathrm{n} / \mathrm{a}$ & $\mathrm{ZnO}$ & & & & made by electrolysis \\
\hline
\end{tabular}

The zinc oxide nanowire sample was provided by the group led by Dr. Rolf Könenkamp at Portland State University. Even though it was included in the table above, the ZnO nanowire sample was not obtained using the method described above. We have also 
experimented with black silicon plated with a thin layer of platinum (sample 86 in the table above).

The dopants in the table above are: (1) Boron (B) - p type dopant in Si and (2)

Phosphorus (P) - $\mathrm{n}$ type dopant in Si. Carrier concentrations and mobility values were obtained by using the online Resistivity \& Mobility Calculator at Brigham Young University [57].

\subsection{Device and circuit formation}

In order to use the devices in an electrical circuit and investigate the response of the SiNW to electromagnetic radiation, two connections one to the bottom of the substrate and the other to the top of the nanowires were established.

When investigated using the low frequency (LF) waveguide, the samples were bonded to brass strips that allowed for easy insertion and removal from the waveguide; the brass strips came in direct contact with the bottom of the LF waveguide. For the microwave investigations the samples were bonded directly to the bottom side of the waveguide. In both cases, the sample substrate was sanded with 400 grit sand paper and cleaned with ethyl alcohol before bonding in order to remove oxide films and contaminants. The waveguide thus forms the first required connection point to the device.

The nanowire side of the samples was contacted with a tungsten probe electrically insulated from substrate contact. The probe was lowered slowly onto the nanowires either by a set screw (in the LF waveguide) or by a micrometer stage (in the microwave 
waveguide). The probe forms the second required contact to the device. The metalsemiconductor junction formed at probe-nanowire interface could be either rectifying (Schottky contact) or ohmic. Since the diameter of the probe is much larger than the diameter of the SiNWs, it is assumed that the probe tip contacts multiple nanowires in parallel. The probe used was type 7A manufactured by Micromanipulator Inc. The probe tip diameter is $127 \mu \mathrm{m}$ ( 5 mil), with a point radius of $0.35 \mu \mathrm{m}$. More details about the probe used are given in Appendix E.

Electrical contact between the sample and the probe was verified either (1) by monitoring the resistance between the back of the sample and the probe with an ohmmeter or (2) by performing I-V sweeps using the Semiconductor Parameter Analyzer.

\subsection{DC device characterization of silicon nanowire diodes}

The initial step of the investigation was to verify that the nanowire devices mounted in the two waveguides and setup in circuits as described in the previous section exhibited non-linear Current-Voltage (I-V) characteristics. An HP 4145B semiconductor parameter analyzer connected to a PC running ICS software was used to characterize the I-V behavior of the samples. The semiconductor parameter analyzer obtains the data for the I-V curve by applying a varying voltage across the device and measuring the current through the device. 


\subsection{Low frequency characterization of silicon nanowire diodes}

Two harmonic generation experiments using low frequency (LF) fundamentals were performed, one using a $70 \mathrm{MHz}$ source the other using a $500 \mathrm{MHz}$ source. Both LF experiments used the same waveguide consisting of a brass strip over an aluminum base plate. The RF excitation signal was coupled in the waveguide using one of the SMA connectors at the ends of the waveguide, and the output signals were guided to the spectrum analyzer through the other SMA connector. The dimensions of the waveguide are marked on the picture below:

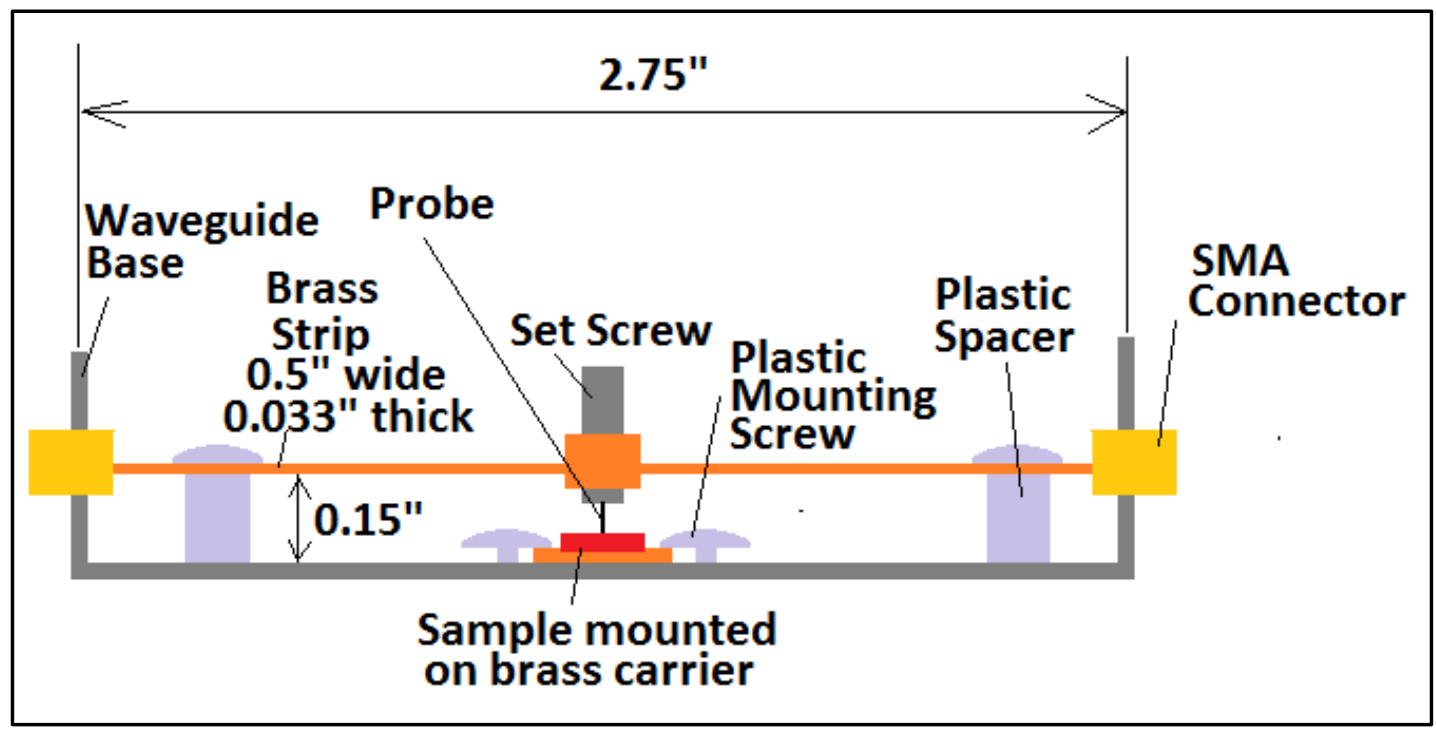

Figure 3-2. Low frequency waveguide details

In order to facilitate the investigation in the low frequency waveguide, the nanowire carrying substrates were cut in approximately rectangular pieces with the side of 0.5 - 1 $\mathrm{cm}$ and mounted on brass strip carriers using conductive silver paint. The brass strip carrier was then inserted into the waveguide and held in contact with the base of the 
waveguide with nylon screws. This provided a low electrical resistance path between the base of the waveguide and the back of the sample. A tungsten probe was mounted with conductive silver paint into an axially drilled long set screw that was lowered through a brass machine nut onto the sample.

\subsubsection{Response to $70 \mathrm{MHz}$ stimulus}

The diagram of the $70 \mathrm{MHz}$ setup is shown in Figure 3-3, and a picture of the setup is shown in Figure 3-4. The $70 \mathrm{MHz}$ signal was generated by an HP $8654 \mathrm{~A}$ signal generator. The purpose of the three filters between the signal generator and the bias-T is to filter the out of band frequencies originating in the signal generator. The bias-T allowed biasing the sample with a DC voltage without feeding back the DC into the signal generator. The DC block after the sample prevents the DC bias applied through the biasT from reaching the spectrum analyzer. Lastly, a high pass filter with a cutoff frequency between the fundamental and the second harmonic was used to prevent the fundamental frequency from entering the spectrum analyzer and interfering with the measurements of the harmonics. The spectrum analyzer used was Tektronix 492P. The results obtained with the $70 \mathrm{MHz}$ setup are summarized in Figure 4-2 in the next chapter. 


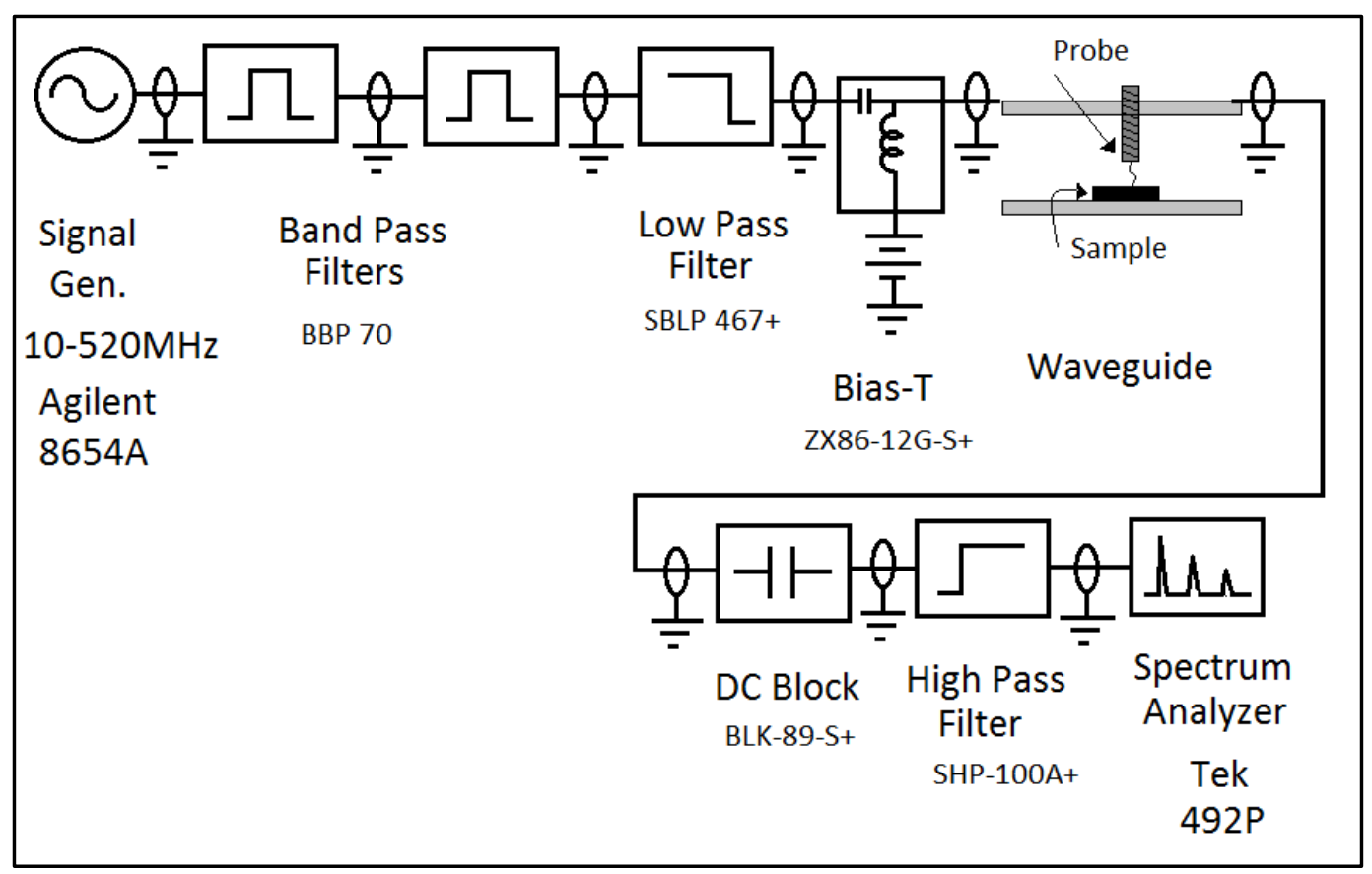

Figure 3-3. 70MHz System Diagram

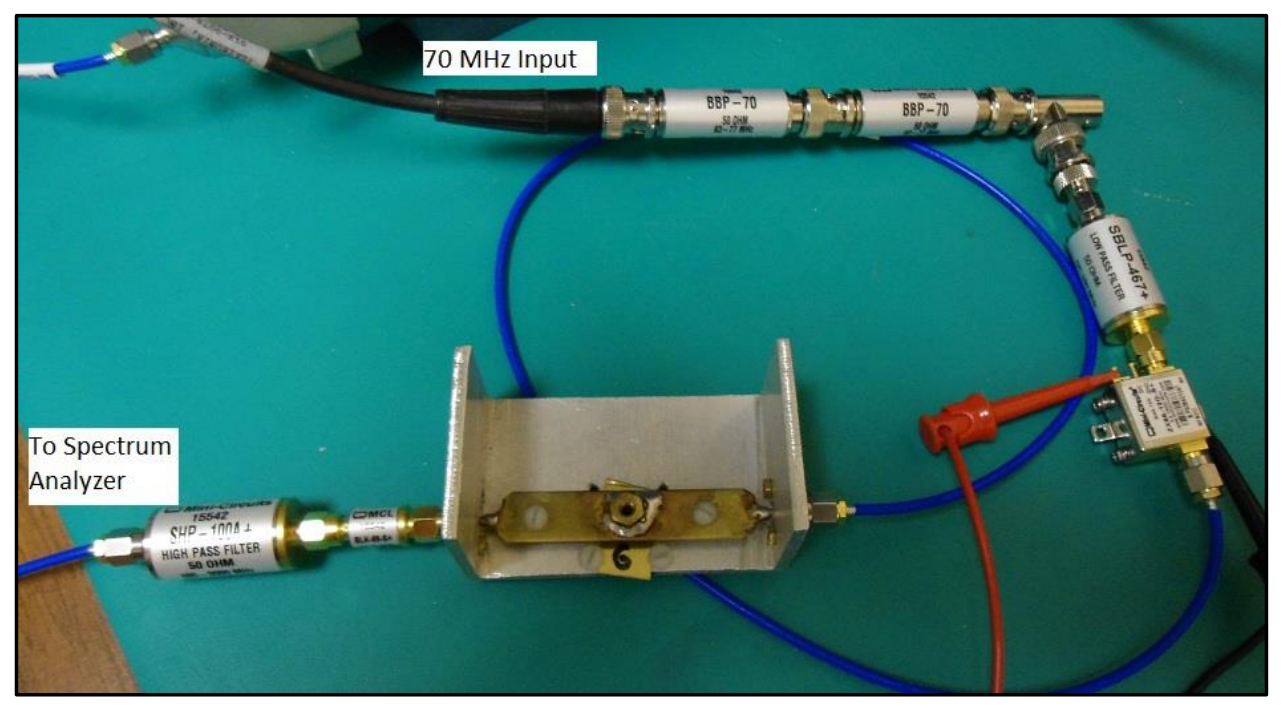

Figure 3-4. 70 MHz System Setup 


\subsubsection{Response to $500 \mathrm{MHz}$ stimulus}

The diagram of the $500 \mathrm{MHz}$ system is given in Figure 3-5, and a picture of the setup is given in Figure 3-6. The purpose of the components used in the $500 \mathrm{MHz}$ setup is the same as those in the $70 \mathrm{MHz}$ setup, but the components were chosen to support the higher frequencies. The results are summarized in Figure 4-3 in the next chapter.

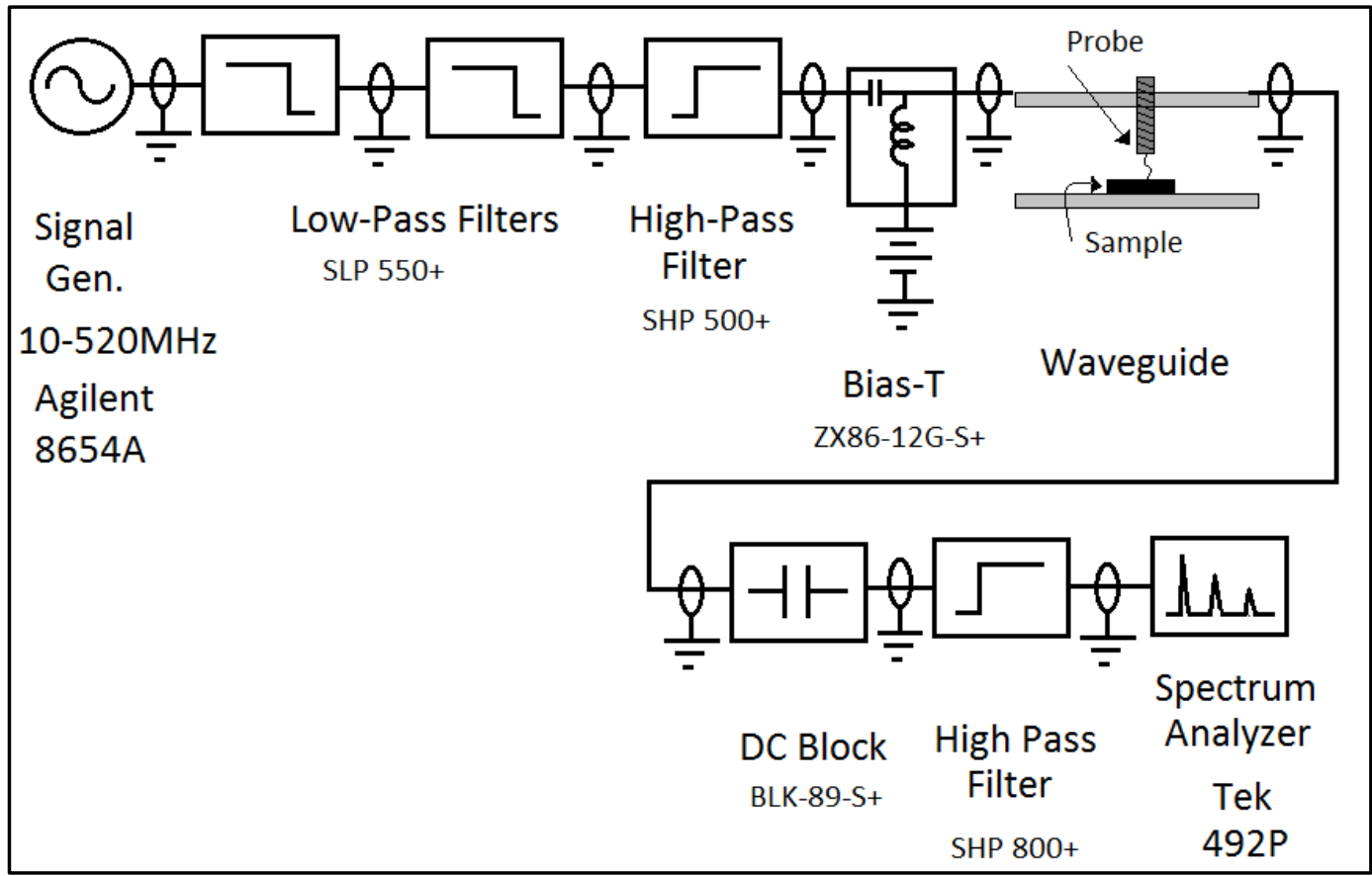

Figure 3-5. $500 \mathrm{MHz}$ System Diagram 


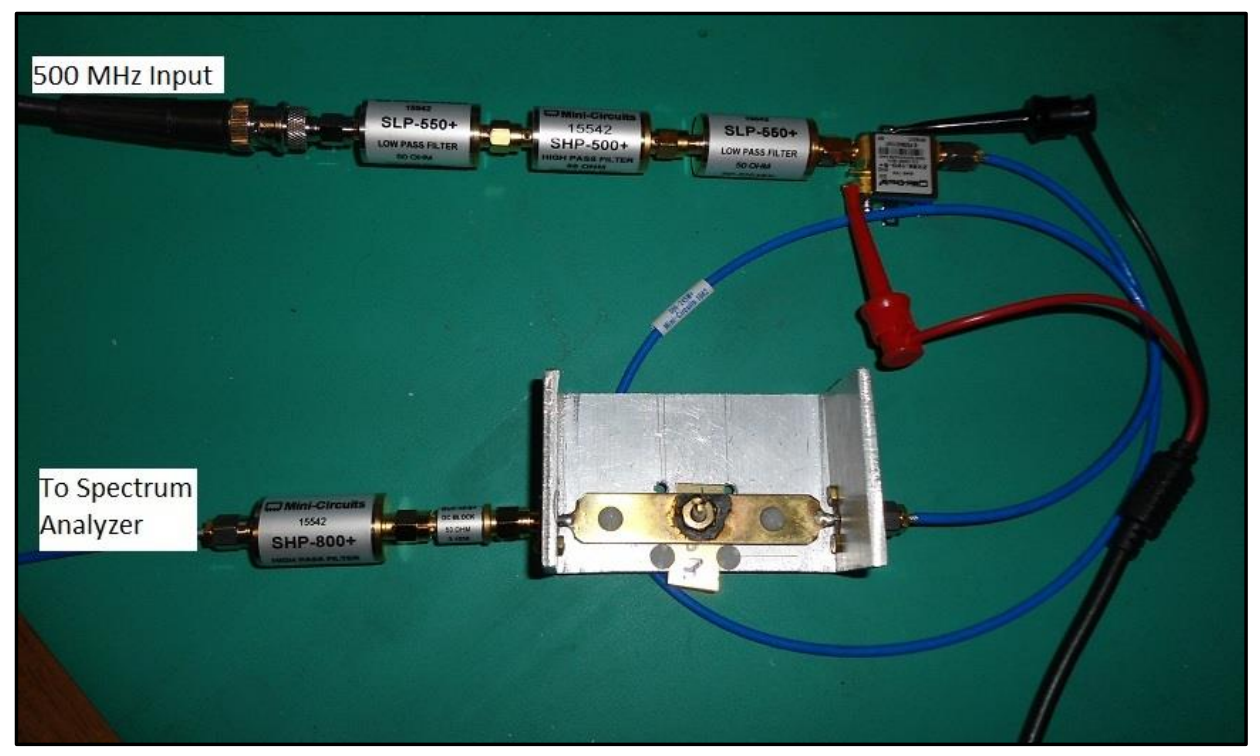

Figure 3-6. $500 \mathrm{MHz}$ System Setup

\subsection{Millimeter and sub-millimeter band characterization of silicon nanowire diodes}

Characterization of the SiNW samples was also performed between $50 \mathrm{GHz}$ and 200

$\mathrm{GHz}$. This range was used because of the available test equipment and budget

constraints. The microwave equipment used in the microwave experiments contains or couples to metal rectangular hollow waveguides.

\subsubsection{Equipment used}

The microwave test equipment used is listed in Table 3-2 and the data acquisition equipment is listed in Table 3-3 below: 
Table 3-2. Microwave Test Equipment

\begin{tabular}{|c|l|l|l|}
\hline & \multicolumn{1}{|c|}{ Device } & \multicolumn{1}{c|}{ Characteristics } & \multicolumn{1}{|c|}{ Manufacturer } \\
\hline 1 & Source: QTM-5017RU & $50.1 \mathrm{GHz}, 17.8 \mathrm{dBm}$ & Quinstar \\
\hline 2 & Source: QTM-9417RW & $94.17 \mathrm{GHz}$ & Quinstar \\
\hline 3 & Isolator: QIF-W00000 & & Quinstar \\
\hline 4 & Attenuator: QAL-W00000 & & Quinstar \\
\hline 5 & $\begin{array}{l}\text { Low pass filter: } \\
\text { QFL-62SU00 }\end{array}$ & $\begin{array}{l}70 \mathrm{GHz} \text { Stop Band, } \\
45 \mathrm{~dB} \text { Attenuation }\end{array}$ & Quinstar \\
\hline 6 & External Mixer: M05HWD & $40-220 \mathrm{GHz}$ & OML Inc. \\
\hline 7 & External Mixer: M10HWD & $75-110 \mathrm{GHz}$ & OML Inc. \\
\hline 8 & External Mixer: M03HWD & $220-325 \mathrm{GHz}$ & OML Inc. \\
\hline 9 & $\begin{array}{l}\text { Spectrum Analyzer: } \\
\text { Tektronix 492P }\end{array}$ & & Tektronix \\
\hline 10 & Microwave Waveguide & WR19, WR10, WR5 & $\begin{array}{l}\text { Custom. } \\
\text { See section 3.6.3 }\end{array}$ \\
\hline
\end{tabular}

Table 3-3. Auxiliary Resources

\begin{tabular}{|c|l|l|l|}
\hline & \multicolumn{1}{|c|}{ Device } & \multicolumn{1}{|c|}{ Characteristics } & \multicolumn{1}{c|}{ Manufacturer } \\
\hline 1 & Controller PC & $\begin{array}{l}\text { Windows Vista } \\
\text { Windows 8 }\end{array}$ & $\begin{array}{l}\text { Dell } \\
\text { Asus Aspire V5 }\end{array}$ \\
\hline 2 & USB-GPIB adapter & $\begin{array}{l}\text { GPIB } \\
\text { communications }\end{array}$ & Prologix \\
\hline 3 & Data acquisition software & $\begin{array}{l}\text { Written in } \\
\text { EZGPIB/Pascal }\end{array}$ & Marius Ghita \\
\hline
\end{tabular}

\subsubsection{Data acquisition}

To eliminate inconsistencies in visually reading signal levels from the spectrum analyzer screen traces, the data acquisition process was automated. Custom software was written in EZ-GPIB to interface with the spectrum analyzer, acquire the spectrum sweeps, and save the data to the controller PC. The source code of the data acquisition program is given in Appendix $F$. 


\subsubsection{Microwave waveguide considerations}

A precision machined microwave waveguide was used to hold the samples and guide the incident microwave radiation towards the sample. The choice of frequency range

and experimental setup were dictated by the equipment available for this research (see Table 3-2). Because of these limitations, it was decided to perform the investigation using a $50 \mathrm{GHz}$ microwave source and a $94 \mathrm{GHz}$ microwave source. Rectangular hollow waveguides were used to guide the microwave radiation to the samples being investigated. The minimum dimensions of the waveguides can be computed with (2.23). Also, in order to minimize losses in the waveguide, the maximum dimensions of the waveguides needed to be kept close to the wavelengths of interest. Further, the size of the waveguides was chosen such that the detector can be coupled to a path that naturally filters out the microwave radiation source fundamental frequency. While the waveguide cross-section dimensions can be chosen somewhat arbitrarily given the above mentioned constraints, the sizes chosen were based on industry standards (see Appendix C). As such, WR19 dimensions were chosen for the longitudinal path, and WR10 and WR5 dimensions were chosen for the transverse paths. The waveguide manufactured under these constraints is shown in Figure 3-7. 


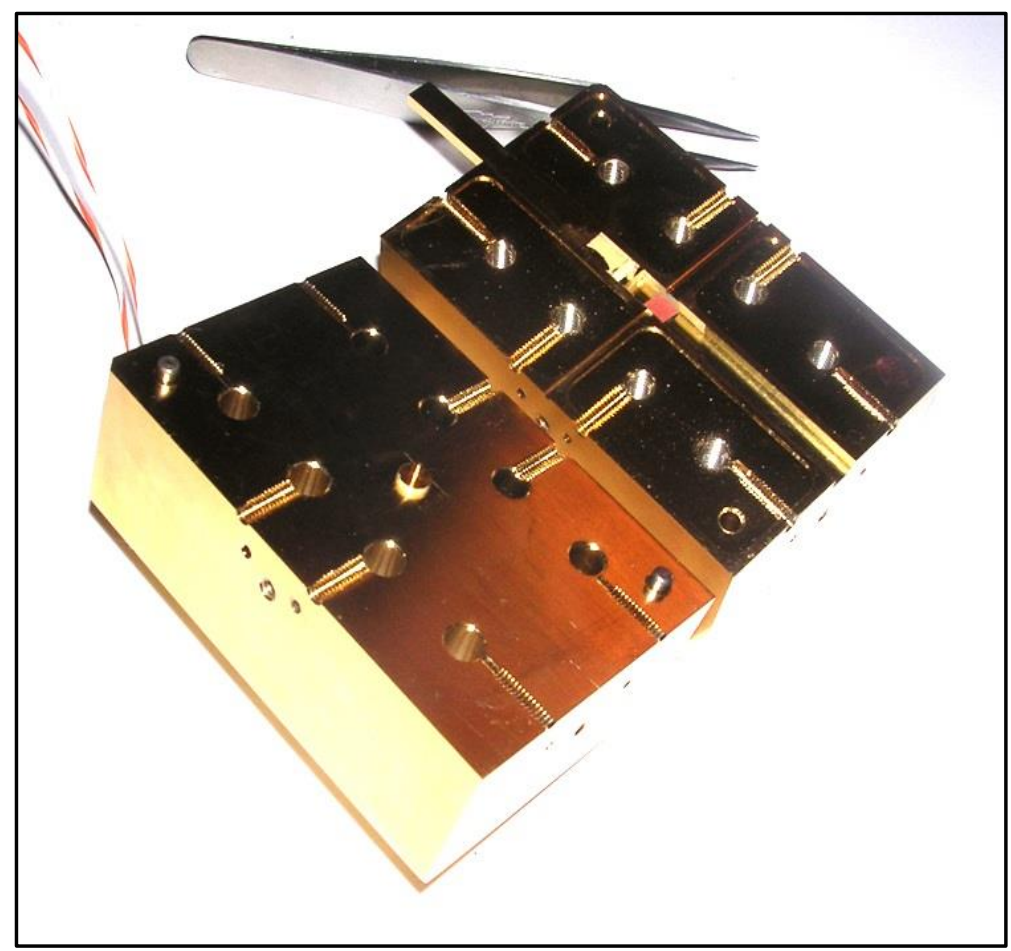

Figure 3-7. Microwave waveguide

The waveguide body consists of two halves bolted together with machine screws. This allowed for mounting of the sample directly in the waveguide at the intersection of the WR19, WR10, and WR5 paths. The top half of the waveguide had a shaft directly above the sample cavity that allowed for the introduction of a probe to contact the sample. Figure 3-8 shows the connections between the microwave waveguide and various test system components. The probe was lowered onto the sample using a micrometer stage mounted to the top half of the waveguide. Electrical insulation was maintained between the probe and the body of the waveguide. The microwave signal generated by the source was coupled to the waveguide through an isolator. The isolator prevented reflections from the waveguide and sample to reach the source and negatively impact 
its operation. The signal generated by the samples was detected with external mixers that were mounted on the appropriate waveguide path as needed. The purpose of the external mixers is to extend the operational range of the spectrum analyzer to frequencies above $50 \mathrm{GHz}$.

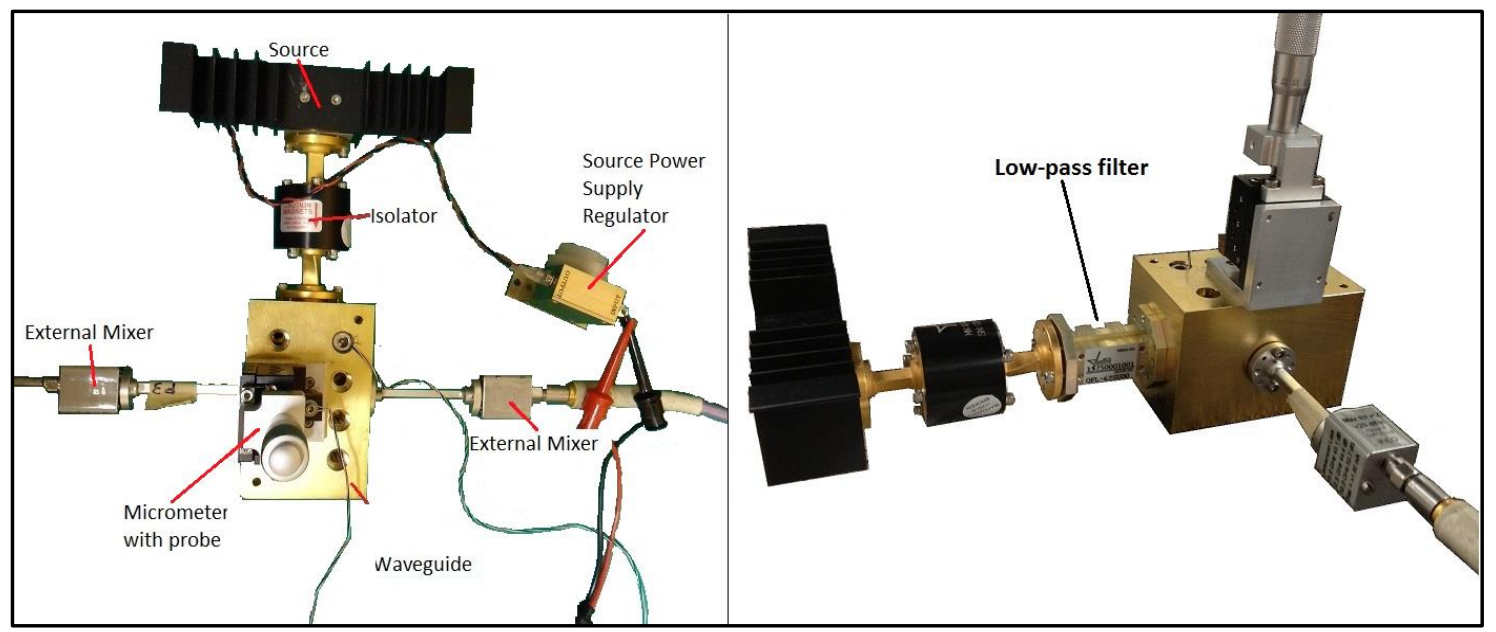

Figure 3-8. Typical Microwave Experiment Setup. Left: without low pass filter. Right: with low pass filter.

\subsubsection{Sample installation}

Samples with their back side cleaned were mounted in the central waveguide cavity using conductive silver paint. After the silver pain dried, the two halves of the Microwave Waveguide were bolted together. The main method of contacting the top of the nanowires was using a tungsten probe mounted on a micrometer and lowered through the shaft onto the sample. A second method of contacting the top of the nanowires via a small gauge wire bonded with silver paint to the top of the sample was briefly investigated, but led to no detectable harmonics. 


\subsubsection{Harmonic search procedure}

Identification of the non-linear response of the nanowires to microwave frequencies was attempted by searching for harmonics of the microwave signal used. The following procedure was used to search for the harmonics:

- The microwave source, spectrum analyzer (SA), and the biasing power supply were turned on and allowed to warm up for at least 30 minutes.

- The SA frequency band was changed appropriately to detect the $2^{\text {nd }}$ harmonic of the source. The second harmonic originating in the source facilitates the initial centering of the SA frequency span around the frequency of interest.

- The harmonic was identified on the SA screen by changing the range to $500 \mathrm{KHz} /$ division and using the IDENTIFY feature of the spectrum analyzer.

- The amplitude the signal displayed on the SA screen was maximized by adjusting a backstop behind the sample and by adjusting the bias current provided by the spectrum analyzer to the detector.

- The Low Pass (LP) filter was then introduced between the source and the microwave cavity. The LP filter minimizes the source harmonics entering the waveguide to an amplitude below the SA noise floor. With the source harmonics minimized, only $2^{\text {nd }}$ harmonic signals originating in the sample will be detected by the SA. An LP filter is necessary because depending on the amplitude of the source harmonics and the amplitude of the harmonics generated by the sample, the non-linear response of the sample can be completely masked by the source harmonics. 
- Sweeps were performed at different noise levels to search for the harmonic.

- The SA sweeps were acquired using a custom developed data acquisition program running on a laptop connected to the SA through a Prologix USB-GPIB adaptor. 


\section{EXPERIMENTAL RESULTS}

This chapter contains the experimental results obtained in this research. The results are reported in two categories: (1) low frequency (LF) and (2) millimeter/submillimeter, with the $\mathrm{LF}$ results being in turn subdivided into the $70 \mathrm{MHz}$ response and the $500 \mathrm{MHz}$ response. Some of the low frequency results were published in [58].

\subsection{Low frequency characterization results}

The frequency sweeps performed with the spectrum analyzer were captured on the computer, the harmonics of the fundamental (the peaks of the sweeps) were extracted from the acquired data and aggregated by excitation frequency.

\subsubsection{Response to $70 \mathrm{MHz}$ fundamental}

An example spectrum analyzer sweep showing the attenuated $70 \mathrm{MHz}$ fundamental and up to the $8^{\text {th }}$ harmonic is given in Figure 4-1. Figure 4-2 summarizes the responses to a $10 \mathrm{dBm}, 70 \mathrm{MHz}$ signal of various samples under various bias conditions. 


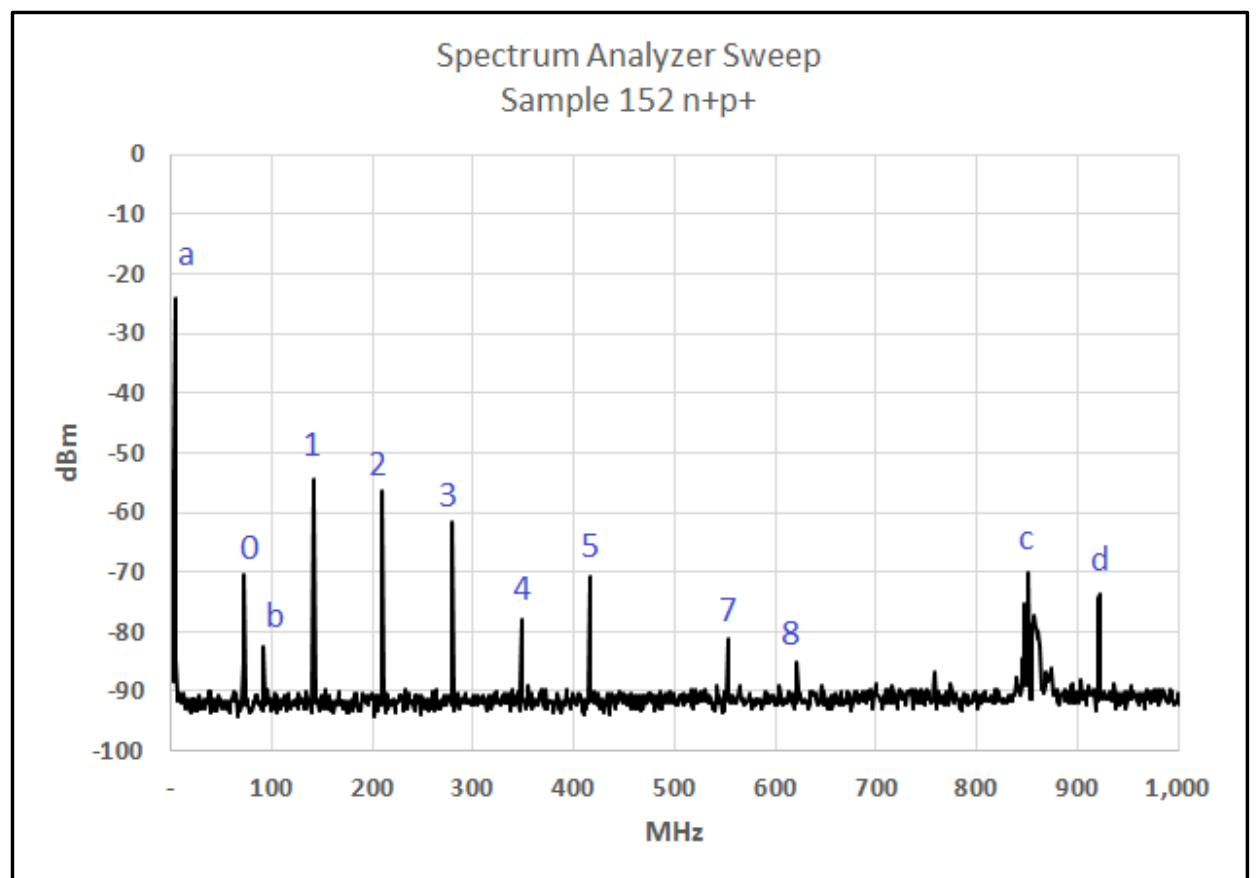

Figure 4-1. Spectrum Analyzer trace capture. $0=$ attenuated excitation signal/fundamental, 1-8=harmonics of the fundamental generated inside sample; b, $c$, $\mathrm{d}=\mathrm{FM}$ radio band, WiFi signals

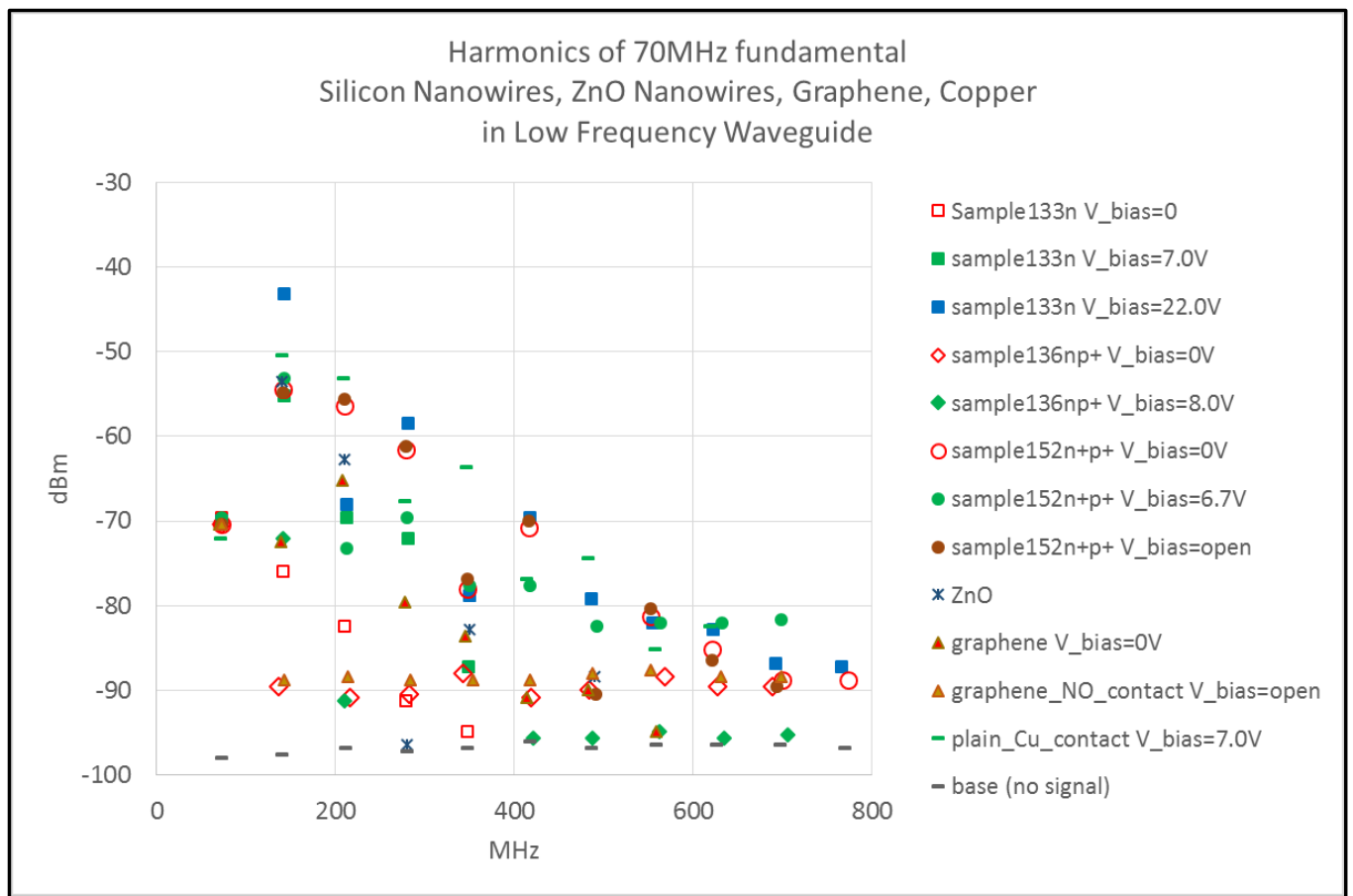

Figure 4-2. Harmonics of $70 \mathrm{MHz}$ fundamental 
The left most points on the graph in the figure above are the $70 \mathrm{MHz}$ excitation signal attenuated by the SHP-100A+ high pass filter. Signals at and above $140 \mathrm{MHz}$ are only minimally affected by the high pass filter, and since the front end filters minimize the source harmonics, the points at and above $140 \mathrm{MHz}$ represent harmonics generated in the sample. In general, it can be seen from the graph that the amplitude of the generated harmonics decreases with frequency. This trend is in agreement with the trend in the terms of (2.19) and is typical of harmonics generated in diodes. The graph also shows that biasing the devices affects the strength of the harmonics generated. This is due to the fact that biasing the device has the effect of moving the operational point of the device closer to or farther from the point of maximum non-linearity.

\subsubsection{Response to $500 \mathrm{MHz}$ fundamental}

The graph in the figure below summarizes the responses to a $10 \mathrm{dBm}, 500 \mathrm{MHz}$ signal by various samples. 


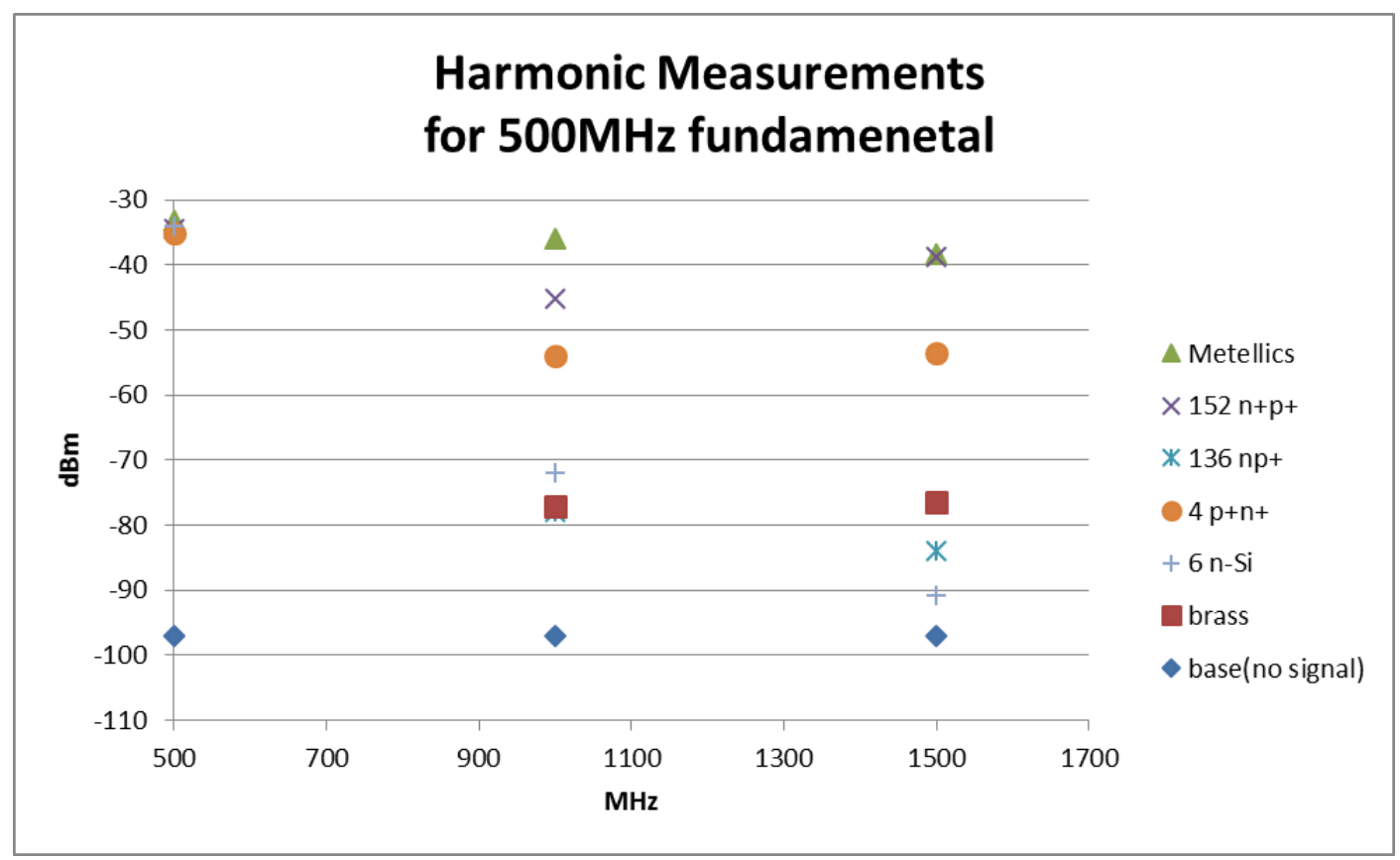

Figure 4-3. Harmonics of $500 \mathrm{MHz}$ fundamental

The explanation of the results obtained with the $500 \mathrm{MHz}$ setup parallels those obtained from the $70 \mathrm{MHz}$ setup. The left most points on the graph are the $500 \mathrm{MHz}$ excitation signal attenuated by the SHP-800+ high pass filter. Signals at and above $500 \mathrm{MHz}$ are only minimally affected by the high pass filter, and since the front end filters minimize the source harmonics, the points at and above $1000 \mathrm{MHz}$ represent harmonics generated in the sample. The decreasing trend in amplitude of the sample generated harmonics is not obvious in this case, as only the first two harmonics were recorded. The noise floor of the system is shown by the base signal, also represented on the graph.

For both the $70 \mathrm{MHz}$ and $500 \mathrm{MHz}$ experiments, the harmonics generated by the samples are attenuated by the waveguide before reaching the spectrum analyzer. 
However, even not correcting for the waveguide attenuation, the figures above clearly show that harmonics of the $70 \mathrm{MHz}$ and $500 \mathrm{MHz}$ fundamentals are generated by the samples analyzed. The impact of the waveguide attenuation on the detected harmonics is investigated further in Appendix D.

\subsection{Millimeter and sub-millimeter band characterization results}

Using the method described in 3.6, the selected SiNW samples were investigated in the microwave waveguide. Some of the samples were treated with HF and then rinsed and dried prior to being mounted in the waveguide in order to determine if the oxide layer that naturally develops on the surface of the nanowires has a significant effect on their behavior. The results of this investigation are given in the following sub-sections.

\subsubsection{Sample $130(n)$ and $148(n)$ in the Microwave Waveguide probed with tungsten probe}

Evidence of contact between the probe and the sample was collected by performing I-V sweeps with the Semiconductor Parameter Analyzer connected to the body of the waveguide and the tungsten probe as it was lowered onto the sample. The diode I-V curves are given below in Figure 4-4. 


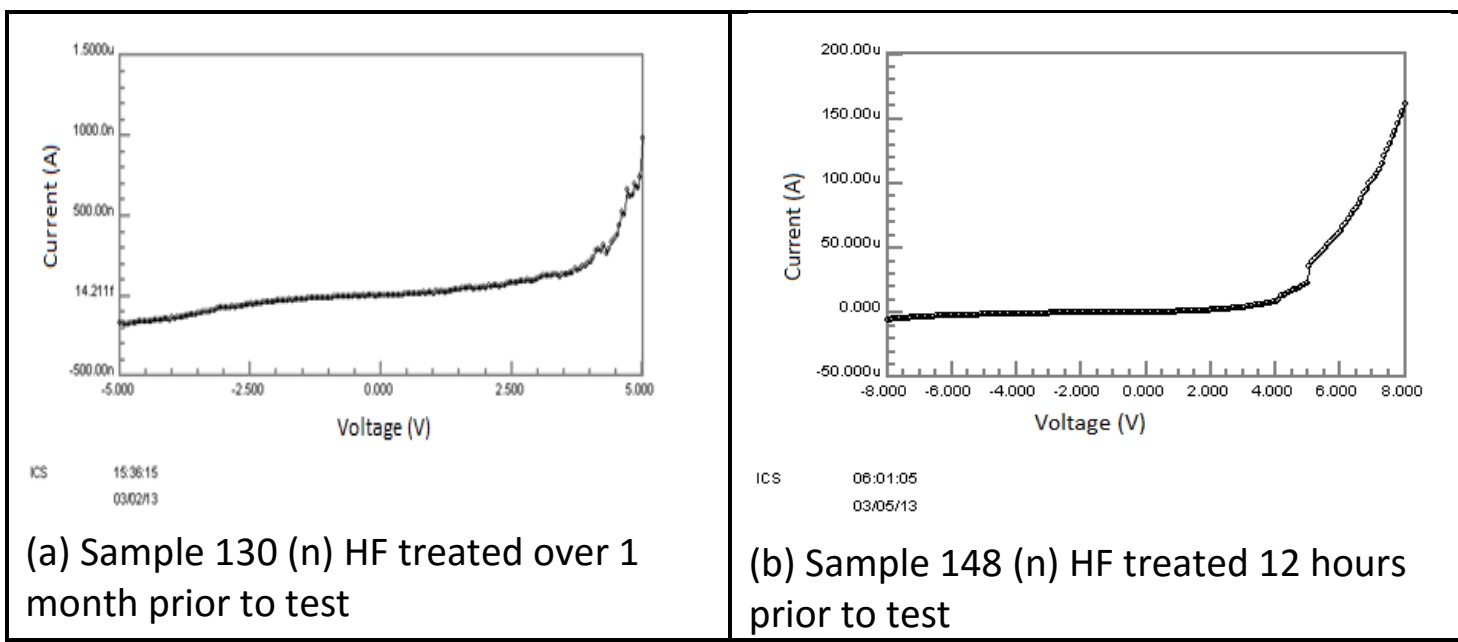

Figure 4-4. I-V response for samples probed in the high frequency waveguide

Like typical diodes, the curves obtained exhibit non-linear/exponential behavior.

However, the onset of the non-linearity is above 3V, while for typical diodes the forward voltage is below $1 \mathrm{~V}$. Since the reverse breakdown voltage threshold is not visible on the graphs, it can be concluded that there is a clear difference in the magnitude of the forward and reverse breakdown voltages these samples exhibit. It can be seen from the figure that the interval of time between treating the samples with HF and when the I-V traces are obtained affects the shape of the curves obtained. However, it must be noted that repeated, successive probing also impacts the shape of the graphs. Further work is needed in order to quantify the effects of oxide thickness and of probing on the I-V curves.

Once probe contact was established as shown by the above I-V traces, a search for harmonics of the $50 \mathrm{GHz}$ signal was performed using the method described in section 
3.6.5. The results of the harmonic search for samples $130(n)$ and $148(n)$ are given in

Table 4-1 below.

Table 4-1. Sample 130 (n) and 148 (n) first harmonic search results

\begin{tabular}{|l|l|l|l|l|l|l|}
\hline Sample & $\begin{array}{l}\text { LP Filter } \\
\text { Used }\end{array}$ & $\begin{array}{l}\text { Range } \\
(\mathrm{GHz})\end{array}$ & $\begin{array}{l}\text { V bias } \\
(\mathrm{V})\end{array}$ & $\begin{array}{l}\text { Noise } \\
\text { Floor }(\mathrm{dBm})\end{array}$ & $\begin{array}{l}\text { Peak } \\
(\mathrm{GHz})\end{array}$ & $\begin{array}{l}\text { Peak } \\
(\mathrm{dBm})\end{array}$ \\
\hline $130(\mathrm{n})$ & no & n/a & OV & -60 & 100 & $-36^{*}$ \\
\hline $130(\mathrm{n})$ & yes & n/a & OV & -60 & Not found & Not found \\
\hline $130(\mathrm{n})$ & yes & n/a & OV & -68 & Not found & Not found \\
\hline $148(\mathrm{n})$ & no & n/a & OV & -60 & 99.841 & $-28^{*}$ \\
\hline $148(\mathrm{n})$ & no & $99.8341-99.934$ & OV & -56.1 & 99.8834 & $-33.6^{*}$ \\
\hline $148(\mathrm{n})$ & yes & $99.804-100.018$ & OV & -68 & Not found & Not found \\
\hline $148(\mathrm{n})$ & yes & $99.791-99.933$ & $5 \mathrm{~V}$ & -68 & Not found & Not found \\
\hline
\end{tabular}

* = peak attributed to source harmonics

The use of the low pass filter between the source and waveguide in a particular sweep was recorded in the "Low Pass Filter Used" column. If available, the extent of the spectrum sweeps is given in the "Range" column. The bias applied to the sample was recorded in column " $\mathrm{V}_{\text {bias" }}$ ", and the noise level above which the SA can identify signals is given in the column labeled "Noise Floor". The frequency and power of any detectable harmonics were recorded in the columns labeled "Peak". Since the second harmonics were only found when no low pass filter was installed between the excitation signal source and the waveguide, it is concluded that for the cases recorded in Table 4-1 the second harmonic signal detected most likely originates in the source and not in the sample. Future work with a high performance spectrum analyzer should clarify this, but 
any harmonics produced will be below the $-68 \mathrm{dBm}$ noise floor, and thus of little practical benefit.

\subsubsection{Sample $152(n+/ p+)$ in the Microwave Waveguide probed with tungsten probe}

Evidence of contact between the probe and the sample was collected with the semiconductor parameter analyzer and is given below in Figure 4-5 below.

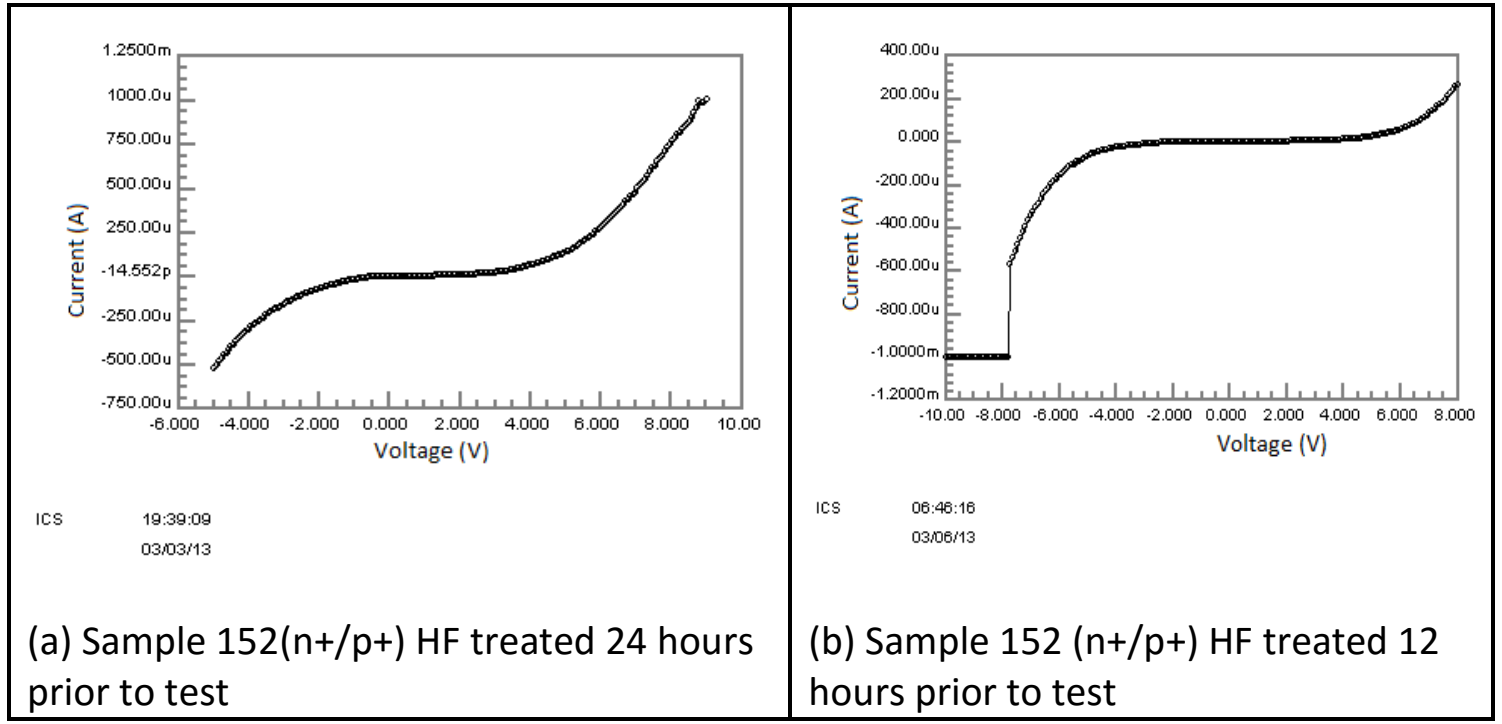

Figure 4-5. I-V response for sample $152(n+p+)$ probed in the high frequency waveguide

The acquired I-V curves for the $n+p+$ samples exhibit non-linear behavior and comparable forward and reverse voltage response. The results of the harmonic search for samples $152(n+p+)$ are given in Table 4-2 below. 
Table 4-2. Sample $152(n+p+)$ first harmonic response at $50 \mathrm{GHz}$ incident signal.

\begin{tabular}{|c|c|c|c|c|c|c|c|}
\hline Sample & $\begin{array}{l}\text { Low Pass } \\
\text { Filter } \\
\text { Used }\end{array}$ & $\begin{array}{l}\text { Range } \\
(\mathrm{GHz})\end{array}$ & $\begin{array}{l}\text { Probe } \\
\text { contact }\end{array}$ & $\begin{array}{l}V_{\text {bias }} \\
(V)\end{array}$ & $\begin{array}{l}\text { Noise } \\
\text { Floor } \\
(\mathrm{dBm})\end{array}$ & $\begin{array}{l}\text { Peak } \\
(\mathrm{GHz})\end{array}$ & $\begin{array}{l}\text { Peak } \\
(\mathrm{dBm})\end{array}$ \\
\hline $\begin{array}{l}152 \\
(n+p+)\end{array}$ & no & $\begin{array}{l}99.9071- \\
100.007\end{array}$ & yes & 0 & -56.2 & 99.927 & $-28.8^{*}$ \\
\hline $\begin{array}{l}152 \\
(n+p+)\end{array}$ & yes & $\begin{array}{l}99.8711- \\
99.971\end{array}$ & yes & 0 & -67.3 & 99.9099 & $\underline{-59.2}$ \\
\hline $\begin{array}{l}152 \\
(n+p+)\end{array}$ & no & $\begin{array}{l}99.83505- \\
99.885\end{array}$ & yes & 0 & -60.4 & 99.8612 & $-29.6 *$ \\
\hline $\begin{array}{l}152 \\
(n+p+)\end{array}$ & no & $\begin{array}{l}99.83585- \\
99.885\end{array}$ & yes & 0 & -60.7 & 99.8629 & $-29.6 *$ \\
\hline $\begin{array}{l}152 \\
(n+p+)\end{array}$ & yes & $\begin{array}{l}99.88151- \\
99.8865\end{array}$ & yes & 0 & -67.3 & 99.9099 & $\underline{-60.4}$ \\
\hline $\begin{array}{l}152 \\
(n+p+)\end{array}$ & yes & $\begin{array}{l}99.87402- \\
99.894\end{array}$ & no & $\mathrm{n} / \mathrm{a}$ & -61.9 & $\begin{array}{l}\text { Not } \\
\text { found }\end{array}$ & $\begin{array}{l}\text { Not } \\
\text { found }\end{array}$ \\
\hline $\begin{array}{l}152 \\
(n+p+)\end{array}$ & no & $\begin{array}{l}99.79301- \\
99.803\end{array}$ & yes & 0 & -62.2 & 99.79764 & $-32 *$ \\
\hline $\begin{array}{l}152 \\
(n+p+)\end{array}$ & yes & $\begin{array}{l}99.86101 \text { - } \\
99.871\end{array}$ & yes & 0 & -61.9 & 99.86118 & $\underline{-56.4}$ \\
\hline $\begin{array}{l}152 \\
(n+p+)\end{array}$ & yes & $\begin{array}{l}99.84201- \\
99.852\end{array}$ & yes & 0 & -62.1 & 99.84411 & $\underline{-57.2}$ \\
\hline $\begin{array}{l}152 \\
(n+p+)\end{array}$ & no & $\begin{array}{l}99.9191- \\
100.0\end{array}$ & yes & 0 & -46.9 & 99.9938 & $-30.0 *$ \\
\hline $\begin{array}{l}152 \\
(n+p+)\end{array}$ & yes & $\begin{array}{l}99.88501- \\
99.895\end{array}$ & yes & 0 & -68.9 & 99.88866 & $\underline{-62.4}$ \\
\hline
\end{tabular}

* = peak attributed to source harmonics

The underlined data in the table above shows that harmonics were detected after the introduction of the low pass filter between the source and waveguide. The presence of 
the harmonics when the filter was used is an indication that harmonics are generated in the sample.

\subsubsection{Sample $136(\mathrm{np}+)$ in the Microwave Waveguide probed with tungsten probe}

Evidence of contact between the probe and the sample was collected with the semiconductor parameter analyzer and is given in Figure 4-6 below.

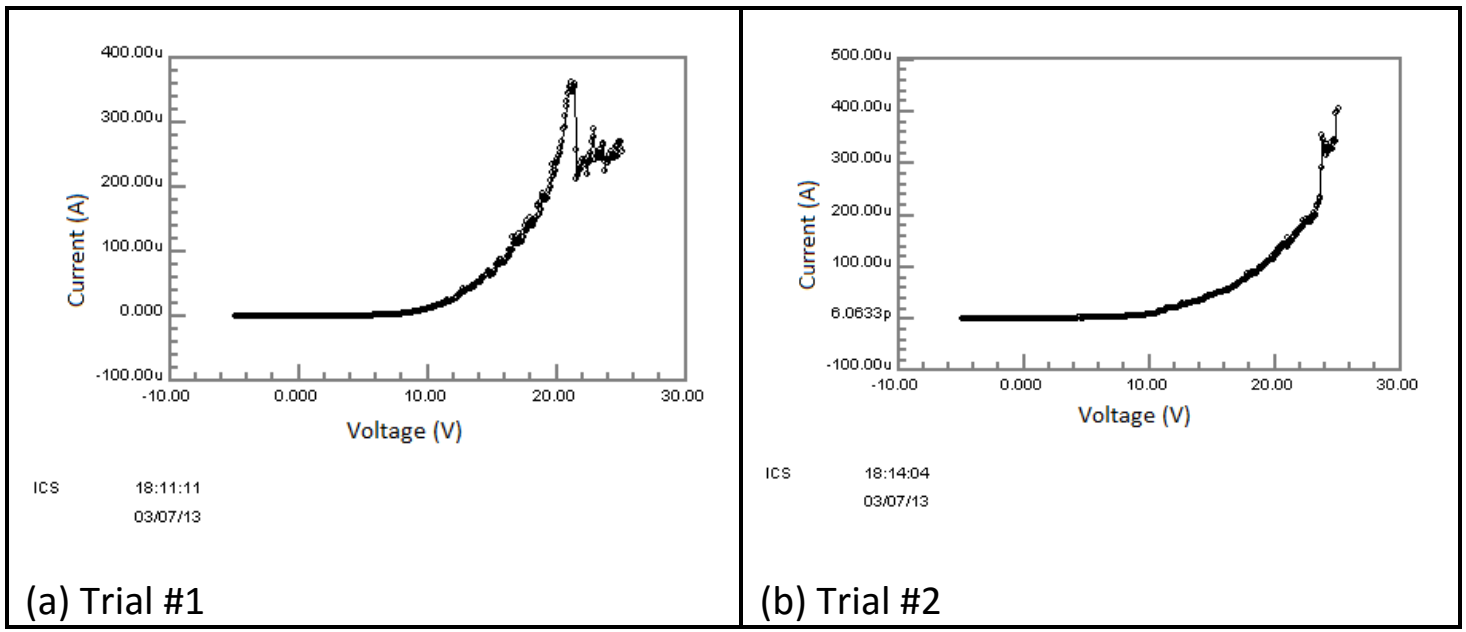

Figure 4-6. Sample136 (np+), probe contact in the high frequency waveguide.

The I-V traces for this sample also exhibit non-linear behavior. The forward voltage $(\sim 10 \mathrm{~V})$ in this case is much higher than that reported for the previous samples. A breakdown voltage for reverse bias was not observed across the voltage investigated. The results of the harmonic search for samples 136(np+) are given in Table 4-3 below. 
Table 4-3. Sample $136(\mathrm{np}+)$ first harmonic response at $50 \mathrm{GHz}$ incident signal.

\begin{tabular}{|l|l|l|l|l|l|l|l|}
\hline Sample & $\begin{array}{l}\text { Low Pass } \\
\text { Filter } \\
\text { Used }\end{array}$ & $\begin{array}{l}\text { Range } \\
(\mathrm{GHz})\end{array}$ & $\begin{array}{l}\text { Probe } \\
\text { contact }\end{array}$ & $\begin{array}{l}\text { V bias } \\
(\mathrm{V})\end{array}$ & $\begin{array}{l}\text { Noise } \\
\text { Floor } \\
(\mathrm{dBm})\end{array}$ & $\begin{array}{l}\text { Peak } \\
(\mathrm{GHz})\end{array}$ & $\begin{array}{l}\text { Peak } \\
(\mathrm{dBm})\end{array}$ \\
\hline $\begin{array}{l}136 \\
(\mathrm{np}+)\end{array}$ & no & $\begin{array}{l}99.8341 \\
-99.934\end{array}$ & yes & 0 & -55.6 & 99.8702 & $-34.8^{*}$ \\
\hline $\begin{array}{l}136 \\
(\mathrm{np}+)\end{array}$ & yes & $\mathrm{n} / \mathrm{a}$ & yes & 0 & -66 & $\begin{array}{l}\text { Not } \\
\text { found }\end{array}$ & $\begin{array}{l}\text { Not } \\
\text { found }\end{array}$ \\
\hline $\begin{array}{l}136 \\
(\mathrm{np}+)\end{array}$ & yes & $\begin{array}{l}99.797- \\
100.068\end{array}$ & yes & 20 & -66 & $\begin{array}{l}\text { not } \\
\text { found }\end{array}$ & $\begin{array}{l}\text { not } \\
\text { found }\end{array}$ \\
\hline
\end{tabular}

* = peak attributed to source harmonics

Since no detectable harmonics signals were detected when the low pass filter was

placed between the source and waveguide, it is concluded that no harmonic signal was generated by in the sample, or if any harmonics were generated, they were below the noise floor of the instrumentation used.

\subsubsection{Sample 133(n), $136(n p+), 152(n+p+)$ in the Microwave Waveguide probed with silver paint bonded copper wire}

This section contains harmonic search results for cases when the top sample contact was a conductive silver paint bonded wired. Evidence of contact between the wire and the sample was collected with the semiconductor parameter analyzer and is given in Figure 4-7 below. 


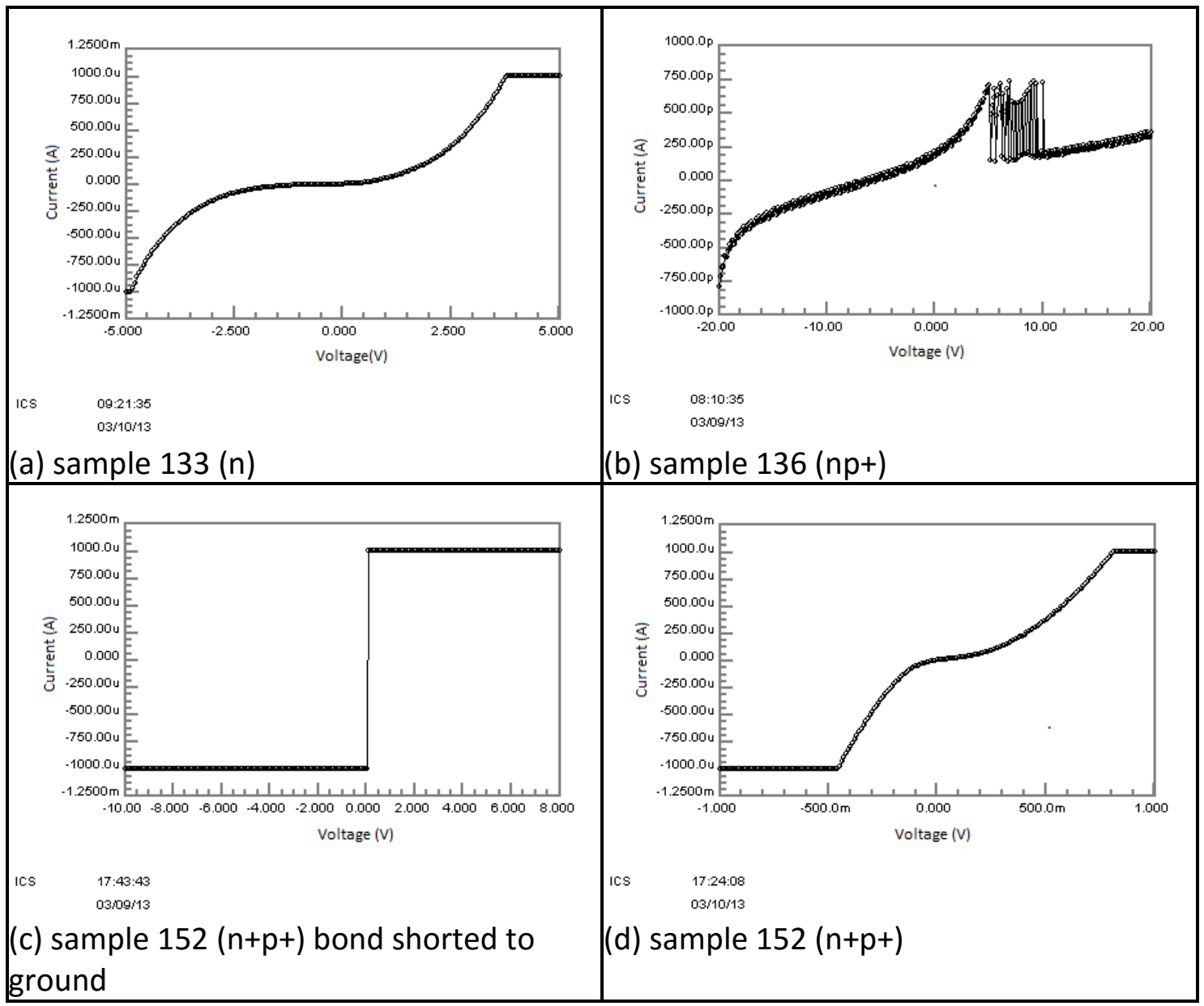

Figure 4-7. I-V curves for devices made by bonding wire to sample using silver paint

The non-linear response of the samples for this method of bonding is significantly different than the response for the tungsten probe contacted nanowires.

The $n$ SiNW samples (Figure 4-7 (a)) display a smaller forward voltage, and also display some symmetry under forward and reverse bias. The shape of the I-V curve is evidence that the Ag paint bond to the top and bottom of the sample is Schottky type. 
The np+ samples (Figure 4-7 (b)) display a much lower forward voltage compared to the reverse breakdown voltage. The sloping around the origin is evidence of a resistive path in parallel with the rectifying devices obtained. It is unclear why the I-V trace displays the noisy behavior between $5 \mathrm{~V}$ and $10 \mathrm{~V}$.

Figure 4-7 (c) shows evidence of electrical short between the silver paint attached wire and bottom of the wafer. For this reason the sample was removed and re-positioned. The resulting I-V curve is given in (d). The forward voltage for this case is much lower than in the case the samples were contacted with the tungsten micro-probe, and more in line with the forward voltage of typical Schottky diodes. However the much reduced reverse breakdown voltage is not typical of common Schottky diodes. The sample also displays a slight sloping around the origin which could be due to a parallel resistive path. The results of the harmonic search for samples contacted with silver paint bonded wire are given in Table 4.4 below.

Table 4-4. First harmonic search result for silver paint bonded probe wire

\begin{tabular}{|l|l|l|l|l|l|l|l|}
\hline Sample & $\begin{array}{l}\text { Low } \\
\text { Pass } \\
\text { Filter } \\
\text { Used }\end{array}$ & $\begin{array}{l}\text { Range } \\
(\mathrm{GHz})\end{array}$ & $\begin{array}{l}\text { Probe } \\
\text { contact }\end{array}$ & $\begin{array}{l}\text { V bias } \\
(\mathrm{V})\end{array}$ & $\begin{array}{l}\text { Noise } \\
\text { Floor } \\
(\mathrm{dBm})\end{array}$ & $\begin{array}{l}\text { Peak } \\
(\mathrm{GHz})\end{array}$ & $\begin{array}{l}\text { Peak } \\
(\mathrm{dBm})\end{array}$ \\
\hline $\begin{array}{l}136 \\
(\mathrm{np}+)\end{array}$ & yes & $\begin{array}{l}\text { not } \\
\text { recorded }\end{array}$ & yes & 0 & -67 & $\begin{array}{l}\text { not } \\
\text { found }\end{array}$ & $\begin{array}{l}\text { not } \\
\text { found }\end{array}$ \\
\hline $\begin{array}{l}136 \\
(\mathrm{np}+)\end{array}$ & yes & $\begin{array}{l}\text { not } \\
\text { recorded }\end{array}$ & yes & 3.5 & -66 & $\begin{array}{l}\text { not } \\
\text { found }\end{array}$ & $\begin{array}{l}\text { not } \\
\text { found }\end{array}$ \\
\hline $133(\mathrm{n})$ & yes & $\begin{array}{l}\text { not } \\
\text { recorded }\end{array}$ & yes & 0 & -66 & $\begin{array}{l}\text { not } \\
\text { found }\end{array}$ & $\begin{array}{l}\text { not } \\
\text { found }\end{array}$ \\
\hline $\begin{array}{l}152 \\
(\mathrm{n}+\mathrm{p}+)\end{array}$ & yes & $\begin{array}{l}99.758- \\
100.032\end{array}$ & yes & 0 & -75 & $\begin{array}{l}\text { not } \\
\text { found }\end{array}$ & $\begin{array}{l}\text { not } \\
\text { found }\end{array}$ \\
\hline
\end{tabular}


The table above shows that no harmonics were detected from any of the samples when the low pass filter was placed between the source and waveguide and contact to the top of the samples was made with Ag-paint.

The results presented in section 4.1 and 4.2 show that the Si NW samples do indeed display non-linear behavior, and for the $n+p+$ sample the non-linear behavior extends into the millimeter band range. 


\section{DISCUSSION OF RESULTS}

\subsection{Types of circuits and diodes obtained}

The structure of the circuits formed by probing the SiNW samples is described in this section. Based on the substrate used (i.e. with or without epi layer, thickness of the epi layer; see Table 3-1) and the length of the nanowires obtained (see section 3.2), and assuming that the contact with the back side of the sample is ohmic, three possible circuits were obtained as shown in Figure 5-1 below:

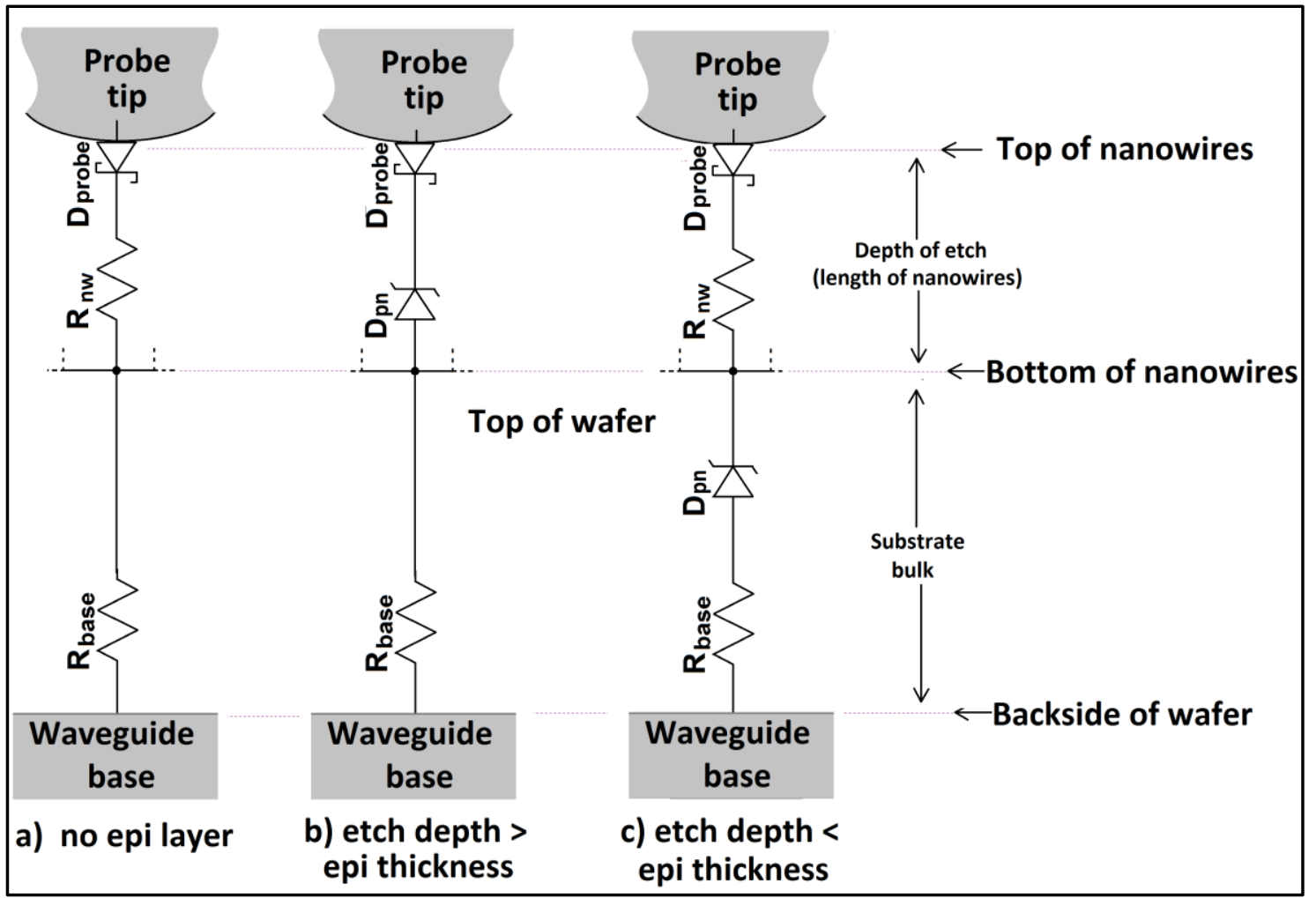

Figure 5-1. Structure of circuits obtained by probing silicon nanowire samples

where: 
- $\mathrm{R}_{\text {base }}$ is the resistance between waveguide and either the SiNW (configurations a

$\& b$ in Figure $5-1$ ) or the $\mathrm{P}-\mathrm{N}$ junction in the bulk (configuration $\mathrm{c}$ ).

- $\mathrm{R}_{n w}$ is the resistance of the nanowire for the cases where there is no P-N junction inside the nanowire.

- $D_{p n}$ is the diode formed at the junction of the epi layer and the wafer substrate. This diode can be either inside the nanowire (configuration b) or inside the bulk (configuration $\mathrm{c}$ ). In the case where the $\mathrm{P}-\mathrm{N}$ junction is inside the nanowire (configuration b), the resistance of the nanowire is lumped into $D_{p n}$.

- $D_{\text {probe }}$ is the Schottky diode formed at the contact of the probe with the SiNW.

The figure shows only the path through one nanowire. Since the probe contacts multiple nanowires at one time, the rest of the circuits between the probe and the substrate are shown with dotted lines. For each sample, the circuits obtained are summarized in the table below. The right most column (labeled "Circuit representation") refers to the types of circuits described in Figure 5-1. The last row in the table refers to a circuit obtained by probing ZnO nanowire samples obtained by a different method. The $\mathrm{ZnO}$ nanowires are randomly distributed on the Au substrate. As such, the current path between the probe and the waveguide may traverse the nanowires either longitudinally or transversally. 
Table 5-1. Types of nanowire diode circuits obtained

\begin{tabular}{|c|c|c|c|c|c|}
\hline \multirow{2}{*}{$\begin{array}{l}\text { Sample \# } \\
\text { type }\end{array}$} & \multirow{2}{*}{$\begin{array}{l}\text { Contact } \\
\text { at the } \\
\text { base }\end{array}$} & \multicolumn{2}{|c|}{$\begin{array}{l}\text { Junction inside } \\
\text { semiconductor }\end{array}$} & \multirow{2}{*}{$\begin{array}{l}\text { Junction at the } \\
\text { probe/NW } \\
\text { interface }\end{array}$} & \multirow{2}{*}{$\begin{array}{l}\text { Circuit } \\
\text { representation }\end{array}$} \\
\hline & & type & location & & \\
\hline $\begin{array}{l}4,152 \\
(\text { epi } n+) / p+\end{array}$ & $\begin{array}{l}\mathrm{p}+/ \mathrm{Ag} \\
\text { paint }\end{array}$ & $n+/ p+$ & $\begin{array}{l}\text { Inside } \\
\text { nanowire }\end{array}$ & $\begin{array}{l}\text { Schottky, } \\
n+\text { Si/W }\end{array}$ & Figure 5-1 (b) \\
\hline $\begin{array}{l}6 \\
n\end{array}$ & $\begin{array}{l}\mathrm{n} / \mathrm{Ag} \\
\text { paint }\end{array}$ & - & - & $\begin{array}{l}\text { Schottky, } \\
\text { n Si/W }\end{array}$ & Figure 5-1 (a) \\
\hline $\begin{array}{l}83 \\
p+\end{array}$ & $\begin{array}{l}\mathrm{p}+/ \mathrm{Ag} \\
\text { paint }\end{array}$ & - & - & $\begin{array}{l}\text { Schottky, } \\
p+\text { Si/W }\end{array}$ & Figure 5-1 (a) \\
\hline $\begin{array}{l}84 \\
p\end{array}$ & $\begin{array}{l}\mathrm{p}+/ \mathrm{Ag} \\
\text { paint }\end{array}$ & - & - & $\begin{array}{l}\text { Schottky, } \\
\text { p Si/W }\end{array}$ & Figure 5-1 (a) \\
\hline $\begin{array}{l}87 \\
n+\end{array}$ & $\begin{array}{l}\mathrm{n}+/ \mathrm{Ag} \\
\text { paint }\end{array}$ & - & - & $\begin{array}{l}\text { Schottky, } \\
n+\text { Si/W }\end{array}$ & Figure 5-1 (a) \\
\hline $\begin{array}{l}n / a \\
(\text { epi } p+) / p++\end{array}$ & $\begin{array}{l}\mathrm{p}++/ \mathrm{Ag} \\
\text { paint }\end{array}$ & - & - & $\begin{array}{l}\text { Schottky, } \\
p+\text { Si/W }\end{array}$ & Figure 5-1 (a) \\
\hline $\begin{array}{l}\text { n/a } \\
(\text { epi n)/p+ }\end{array}$ & $\begin{array}{l}\mathrm{p}+/ \mathrm{Ag} \\
\text { paint }\end{array}$ & $n / p+$ & $\begin{array}{l}\text { Inside } \\
\text { bulk }\end{array}$ & $\begin{array}{l}\text { Schottky, } \\
\text { n Si/W }\end{array}$ & Figure 5-1 (c) \\
\hline $\begin{array}{l}\mathrm{n} / \mathrm{a} \\
\mathrm{ZnO}\end{array}$ & $\mathrm{Au} / \mathrm{ZnO}$ & - & - & Schottky, ZnO/W & $\mathrm{n} / \mathrm{a}$ \\
\hline
\end{tabular}

\subsection{Device parameter calculations for the $\mathrm{P}-\mathrm{N}$ junctions obtained}

Assuming the $\mathrm{P}-\mathrm{N}$ junctions are abrupt, $\mathrm{P}-\mathrm{N}$ junction parameters for selected samples used can be calculated using (2.9), (2.11), (2.12), and (2.14). The values for the avalanche breakdown voltage were estimated from Figure 2-2. 
Table 5-2. Characteristics of the P-N junctions obtained

\begin{tabular}{|c|c|c|c|c|c|c|c|c|c|}
\hline Sample & $\mathrm{N}_{\mathrm{D}}$ & $\mathrm{N}_{\mathrm{A}}$ & $\begin{array}{l}V_{b i} \\
(V)\end{array}$ & $\begin{array}{c}x_{n} \\
(\mu \mathrm{m})\end{array}$ & $\begin{array}{c}\text { W } \\
(\mu \mathrm{m})\end{array}$ & $\begin{array}{c}\mathrm{C}_{0} \\
\left(\mathrm{pF} / \mathrm{cm}^{2}\right)\end{array}$ & $\begin{array}{c}\mathrm{C}_{0} \\
(\mathrm{pF})\end{array}$ & $\begin{array}{c}\mathrm{Rs}_{\mathrm{s}} \\
(\Omega)^{* * *}\end{array}$ & $\begin{array}{l}V_{b r} \\
\text { (V) }\end{array}$ \\
\hline $\begin{array}{l}152, \\
n+(\text { epi }) / \\
p+\end{array}$ & $\begin{array}{l}1.66 \\
E+16\end{array}$ & $\begin{array}{l}3.10 \\
E+18\end{array}$ & 0.876 & 0.2617 & 0.2631 & 39691.37 & $\begin{array}{l}3.82 \\
E-07^{*}\end{array}$ & $\begin{array}{l}2.0582 \\
E+07\end{array}$ & 39 \\
\hline $\begin{array}{l}152, \\
n+(\text { epi }) / \\
p+\end{array}$ & $\begin{array}{l}1.66 \\
E+16\end{array}$ & $\begin{array}{l}8.40 \\
E+18\end{array}$ & 0.901 & 0.2660 & 0.2665 & 39185.75 & $\begin{array}{l}3.77 \\
E-07^{*}\end{array}$ & $\begin{array}{l}2.0572 \\
E+07\end{array}$ & 39 \\
\hline $\begin{array}{l}n(\text { epi)/ } \\
p+\end{array}$ & $\begin{array}{l}8.61 \\
E+14\end{array}$ & $\begin{array}{l}3.10 \\
E+18\end{array}$ & 0.799 & 1.0999 & 1.1002 & 9491.71 & $\begin{array}{l}2.3729 \\
E+03^{* *}\end{array}$ & $\begin{array}{l}1.1025 \\
E+09\end{array}$ & 380 \\
\hline $\begin{array}{l}n(\text { epi)/ } \\
p+\end{array}$ & $\begin{array}{l}8.61 \\
E+14\end{array}$ & $\begin{array}{l}8.40 \\
E+18\end{array}$ & 0.825 & 1.1176 & 1.1177 & 9343.11 & $\begin{array}{l}2.3358 \\
E+03^{* *}\end{array}$ & $\begin{array}{l}1.1025 \\
E+09\end{array}$ & 380 \\
\hline \multicolumn{10}{|c|}{$\begin{array}{l}* \text { calculated for a circular junction inside a nanowire of } 35 \mathrm{~nm} \text { diameter } \\
* * \text { calculated for a rectangular junction inside a square sample of } 0.5 \times 0.5 \mathrm{~cm} \\
* * * \text { calculated per nanowire (excluding the depletion region of the } \mathrm{P}-\mathrm{N} \text { junction if } \\
\text { inside the nanowire. The contact resistance was not included because it is voltage } \\
\text { dependent) }\end{array}$} \\
\hline
\end{tabular}

For nanowire lengths of $20-25 \mathrm{~nm}$ and of calculated $\mathrm{n}$-side and total depletion widths given above, the depletion region around the $\mathrm{P}-\mathrm{N}$ junctions is completely inside the nanowire (for $n+/ p+$ sample) or completely inside the bulk of the substrate $(n / p+$ sample). Moreover, the large difference in the doping concentration on the two sides of the junction causes the depletion region to be located largely in the epi layer ( $n$-side) due to its lower impurity concentration.

Figure $5-2$ shows more structural details for the $n+/ p+$ and $n / p+$ devices obtained. The left side corresponds to configuration (b) of Figure 5-1, and the right side to configuration (c). 


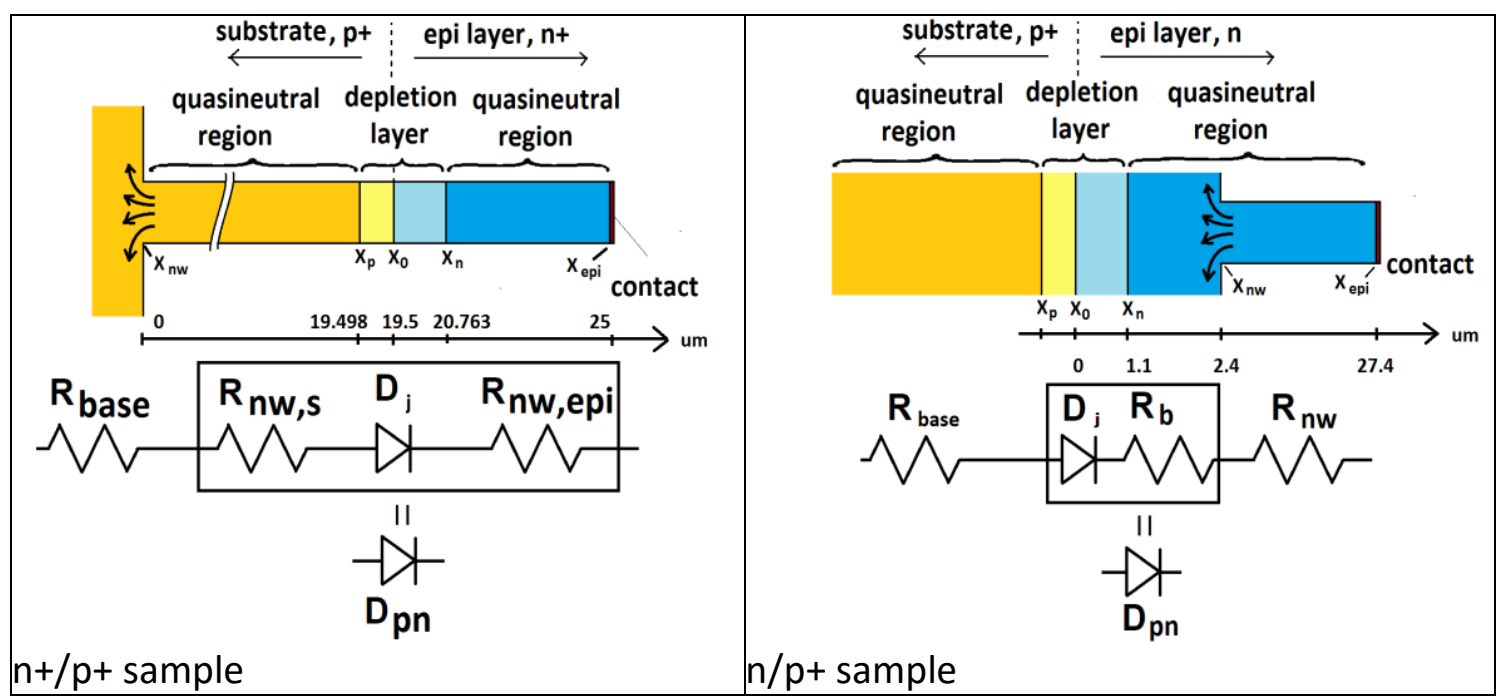

Figure 5-2. P-N Device details (not to scale)

Nanowire Series Resistance: Using (2.9) and considering the device structure in Figure

$5-2$, the series resistance of the nanowire portion of the device was calculated.

Assuming the diameter of the nanowires is $35 \mathrm{~nm}$, the results are shown in column 9

labeled 'Rs $(\Omega)$ ' of Table $5-2$. The series resistance $R_{s}$ of the $p+/ n+$ nanowire has three

components: $R_{n w, s}, R_{n w, e p i}$ and the spreading resistance. The series resistance $R_{s}$ for the $\mathrm{n} / \mathrm{p}+$ nanowire has only two components: $\mathrm{R}_{\mathrm{nw}}$ and the spreading resistance (the bulk resistance between the junction and the nanowire was ignored as the thickness of that region is about $1 / 20^{\text {th }}$ of the length of the nanowire). In both cases in Figure $5-2$, the spreading resistance is only shown with diverging arrows and no circuit component was displayed in the figure.

The $n+/ p+$ sample has a calculated depletion width considerably less than the dimension needed for the Zener effect, as mentioned in section 2.1.1.2. Moreover, the left side of the I-V curve of Figure 4-5 exhibits the "soft" knee typical of the Zener effect. The 
narrow depletion width and the soft knee for negative voltage are a strong indicator that the $n+/ p+$ devices exhibit the Zener effect.

There are evident differences in the shape of the I-V curves obtained for the samples contacted with the tungsten probe (see Figure 4-5 and Figure 4-6) and the I-V curves from samples contacted with Ag-paint bonded wire (see Figure 4-7). The I-V curves of the samples contacted with Ag-paint bonded wire exhibit a slope around the origin. This suggests a resistive/ohmic path in parallel with the $\mathrm{P}-\mathrm{N}$ junctions investigated. Assuming the resistance of the parallel path is approximately equal to the inverse of the slope around $\mathrm{OV}$, and correcting for this resistance, one obtains the I-V curves in the figures below:

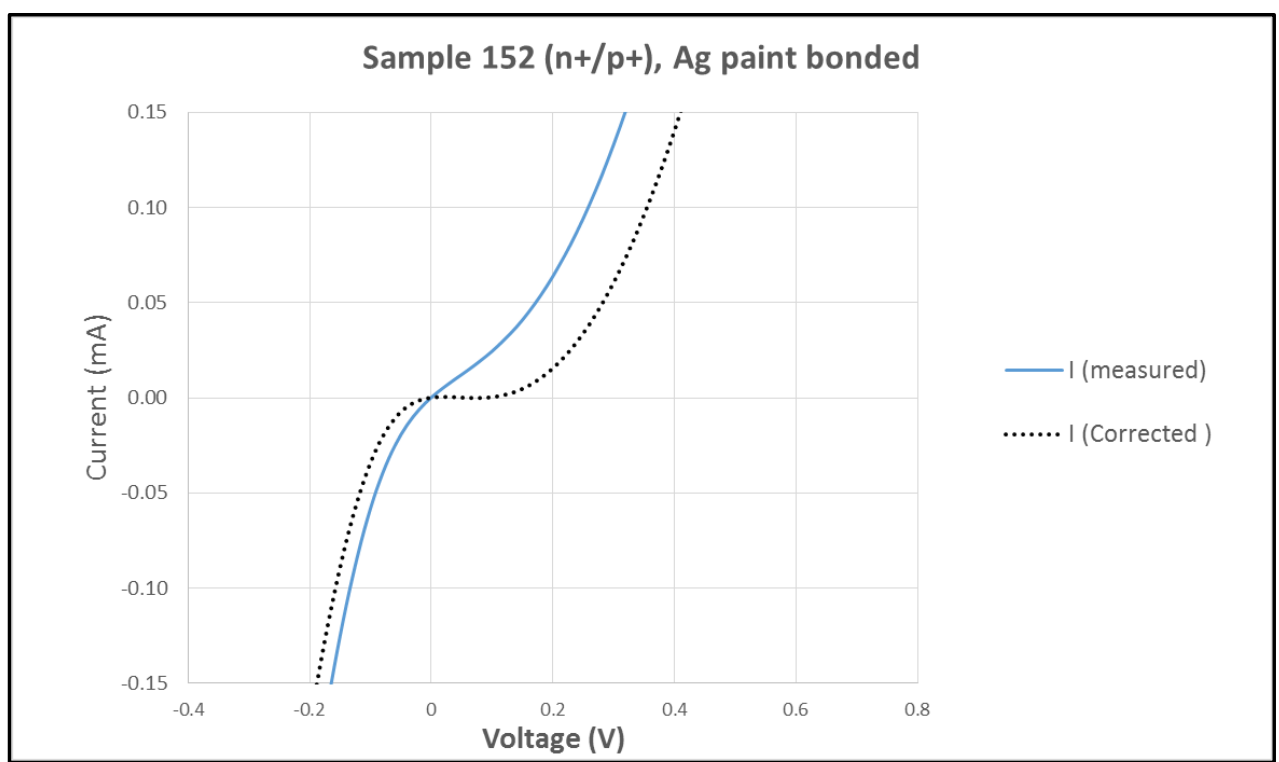

Figure 5-3. Sample $152(n+/ p+)$, Ag paint bonded probe wire, corrected for $R_{||}$ 


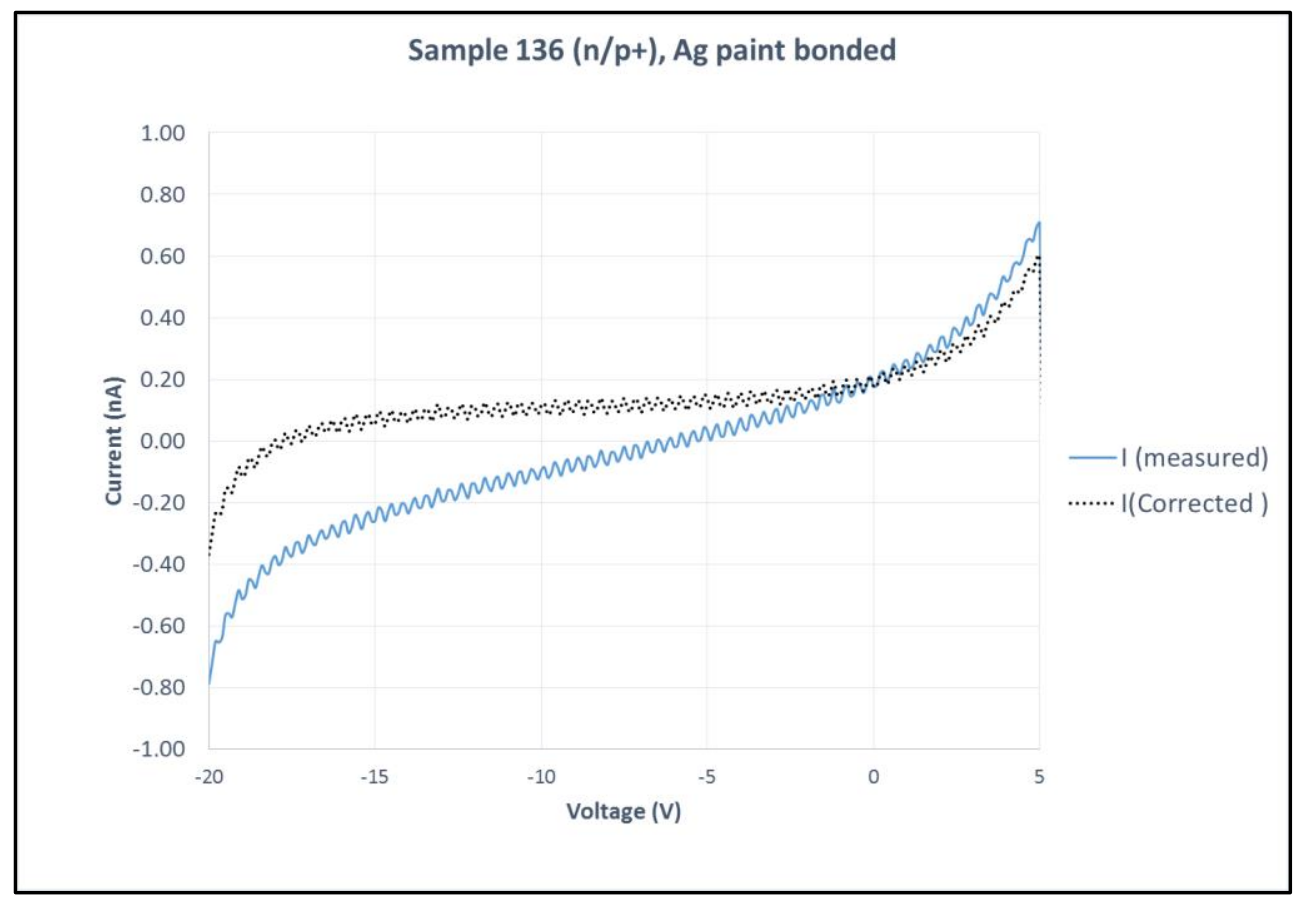

Figure 5-4. Sample $136(n / p+), A g$ paint bonded probe wire, corrected for $R_{||}$

The corrected I-V curve in Figure 5-3 displays a weak rectifying effect. The likely explanation for the weak rectifying effect is that $\mathrm{Ag}$ paint wicked around and passed the $\mathrm{P}-\mathrm{N}$ junctions located in the nanowires and formed an ohmic contact with the substrate. Further physical analysis is needed to confirm the wicking of the Ag paint around the SiNW. An ohmic contact is not expected to produce harmonics in response to microwave radiation, and this prediction is indeed supported by the (negative) results recorded in Table 4-4.

The uncorrected I-V curve of $n / p+$ sample however does show a pronounced rectifying behavior. The position of the inflection during reverse bias is at a negative voltage larger than $6.8 \mathrm{~V}\left(=6 \mathrm{E}_{\mathrm{g}} / \mathrm{q}\right.$, the onset of avalanche breakdown in silicon). This leads to the 
conclusion that the dominant reverse bias breakdown effect in this case is most likely avalanche breakdown. The corrected I-V curve of the $n / p+$ sample shows a clear rectifying effect. However, as recorded in Table 4-4, the search for harmonic generation had a negative outcome. The reason for the negative result in this case is the large area of the P-N junction, which for the $n / p+$ sample is not inside the nanowire, but inside the bulk of the substrate, leading to a high circuit capacitance and thus a low cutoff frequency.

\subsection{Sources of device characteristics variation}

As it can be seen from the I-V curves presented in Figure 4-4 through Figure 4-6, the contact to the sample cannot be controlled reliably. Unreliable contact has been a problem for researchers and manufacturers of point contact diodes since the beginning of the $20^{\text {th }}$ century. The point contact diodes were eventually successfully produced when the top contact was obtained by metal deposition. The I-V curves from the above mentioned figures show the effects of two types of sources for variation of the devices obtained:

\subsubsection{Variations in the current magnitude of the I-V measurements}

Assuming that the impedance of the external circuit (i.e. biasing circuit, test circuit) is negligible, the most important source of the variation in the current magnitude is the number of nanowires being contacted. The number of nanowires contacted can vary from experiment to experiment for four reasons: 
a. Nanowire orientation. As it can be seen from Figure 3-1, the top of the nanowire samples are not oriented perfectly perpendicular to the substrate they are obtained from.

b. Nanowire density/uniformity. Variations in the process used for obtaining the nanowires can cause variations in their density and diameter.

c. Probe overdrive. The probing overdrive (probe travel toward the substrate after the first nanowire is contacted) cannot be controlled precisely. The pressure exerted by the probe on the silicon affects the conductivity of the devices as shown by $[59,60]$.

d. Probe tip radius. The radius of the probe tip used limits the total number of nanowires being contacted. Assuming that all the nanowires inside the radius of the probe tip are perfectly cylindrical, uniformly distributed to the maximum possible density, and are all contacted by the probe, the number of nanowires contacted was calculated with the online calculator [61]. The results are provided below: 
Table 5-3. Maximum number of contacts

\begin{tabular}{|l|l|l|}
\hline $\begin{array}{l}\text { Nanowire } \\
\text { Diameter }\end{array}$ & $\begin{array}{l}\text { Diameter of } \\
\text { bounding circle }\end{array}$ & $\begin{array}{l}\text { Number of } \\
\text { contacts }\end{array}$ \\
\hline 20 & $700 \mathrm{~nm}$ & 951 \\
\hline 30 & $700 \mathrm{~nm}$ & 421 \\
\hline 35 & $700 \mathrm{~nm}$ & 308 \\
\hline 40 & $700 \mathrm{~nm}$ & 235 \\
\hline 50 & $700 \mathrm{~nm}$ & 149 \\
\hline 60 & $700 \mathrm{~nm}$ & 103 \\
\hline 35 & $1000 \mathrm{~nm}$ & 634 \\
\hline 35 & $2000 \mathrm{~nm}$ & 2549 \\
\hline 35 & $2700 \mathrm{~nm}$ & 4653 \\
\hline 35 & $3000 \mathrm{~nm}$ & 5748 \\
\hline 35 & $10000 \mathrm{~nm}$ & 64041 \\
\hline 35 & $14200 \mathrm{~nm}$ & 129177 \\
\hline
\end{tabular}

The last 4 rows of the table above were included to show the number of contacts if the probe tip was flattened by repeated contacts or skidding on various probed surfaces.

The linear portion of the right side of the I-V curve in Figure 4-5(a) can be used to estimate the series resistance of the $n+/ p+$ sample. Considering values between $7-8 \mathrm{~V}$, the series resistance computed from the measured I-V data is $R_{s}=3.605 \mathrm{~K} \Omega$, while the calculated nanowire series resistance is $20.582 \mathrm{M} \Omega$ (see Table $5-2$ ). Assuming uniform distribution of the nanowires, it is estimated that $\mathrm{N}=20.582 \mathrm{M} \Omega / 3.605 \mathrm{~K} \Omega=5709$ nanowires were contacted by the probe. Comparing this number with the numbers given in Table 5-3, it is believed that the contact area of the probe goes well beyond the tip of the probe (the published specification for the probe tip radius is $0.35 \mu \mathrm{m}$ ). Applying the same analysis to Figure 4- 6 we obtain $R_{s}=8.549 \mathrm{~K} \Omega$, and the number of nanowires probed would have to be $\mathrm{N}=1.1025 \mathrm{G} \Omega / 8.549 \mathrm{~K} \Omega=128,957$. As with the 
previous sample, the tip diameter of the probe is much smaller than the radius of a circle that can bind the nanowires, and the difference cannot be explained easily.

\subsubsection{Variations in forward and reverse voltage for devices obtained from the same substrate}

The variations in forward voltage of the diodes obtained are due to the surface uniformity of the nanowire-probe interface and the pressure exerted by the probe. The fact that for point contact diodes the surface states cannot be controlled reliably leads to variations in the surface states as presented in more detail in section 2.1.2.2.

Moreover, as Figure 2-8 shows, a progressively thicker oxide barrier leads to an increase in the diode forward voltage and a decrease of the breakdown voltage.

\subsection{Note on device modeling}

The large number of variables that can affect the device parameters and the difficulty posed by controlling them reliably make it difficult to develop device models for the devices obtained. Further work is needed to devise a method to obtain repeatable contact characteristics. While the results and calculations of device parameters from Table 5-2 may be used as a starting point in device modeling, the usefulness of such a model would be limited unless at a minimum the contact pressure and oxide thickness are well controlled and taken into account. 


\section{CONCLUSION}

As evident from the I-V curves recorded, nanowire diodes were successfully obtained and used in circuits where their non-linear behavior could be investigated further. Two methods of contacting the nanowires were investigated: (1) probing with a catwhisker probe, and (2) Ag-paint bonded wire. The evidence suggests that when Agpaint is used on the surface of the nanowire samples, the Ag-paint may wick towards the base of the nanowires and electrically connect to the substrate. Therefore, the method of contacting the nanowires with Ag-paint bonded wire is not appropriate for the investigation of free standing nanowire devices. The current-voltage characteristics of the devices obtained by cat whisker probe contact show that this method can be used to investigate the nanowire samples. The drawback of this method however is the variability in the quality of the contact.

A low frequency waveguide was successfully used to investigate the response of the SiNW devices to $70 \mathrm{MHz}$ and $500 \mathrm{MHz}$ signals. The much lower level of harmonic generation in the $n / p+$ devices (with junction in the bulk of the substrate) as compared to the $n+/ p+$ devices (with the junction in the nanowire) is an indication that the size of the P-N junction affects the high speed response of the diodes. This is in agreement with predictions of existing theory and with trends found in the characteristics of commercially available diodes.

The response of the nanowire diodes to a $50 \mathrm{GHz}$ signal was also investigated. It was found that one of samples investigated $(n+/ p+)$ exhibited a measurable non-linear 
response to the $50 \mathrm{GHz}$ signal. The evidence for the non-linear response was the detection of the $100 \mathrm{GHz}$ harmonic of the $50 \mathrm{GHz}$ stimulus. The successful detection of the $100 \mathrm{GHz}$ signal generated in the nanowire diodes validated the hypothesis that silicon nanowires can exhibit non-linear behavior in the microwave/mm-wave region of the spectrum.

This work showed for the first time that nanowires provide a low-cost option for the generation of high frequencies by employing the non-linear property of frequency multiplication.

\section{Avenues for future work}

Given the evidence presented that SiNW display a non-linear behavior when exposed to continuous radiation of up to $100 \mathrm{GHz}$, future work may be performed in three directions:

- Investigate the response of the nanowires to even higher frequencies, ideally in the $\mathrm{THz}$ band. The easiest way to accomplish this is to start with higher intensity of the fundamental frequency so that the higher harmonics can be detected easily. If the higher frequency response is detected, a demonstration of higher harmonic generation starting with lower frequency signals would be of practical interest.

- Increase the reliability and repeatability of the top contact. Binding the vertically aligned nanowires with an insulating material then polishing the sample until the top of the nanowires is exposed may allow for a contact that is more mechanically stable. This would also allow for patterning of a top electrode that contacts the top 
of the nanowires, thus eliminating the repeatability issues that arise from contacting the sample with a probe.

- Develop a model for the SiNW devices. The effects of variations in doping level, SiNW diameter, and series resistance (controlled through the length of the nanowire and position of the junction/epi layer thickness) can be investigated. 


\section{BIBLIOGRAPHY}

[1] "http://www.boeing.com/defensespace/space/bss/factsheets/government/milstar_ii/milstar_ii.html," [Online].

[2] "W band," Wikipedia, 24 December 2014. [Online]. Available: http://en.wikipedia.org/wiki/W_band. [Accessed 24 August 2015].

[3] T. R. Globus, D. L. Woolard, T. Khromova, T. W. Crowe, M. Bykhovskaia, B. L. Gelmont, J. Hesler and A. C. Samuels, "THz-Spectroscopy of Biological Molecules," Journal of Biological Physics, vol. 29, p. 89-100, 2003.

[4] C. P. Beetz and G. Ascarelli, "Far-Infrared Absorption of Nucleotides and Poly(I)Poly(C) RNA," Biopolymers, vol. 21, no. 8, 2004.

[5] P. Siegel, "Terahertz Technology in Biology and Medicine," IEEE Transactions on Microwave Theory and Techniques, vol. 52, no. 10, pp. 2438-2447, 2004.

[6] Tera View, Ltd, "Terrahertz sensors demonstrate demonstrate the potential for detections of explosives hidden by cloting and shoes," Tera View, 2010. [Online]. Available:

http://teraview.com/downloads/teraViewexplosivesdetectiontechnology.pdf. [Accessed 2011].

[7] J. M. Chamberlain, "Where Optics Meets Electronics: Recent Progress in Decreasing the Terahertz Gap," Philosophical Transactions: Mathematical, Physical and Engineering Sciences, vol. 362, pp. 199-213.

[8] J. M. Chamberlain, P. M. Simmonds, R. A. Strading and C. C. Bradley, "Excitedstate laser spectroscopy of the impurities in III-V and II-VI semiconductors," Solid State Comm., vol. 11, no. 3, p. 463-468, 1972.

[9] C. C. Bradley, "Gain and frequency characteristics of a $20 \mathrm{~mW} \mathrm{C.W.} \mathrm{water} \mathrm{vapour}$ laser oscillating at 118.6 microm," Infrared Phys., vol. 12, p. 287, 1972. 
[10] K. Kawase, M. Sato, T. Taniuchi and H. Ito, "Coherent tunable THz-wave generation from LiNbO3 with monolithic grating coupler," Appl. Phys. Lett., vol. 68 , no. 18 , p. $2483,1996$.

[11] G. Matsuura, G. A. Blake, R. A. Wyss, J. C. Pearson, C. Kadow, A. W. Jackson and A. C. Gossard, "A traveling-wave THz photomixer based on angle-tuned phase matching," Appl. Phys. Lett., vol. 74, no. 19, p. 2872, 1999.

[12] E. R. Brown, J. R. Soderstrom, C. D. Parker, L. J. Mahoney, K. M. Molvar and T. C. McGill, "Oscillations up to $712 \mathrm{GHz}$ in InAs/AlSb resonant-tunneling diodes," Appl. Phys. Lett., vol. 58, no. 20, p. 2291, 1991.

[13] Q. Zhang and X.-C. Wu, "7 terahertz broadband GaP electro-optic sensor," Appl. Phys. Lett., vol. 70, no. 14, p. 1784, 1997.

[14] T. Tanabe, K. Suto, J. Nishizawa, K. Saito and T. Kimura, "Tunable terahertz wave generation in the 3- to 7-THz region from GaP," Appl. Phys. Lett., vol. 83, no. 2, pp. 237-239, 2003.

[15] Y. J. Ding and W. Shi, "Tunable terahertz waves generated by mixing two copropagating infrared beams in GaP," Opt. Lett., vol. 30, p. 1030, 2005.

[16] G. D. Chern, E. D. Readinger, H. Shen, M. Wraback, C. S. Gallinat, G. Koblmuller and J. S. Speck, "Excitation wavelength dependence of terahertz emission from InN and InAs," Appl. Phys. Lett., vol. 89, no. 14, p. 14115, 2006.

[17] C. Weiss, R. Wallenstein and R. Beigang, "Magnetic-field-enhanced generation of terahertz radiation," Appl. Phys. Lett., vol. 77, no. 25, pp. 4160-4162, 2000.

[18] R. A. Lewis, M. L. Smith, R. Mendis and R. E. M. Vickers, "THz generation in InAs," Physica B, Vols. 376-377, pp. 618-671, 2006.

[19] X. Mu, I. B. Zotova and Y. J. Ding, "Power Scaling on Efficient Generation of Ultrafast Terahertz Pulses," IEEE J. Selected topics in Quant. Elect., vol. 14, no. 2, p. 315, 2008.

[20] P. Hoyer, M. Theur, R. Beigang and E. B. Kley, "Terahertz emission from black silicon," Appl. Phys. Lett., vol. 93, no. 9, 2008. 
[21] Y. J. Choa, G. B. Junga, Y. Myung, H. S. Kim, Y. S. Seo and J. Park, "Terahertz Emission from Vertically-aligned Silicon Nanowires," in Materials Research Society Spring Meeting, 2010.

[22] N. Vanderwal, "A microwave Schottky-barrier varistor using gallium arsenide for low series resistance," in Electron Devices Meeting, 1967 International (Volume:13) , 1967.

[23] R. Brazis, R. Raguotis and M. R. Siegrist, "Suitability of drift nonlinearity in Si, GaAs, and InP for high-power frequency converters with a $1 \mathrm{THz}$ radiation output," J. Appl. Physics, vol. 84, no. 7, p. 3474, 1998.

[24] J. Hesler, D. Porterfield, W. Bishop, T. Crowe, A. Baryshev, R. Hesper and J. Baselmans, "Development and Characterization of an Easy-to-Use THz Source," in 16th Int. Sym. on Space Terahertz Tech., May 3, Goteberg, Sweden, 2005.

[25] W. Shockley, "The theory of $p-n$ junctions in semiconductors and $p-n$ junction transistors," The Bell System Technical Journal, vol. 28, no. 3, pp. 435 - 489, 1949.

[26] C.-T. Sah, R. N. Noyce and W. Shockley, "Carrier Generation and Recombination in P-N Junctions and P-N Junction Characteristics," Proceedings of the IRE, vol. 45, no. 9, pp. 1228 - 1243, 1957.

[27] J. L. Moll, "The Evolution of the Theory for the Voltage-Current Characteristic of P-N Junctions," Proceedings of the IRE, vol. 46, no. 6, pp. 1076 - 1082, 1958.

[28] S. M. Sze, Physics of Semiconductor Devices, John Wiley \& Sons, 1981.

[29] R. F. Pierret, "Semiconductor Device Fundamentals," Addison Wesley, 1996.

[30] S. M. Sze and G. Gibbons, "Avalanche Breakdown Voltage of Abrupt and Linearly Graded p-n Junctions in Ge, Si, GaAs, and GaP," Applied Physics Letters, vol. 8, p. 111, 1966.

[31] C. Zener, Poceedings of the Royal Society (London), vol. 145, p. 523, 1934. 
[32] A. G. Chynoweth, W. L. Feldman, C. A. Lee, R. A. Logan, G. L. Pearson and P. Aigrain, "Internal Field Emission at Narrow Silicon and Germanium p-n Junctions," Physical Review, vol. 118, no. 2, p. 425, 1960.

[33] A. Y. C. Yu, "Electron Tunneling and Contact Resistance of Metal-Silicon Contact Barriers," Solid-State Electronics, vol. 13, pp. 239-247, 1970.

[34] C. Y. Chang, Y. K. Fang and S. M. Sze, "Specific Contact resistance of metal semiconductor barriers," Solid-state electronics, vol. 14, no. 7, pp. 541-550, 1971.

[35] H. A. Watson, Microwave Semiconductor Devices and Their Circuit Applications, McGraw-Hill, 1969.

[36] D. P. Kennedy, "Spreading Resistance in Cylindrical Semiconductor Devices," Journal of Applied Phyiscs, vol. 31, no. 8, p. 1490, 1960.

[37] R. Brooks and H. G. Mattes, "Spreading Resistance Between Constant Potential Surfaces," The Bell Systems Technical Journal, vol. 50, no. 3, March 1971.

[38] A. Wilson, "A Note on the Theory of Rectification," Proceedings of the Royal Society of London. Series A, Containing Papers of a Mathematical and Physical Character, vol. 136, no. 830, pp. 487-498, 1932.

[39] N. F. Mott, "Note on the contact between a metal and an insulator or semiconductor," Mathematical Proceedings of the Cambridge Philosophical Society, vol. 34, no. 4, pp. 568-572, 1938.

[40] W. Schottky, "(Abstract in English as "Semiconductor Theory of the Blocking Layer" in Sze, S.M. Semiconductor Devices: Pioneering Papers. World Scientific Publishing Co., 1991 pp. 381)," Naturwissenschaffen, vol. 26, p. 843, 1938.

[41] H. A. Bethe, "Theory of the Boundary Layer of Crystal Rectifier, Report No. 43/12," MIT Radiation Laboratory, 1942.

[42] S. M. Sze, Semiconductor Devices: Pioneering Papers, Singapore: JBW Printers and Binders Pte. Ltd., 1991. 
[43] J. Bardeen, "Surface States and Rectification at a Metal Semi-Conductor Contact," Phys. Rev., vol. 71, no. 10, p. 717, 1947.

[44] A. Cowley, "Depletion Capacitance and Diffusion Potential of Gallium Phoshpide Schottky-Barrier Diodes," Journal of Applied Physics, vol. 37, no. 8, pp. 30243032, 1966.

[45] H. C. Card and E. H. Rhoderick, "Studies of tunnel MOS diodes I. Interface effects in silicon Schottky diodes," J. Phys. D: Applied Physics, vol. 4, p. 1589, 1971.

[46] H. C. Card and E. H. Rhoderick, "Studies of tunnel MOS diodes II. Thermal equilibrium considerations," J. Phys. D: Applied Physics, vol. 4, p. 1602, 1971.

[47] R. H. Williams and E. H. Rhoderick, Metal Semiconductor Contacts, New York: Oxford Univeristy Press, 1988.

[48] K. S. Champlin and G. Eisenstein, "Cutoff Frequency of Submillimeter SchottkyBarrier Diodes," IEEE: Transactions on Microwave Theory and Techniques, vol. 26, pp. 31-34, 1978.

[49] J. F. White, Microwave Semiconductor Engineering.

[50] A. G. Cullis and L. T. Canham, "Visible light emission due to quantum size effects in highly porous crystalline silicon," Nature, vol. 353, no. 6342, p. 335, 1991.

[51] A. J. Read, R. J. Needs, K. Nash, L. T. Canham, P. D. J. Calcott and A. Qteish, "FirstPrinciples Calculations of the Electronic Properties of Silicon Quantum Wires," Physical Review Letters, vol. 69, no. 8, pp. 1232-1235, 1992.

[52] D. D. D. Ma, C. S. Lee, F. C. K. Au, S. Y. Tong and S. T. Lee, "Small-Diameter Silicon Nanowire Surfaces," Science, vol. 229, 2003.

[53] R. S. Wagner and W. C. Ellis, "Vapor-Liquid-Solid Mechanism of Single Crystal Growth," Applied Physics Letters, vol. 4, no. 5, 1964.

[54] K. Peng, Y. Yan, S. Gao and J. Zhu, "Dendrite-Assistend Growth of Silicon Nanowires in Electroless Metal Deposition," Adv. Func. Mater., vol. 13, no. 2, pp. 127-132, 2003. 
[55] J. D. Jackson, Classical Electrodynamics, New York: John Wiley \& Sons, 1999.

[56] C. A. Balanis, Advanced Engineering Electromagnetics, John Wiley, 2012.

[57] "Resistivity \& Mobility Calculator/Graph for Various Doping Concentrations in Silicon," Brigham Young University, [Online]. Available: http://www.cleanroom.byu.edu/ResistivityCal.phtml. [Accessed 28 May 2015].

[58] M. M. Ghita, E. Godshalk and G. Goncher, "Frequency multiplication in nanowires," Applied Physics Letters, vol. 99, 2011.

[59] W. Paul, "The effect of pressure on the properties of germanium and silicon," Journal of Physics and Chemistry of Solids, vol. 8, p. 196-204, 1959.

[60] A. J. Kerecman, "The Tungsten - P Type Silicon Point Contact," in Microwave Symposium, 1973 IEEE G-MTT International , Boulder, CO, USA, 1973.

[61] "The Engineering Toolbox - Smaller Circles in Larger Circles," [Online]. Available: http://www.engineeringtoolbox.com/smaller-circles-in-larger-circled_1849.html. [Accessed 1910 2015].

[62] Aeroflex, Inc, MHV505-11 Silicon Hyperabrupt Tuning Varactor Diode Datasheet, 2012.

[63] Skyworks, Semiconductor Discretes for RF-Microwave Applications, 2009.

[64] "Waveguide (electromagnetism)," Wikipedia, [Online]. Available: http://en.wikipedia.org/wiki/Waveguide_\%28electromagnetism\%29\#Waveguide _in_practice. [Accessed 5 March 2015].

[65] M. Urban, C. Nieswand, M. R. Siegrist and F. Keilmann, "Intensity dependence of the third-harmonic-generation efficiency for high-power far-infrared radiation in n-silicon," J. Appl. Phys, vol. 3, no. 77, p. 981, 1995.

[66] A. Mayer and F. Keilmann, "Far-infrared nonlinear optics. II. X(3) contributions from the dynamics of free carriers in semiconductors," Physical Review B, vol. 33, no. 10, pp. 6962-6968, 1986. 


\section{APPENDIX A. COMMERCIAL DIODE PARAMETERS AND CALCULATED CUT-OFF FREQUENCIES}

Device parameters reference: MA [49], MNP [62], apd [63].

Table A-1. Device parameters

\begin{tabular}{|c|c|c|c|c|c|c|c|c|c|c|c|c|c|c|}
\hline Symbol & $\begin{array}{c}\text { Electrical \& } \\
\text { physical } \\
\text { parameter }\end{array}$ & Units & $\begin{array}{c}\text { MA- } \\
47891\end{array}$ & $\begin{array}{c}\text { MA- } \\
47892\end{array}$ & $\begin{array}{c}\text { MA- } \\
47893\end{array}$ & $\begin{array}{c}\text { MA- } \\
47894\end{array}$ & $\begin{array}{c}\text { MA- } \\
47895\end{array}$ & $\begin{array}{c}\text { MA- } \\
47896\end{array}$ & $\begin{array}{c}\text { MA- } \\
47897\end{array}$ & $\begin{array}{c}\text { MA- } \\
47898\end{array}$ & $\begin{array}{c}\text { MA- } \\
47899\end{array}$ & $\begin{array}{c}\text { MA- } \\
47152\end{array}$ & $\begin{array}{c}\text { MA- } \\
47154\end{array}$ & $\begin{array}{c}\text { MA- } \\
47156\end{array}$ \\
\hline$C_{j}$ & $\begin{array}{l}\text { Junction } \\
\text { Capacitance }\end{array}$ & $\mathrm{pF}$ & 2 & 1 & 0.2 & 0.1 & 0.7 & 0.2 & 0.1 & 0.2 & 0.1 & 0.1 & 0.1 & 0.1 \\
\hline R_F & $\begin{array}{l}\text { Forward } \\
\text { Resistance @ } \\
1 \mathrm{GHz} @ \text { ।_F } \\
\end{array}$ & $\Omega$ & 0.3 & 0.4 & 0.8 & 1 & 0.4 & 0.7 & 1 & 0.9 & 1 & 1 & 1 & 1 \\
\hline R_R & $\begin{array}{l}\text { Reverse } \\
\text { Resistance @ } \\
1 \mathrm{GHz} @ \mathrm{~V} \_\mathrm{R} \\
\end{array}$ & $\Omega$ & 0.3 & 0.5 & 3 & 6 & 0.6 & 3 & 4 & 2 & 4 & 4 & 4 & 3 \\
\hline f_c & $\begin{array}{l}\text { Cutoff } \\
\text { frequency } \\
\text { (reverse bias) }\end{array}$ & $\mathrm{GHz}$ & 250 & 300 & 250 & 250 & 350 & 250 & 400 & 400 & 400 & 400 & 400 & 550 \\
\hline f_CS & $\begin{array}{l}\text { Switching } \\
\text { cutoff } \\
\text { frequency }\end{array}$ & $\mathrm{GHz}$ & 250 & 350 & 500 & 600 & 350 & 550 & 700 & 600 & 800 & 800 & 800 & 800 \\
\hline W & $\begin{array}{l}\text { Width of } \\
\text { device } \\
\text { (assuming } \\
\text { square die) }\end{array}$ & $\mathrm{mm}$ & 0.085 & 0.065 & 0.025 & 0.025 & 0.033 & 0.025 & 0.015 & 0.015 & 0.015 & 0.015 & 0.015 & 0.015 \\
\hline
\end{tabular}




\begin{tabular}{|c|c|c|c|c|c|c|c|c|c|c|c|c|c|c|}
\hline Symbol & $\begin{array}{c}\text { Electrical \& } \\
\text { physical } \\
\text { parameter }\end{array}$ & Units & $\begin{array}{c}\text { MA- } \\
47891\end{array}$ & $\begin{array}{c}\text { MA- } \\
47892\end{array}$ & $\begin{array}{c}\text { MA- } \\
47893\end{array}$ & $\begin{array}{l}\text { MA- } \\
47894\end{array}$ & $\begin{array}{l}\text { MA- } \\
47895\end{array}$ & $\begin{array}{c}\text { MA- } \\
47896\end{array}$ & $\begin{array}{c}\text { MA- } \\
47897\end{array}$ & $\begin{array}{c}\text { MA- } \\
47898\end{array}$ & $\begin{array}{c}\text { MA- } \\
47899\end{array}$ & $\begin{array}{c}\text { MA- } \\
47152\end{array}$ & $\begin{array}{c}\text { MA- } \\
47154\end{array}$ & $\begin{array}{c}\text { MA- } \\
47156\end{array}$ \\
\hline $\mathrm{H}$ & $\begin{array}{l}\text { Height of } \\
\text { device (from } \\
\text { top contact to } \\
\text { bottom) }\end{array}$ & $\mathrm{mm}$ & 0.009 & 0.01 & 0.009 & 0.009 & 0.007 & 0.007 & 0.006 & 0.006 & 0.006 & 0.006 & 0.006 & 0.006 \\
\hline $\begin{array}{l}\text { Com- } \\
\text { puted }\end{array}$ & $\begin{array}{l}\text { Geometry } \\
\text { factor }(\mathrm{W} / \mathrm{H})\end{array}$ & - & 9.44 & 6.50 & 2.78 & 2.78 & 4.71 & 3.57 & 2.50 & 2.50 & 2.50 & 2.50 & 2.50 & 2.50 \\
\hline & Top Contact & $\mathrm{mm}$ & 1.56 & 1.10 & 0.49 & 0.35 & 0.65 & 0.35 & 0.25 & 0.25 & 0.18 & 0.12 & 0.09 & 0.05 \\
\hline$w_{-} i$ & I region width & $\mu \mathrm{m}$ & 100 & 100 & 100 & 100 & 50 & 50 & 50 & 25 & 25 & 12 & 6 & 2 \\
\hline $\begin{array}{l}\text { Com- } \\
\text { puted }\end{array}$ & $\begin{array}{l}f \_c= \\
1 /\left(2^{*} \pi^{*} C_{j} * R_{s}\right) / \\
10^{\wedge} 6\end{array}$ & $\mathrm{MHz}$ & $\begin{array}{c}265.2 \\
6\end{array}$ & $\begin{array}{c}397.8 \\
9\end{array}$ & $\begin{array}{c}994.7 \\
2\end{array}$ & $\begin{array}{c}1591 . \\
5\end{array}$ & $\begin{array}{c}568.4 \\
1\end{array}$ & $\begin{array}{c}1136 . \\
8\end{array}$ & $\begin{array}{c}1591 . \\
5\end{array}$ & $\begin{array}{c}884.1 \\
9\end{array}$ & $\begin{array}{c}1591 . \\
5\end{array}$ & $\begin{array}{c}1591 . \\
5\end{array}$ & $\begin{array}{c}1591 . \\
5\end{array}$ & $\begin{array}{c}1591 . \\
5\end{array}$ \\
\hline
\end{tabular}

(Table continues on the next page) 
(cont)

\begin{tabular}{|c|c|c|c|c|c|c|c|}
\hline Symbol & \begin{tabular}{|l} 
Electrical \\
\&physical \\
parameter
\end{tabular} & Units & MNP0008 & MNP0014 & $\begin{array}{l}\text { apd0505- } \\
000\end{array}$ & $\begin{array}{c}\text { apd0510- } \\
000\end{array}$ & $\begin{array}{c}\text { apd0520- } \\
000\end{array}$ \\
\hline $\mathrm{C}_{\mathrm{j}}$ & $\begin{array}{l}\text { Junction } \\
\text { Capacitance }\end{array}$ & $\mathrm{pF}$ & 0.08 & 0.12 & 0.05 & 0.1 & 0.2 \\
\hline R_F & $\begin{array}{l}\text { Forward } \\
\text { Resistance @ } \\
\text { 1GHz @I_F }\end{array}$ & $\Omega$ & 0.12 & 0.18 & 2 & 1.5 & 1 \\
\hline$R \_R$ & \begin{tabular}{|l} 
Reverse \\
Resistance @ \\
$1 \mathrm{GHz} @ \mathrm{~V} \_\mathrm{R}$ \\
\end{tabular} & $\Omega$ & & & & & \\
\hline$f_{-} C$ & $\begin{array}{l}\text { Cutoff } \\
\text { frequency } \\
\text { (reverse bias) }\end{array}$ & $\mathrm{GHz}$ & & & & & \\
\hline $\mathrm{f}_{-} \mathrm{CS}$ & $\begin{array}{l}\text { Switching } \\
\text { cutoff } \\
\text { frequency }\end{array}$ & $\mathrm{GHz}$ & & & & & \\
\hline w & \begin{tabular}{|l} 
Width of \\
device \\
(assuming \\
square die) \\
\end{tabular} & $\mathrm{mm}$ & 0.432 & 0.965 & & & \\
\hline $\mathrm{H}$ & $\begin{array}{l}\text { Height of } \\
\text { device (from } \\
\text { top contact to } \\
\text { bottom) }\end{array}$ & $\mathrm{mm}$ & 0.15 & 0.1 & 5 & 5 & 5 \\
\hline
\end{tabular}




\begin{tabular}{|c|l|c|c|c|c|c|c|}
\hline Symbol & $\begin{array}{l}\text { Electrical } \\
\text { \&physical } \\
\text { parameter }\end{array}$ & Units & MNP0008 & MNP0014 & $\begin{array}{c}\text { apd0505- } \\
000\end{array}$ & $\begin{array}{c}\text { apd0510- } \\
000\end{array}$ & $\begin{array}{c}\text { apd0520- } \\
000\end{array}$ \\
\hline $\begin{array}{c}\text { Com- } \\
\text { puted }\end{array}$ & $\begin{array}{l}\text { Geometry } \\
\text { factor }(\mathrm{W} / \mathrm{H})\end{array}$ & - & & & & & \\
\hline Wop Contact & $\mathrm{mm}$ & 0.023 & 0.05 & 0.038 & 0.064 & 0.089 \\
\hline $\begin{array}{c}\text { Com- } \\
\text { puted }\end{array}$ & $\begin{array}{l}\mathrm{f}-\mathrm{c}= \\
1 /\left(2^{*} \pi^{*} \mathrm{C}_{\mathrm{j}}^{*} \mathrm{R}_{\mathrm{s}}\right) /\end{array}$ & $\mathrm{MHz}$ & 16579 & 7368.3 & 1591.5 & 1061 & 795.77 \\
\hline
\end{tabular}




\section{APPENDIX B. RADIO AND MICROWAVE BANDS}

Table B-1. Radio and microwave bands

\begin{tabular}{|c|c|c|c|c|c|}
\hline \multicolumn{3}{|c|}{$\begin{array}{c}\text { Designation/ } \\
\text { Band }\end{array}$} & Frequency & Wavelength & Origin \\
\hline \multicolumn{3}{|c|}{ ELF } & $3-30 \mathrm{~Hz}$ & $10,000-100,000 \mathrm{~km}$ & Extremely Low Frequency \\
\hline \multicolumn{3}{|c|}{ SLF } & $30-300 \mathrm{~Hz}$ & $1,000 \mathrm{~km}-10,000 \mathrm{~km}$ & Super Low Frequency \\
\hline \multicolumn{3}{|c|}{ ULF } & $300-3,000 \mathrm{~Hz}$ & $100 \mathrm{~km}-1,000 \mathrm{~km}$ & Ultra Low Frequency \\
\hline \multicolumn{3}{|c|}{ VLF } & $3-30 \mathrm{KHz}$ & $10 \mathrm{~km}-100 \mathrm{~km}$ & Very Low Frequency \\
\hline \multicolumn{3}{|l|}{ LF } & $30-300 \mathrm{KHz}$ & $1 \mathrm{~km}-10 \mathrm{~km}$ & Low Frequency \\
\hline \multicolumn{3}{|c|}{$\mathrm{MF}$} & $300-3,000 \mathrm{KHz}$ & $100 m-1,000 m$ & Medium Frequency \\
\hline \multicolumn{3}{|l|}{$\mathrm{HF}$} & $3-30 \mathrm{MHz}$ & $100 m-10 m$ & High Frequency \\
\hline \multicolumn{3}{|c|}{ VHF } & $30-300 \mathrm{MHz}$ & $10 m-1 m$ & Very High Frequency \\
\hline \multicolumn{3}{|c|}{ UHF } & $300-1000 \mathrm{MHz}$ & $100 \mathrm{~cm}-30 \mathrm{~cm}$ & Ultra High Frequency \\
\hline & \multicolumn{2}{|l|}{$\mathrm{L}$} & $1-2 \mathrm{GHz}$ & $30 \mathrm{~cm}-15 \mathrm{~cm}$ & Long Wave \\
\hline & \multicolumn{2}{|l|}{$S$} & $2-4 \mathrm{GHz}$ & $15 \mathrm{~cm}-7.5 \mathrm{~cm}$ & Short Wave \\
\hline & \multicolumn{2}{|l|}{ C } & $4-8 \mathrm{GHz}$ & $7.5 \mathrm{~cm}-3.75 \mathrm{~cm}$ & Compromise between $S$ and $X$ \\
\hline \multirow{7}{*}{ 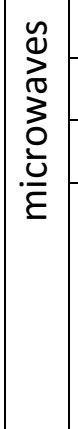 } & \multicolumn{2}{|l|}{$x$} & $8-12 \mathrm{GHz}$ & $3.75 \mathrm{~cm}-2.50 \mathrm{~cm}$ & WWII: $X$ for cross \\
\hline & \multicolumn{2}{|l|}{$\mathrm{Ku}$} & $12-18 \mathrm{GHz}$ & $2.50 \mathrm{~cm}-1.67 \mathrm{~cm}$ & Kurtz-under \\
\hline & \multicolumn{2}{|l|}{ K } & $18-27 \mathrm{GHz}$ & $1.67 \mathrm{~cm}-1.11 \mathrm{~cm}$ & Kurtz: German for short \\
\hline & \multirow{4}{*}{$\begin{array}{l}\mathscr{D} \\
\sum_{j}^{\infty} \\
\xi \\
\varepsilon \\
\varepsilon\end{array}$} & $\mathrm{Ka}$ & $27-40 \mathrm{GHz}$ & $1.11 \mathrm{~cm}-.75 \mathrm{~cm}$ & Kurtz-above \\
\hline & & $\mathrm{V}$ & $40-75 \mathrm{GHz}$ & $7.5 \mathrm{~mm}-4.0 \mathrm{~mm}$ & \\
\hline & & W & $75-110 \mathrm{GHz}$ & $4.0 \mathrm{~mm}-2.7 \mathrm{~mm}$ & \\
\hline & & $\mathrm{mm}$ & $110-300 \mathrm{GHz}$ & $2.7 \mathrm{~mm}-1.0 \mathrm{~mm}$ & \\
\hline & \multicolumn{2}{|c|}{$\begin{array}{l}\text { sub-mm } \\
/ \mathrm{THz}\end{array}$} & $\begin{array}{l}300 \mathrm{GHz}- \\
10 \mathrm{THz}\end{array}$ & $1.0 \mathrm{~mm}-30 \mu \mathrm{m}$ & \\
\hline
\end{tabular}


Table C-1. Standard sizes of rectangular waveguides

\begin{tabular}{|c|c|c|c|c|c|c|c|}
\hline \multicolumn{3}{|c|}{ Waveguide name } & \multirow{2}{*}{$\begin{array}{l}\text { Band } \\
\text { Name }\end{array}$} & \multirow{2}{*}{$\begin{array}{c}\text { Recommended } \\
\text { frequency band } \\
\text { of operation } \\
(\mathrm{GHz})\end{array}$} & \multirow{2}{*}{ 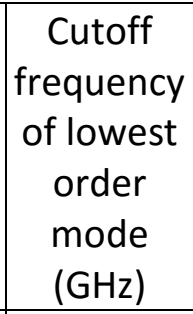 } & \multirow{2}{*}{$\begin{array}{c}\text { Cutoff } \\
\text { frequency } \\
\text { of next } \\
\text { mode } \\
(\mathrm{GHz})\end{array}$} & \multirow{2}{*}{$\begin{array}{l}\text { Inner } \\
\text { dimensions } \\
\text { of } \\
\text { waveguide } \\
\text { opening } \\
\text { (inch) }\end{array}$} \\
\hline EIA & $\mathrm{RCSC}$ & IEC & & & & & \\
\hline WR2300 & WG0.0 & R3 & & $0.32-0.45$ & 0.257 & 0.513 & $\begin{array}{c}23.000 \times \\
11.500\end{array}$ \\
\hline WR 2100 & WG0 & $\mathrm{R} 4$ & & $0.35-0.50$ & 0.281 & 0.562 & $\begin{array}{c}21.000 \times \\
10.500\end{array}$ \\
\hline WR1800 & WG1 & R5 & & $0.45-0.63$ & 0.328 & 0.656 & $\begin{array}{c}18.000 \times \\
9.000\end{array}$ \\
\hline WR1500 & WG2 & $\mathrm{R} 6$ & & $0.50-0.75$ & 0.393 & 0.787 & $\begin{array}{c}15.000 \times \\
7.500\end{array}$ \\
\hline WR1150 & WG3 & $\mathrm{R} 8$ & & $0.63-0.97$ & 0.513 & 1.026 & $\begin{array}{c}11.500 \times \\
5.750\end{array}$ \\
\hline WR975 & WG4 & R9 & & $0.75-1.15$ & 0.605 & 1.211 & $\begin{array}{c}9.750 \times \\
4.875\end{array}$ \\
\hline WR770 & WG5 & R12 & & $0.97-1.45$ & 0.766 & 1.533 & $\begin{array}{c}7.700 \times \\
3.850\end{array}$ \\
\hline WR650 & WG6 & R14 & $\mathrm{L}^{*}$ & $1.15-1.72$ & 0.908 & 1.816 & $\begin{array}{c}6.500 \times \\
3.250 \\
\end{array}$ \\
\hline WR510 & WG7 & R18 & & $1.45-2.20$ & 1.157 & 2.314 & $\begin{array}{c}5.100 \times \\
2.550\end{array}$ \\
\hline WR430 & WG8 & $\mathrm{R} 22$ & & $1.72-2.60$ & 1.372 & 2.745 & $\begin{array}{c}4.300 \times \\
2.150\end{array}$ \\
\hline WR340 & WG9A & $\mathrm{R} 26$ & $S^{*}$ & $2.20-3.30$ & 1.736 & 3.471 & $\begin{array}{c}3.400 \times \\
1.700\end{array}$ \\
\hline WR284 & WG10 & R32 & $\mathrm{S}^{*}$ & $2.60-3.95$ & 2.078 & 4.156 & $\begin{array}{l}2.840 \times \\
1.340^{+}\end{array}$ \\
\hline WR229 & WG11A & R40 & $C^{*}$ & $3.30-4.90$ & 2.577 & 5.154 & $\begin{array}{c}2.290 \times \\
1.145\end{array}$ \\
\hline WR187 & WG12 & $\mathrm{R} 48$ & $C^{*}$ & $3.95-5.85$ & 3.153 & 6.305 & $\begin{array}{l}1.872 \times \\
0.872^{+}\end{array}$ \\
\hline WR159 & WG13 & R58 & $C^{*}$ & $4.90-7.05$ & 3.712 & 7.423 & $\begin{array}{c}1.590 \times \\
0.795\end{array}$ \\
\hline
\end{tabular}




\begin{tabular}{|c|c|c|c|c|c|c|c|}
\hline \multicolumn{3}{|c|}{ Waveguide name } & \multirow{2}{*}{$\begin{array}{l}\text { Band } \\
\text { Name }\end{array}$} & \multirow{2}{*}{$\begin{array}{c}\text { Recommended } \\
\text { frequency band } \\
\text { of operation } \\
(\mathrm{GHz})\end{array}$} & \multirow{2}{*}{\begin{tabular}{|c} 
Cutoff \\
frequency \\
of lowest \\
order \\
mode \\
$(\mathrm{GHz})$ \\
\end{tabular}} & \multirow{2}{*}{\begin{tabular}{|} 
Cutoff \\
frequency \\
of next \\
mode \\
$(\mathrm{GHz})$
\end{tabular}} & \multirow{2}{*}{$\begin{array}{c}\text { Inner } \\
\text { dimensions } \\
\text { of } \\
\text { waveguide } \\
\text { opening } \\
\text { (inch) } \\
\end{array}$} \\
\hline EIA & $\mathrm{RCSC}$ & IEC & & & & & \\
\hline WR137 & WG14 & R70 & $C^{*}$ & $5.85-8.20$ & 4.301 & 8.603 & $\begin{array}{l}1.372 \times \\
0.622^{+} \\
\end{array}$ \\
\hline WR112 & WG15 & R84 & - & $7.05-10.00$ & 5.26 & 10.52 & $\begin{array}{l}1.122 \times \\
0.497^{+}\end{array}$ \\
\hline WR90 & WG16 & R100 & $x$ & $8.20-12.40$ & 6.557 & 13.114 & $\begin{array}{l}0.900 \times \\
0.400^{+}\end{array}$ \\
\hline WR75 & WG17 & R120 & - & $10.00-15.00$ & 7.869 & 15.737 & $\begin{array}{c}0.750 \times \\
0.375 \\
\end{array}$ \\
\hline WR62 & WG18 & R140 & $\mathrm{Ku}$ & $12.40-18.00$ & 9.488 & 18.976 & $\begin{array}{c}0.622 \times \\
0.311 \\
\end{array}$ \\
\hline WR51 & WG19 & R180 & - & $15.00-22.00$ & 11.572 & 23.143 & $\begin{array}{c}0.510 \times \\
0.255\end{array}$ \\
\hline WR42 & WG20 & R220 & K & $18.00-26.50$ & 14.051 & 28.102 & $\begin{array}{l}0.420 \times \\
0.170^{\dagger}\end{array}$ \\
\hline WR34 & WG21 & R260 & - & $22.00-33.00$ & 17.357 & 34.715 & $\begin{array}{c}0.340 \times \\
0.170\end{array}$ \\
\hline WR28 & WG22 & R320 & $\mathrm{Ka}$ & $26.50-40.00$ & 21.077 & 42.154 & $\begin{array}{c}0.280 \times \\
0.140\end{array}$ \\
\hline WR22 & WG23 & R400 & $Q$ & $33.00-50.00$ & 26.346 & 52.692 & $\begin{array}{c}0.224 \times \\
0.112 \\
\end{array}$ \\
\hline WR19 & WG24 & R500 & $U$ & $40.00-60.00$ & 31.391 & 62.782 & $\begin{array}{c}0.188 \times \\
0.094\end{array}$ \\
\hline WR15 & WG25 & R620 & V & $50.00-75.00$ & 39.875 & 79.75 & $\begin{array}{c}0.148 \times \\
0.074\end{array}$ \\
\hline WR12 & WG26 & R740 & $E$ & $60.00-90.00$ & 48.373 & 96.746 & $\begin{array}{c}0.122 \times \\
0.061 \\
\end{array}$ \\
\hline WR10 & WG27 & R900 & W & $75.00-110.00$ & 59.015 & 118.03 & $\begin{array}{c}0.100 \times \\
0.050\end{array}$ \\
\hline WR8 & WG28 & R1200 & $\mathrm{F}$ & $90.00-140.00$ & 73.768 & 147.536 & $\begin{array}{c}0.080 \times \\
0.040\end{array}$ \\
\hline $\begin{array}{l}\text { WR6, } \\
\text { WR7 }\end{array}$ & WG29 & R1400 & $\mathrm{D}$ & $\begin{array}{c}110.00- \\
170.00\end{array}$ & 90.791 & 181.583 & $\begin{array}{c}0.0650 \times \\
0.0325\end{array}$ \\
\hline WR5 & WG30 & R1800 & & $\begin{array}{c}140.00- \\
220.00\end{array}$ & 115.714 & 231.429 & $\begin{array}{c}0.0510 \times \\
0.0255\end{array}$ \\
\hline
\end{tabular}




\begin{tabular}{|c|c|c|c|c|c|c|c|}
\hline \multicolumn{3}{|c|}{ Waveguide name } & \multirow{2}{*}{$\begin{array}{l}\text { Band } \\
\text { Name }\end{array}$} & \multirow{2}{*}{$\begin{array}{l}\text { Recommended } \\
\text { frequency band } \\
\text { of operation } \\
(\mathrm{GHz})\end{array}$} & \multirow{2}{*}{$\begin{array}{c}\text { Cutoff } \\
\text { frequency } \\
\text { of lowest } \\
\text { order } \\
\text { mode } \\
(\mathrm{GHz})\end{array}$} & \multirow{2}{*}{$\begin{array}{l}\text { Cutoff } \\
\text { frequency } \\
\text { of next } \\
\text { mode } \\
(\mathrm{GHz})\end{array}$} & \multirow{2}{*}{$\begin{array}{c}\text { Inner } \\
\text { dimensions } \\
\text { of } \\
\text { waveguide } \\
\text { opening } \\
\text { (inch) }\end{array}$} \\
\hline EIA & RCSC & IEC & & & & & \\
\hline WR4 & WG31 & R2200 & & $\begin{array}{c}172.00- \\
260.00\end{array}$ & 137.243 & 274.485 & $\begin{array}{c}0.0430 \times \\
0.0215 \\
\end{array}$ \\
\hline WR3 & WG32 & R2600 & & $\begin{array}{c}220.00- \\
330.00\end{array}$ & 173.571 & 347.143 & $\begin{array}{c}0.0340 \times \\
0.0170\end{array}$ \\
\hline
\end{tabular}

Source: [49] $\quad *$ e partial $\quad \dagger=$ outside dimensions are 2:1 


\section{APPENDIX D. $\quad$ LOW FREQUENCY WAVEGUIDE ATTENUATION}

\section{D.1 Purpose}

The purpose of this investigation is to determine the impact the Low Frequency (LF) waveguide has on the amplitude of the signals reaching the spectrum analyzer.

\section{D.2 Estimation of waveguide characteristics}

The LF waveguide physical dimensions are given in the table below:

Table D-1. LF Waveguide Parameters

\begin{tabular}{|l|l|l|}
\hline \multicolumn{1}{|c|}{ Parameter } & \multicolumn{1}{c|}{ Inch } & \multicolumn{1}{c|}{$\mathrm{mm}$} \\
\hline Strip length $(\mathrm{L})$ & 2.75 & 69.85 \\
\hline Strip width $(\mathrm{W})$ & 0.5 & 12.7 \\
\hline Height above ground $(\mathrm{H})$ & 0.15 & 3.81 \\
\hline Strip thickness & 0.033 & 0.8382 \\
\hline
\end{tabular}

Using (2.21) and the waveguide parameters given above, the characteristic impedance of the waveguide was computed to be $Z_{c}(0) \approx 61.9 \Omega$.

If the wavelengths of the signals propagating through the waveguide are larger than the separation between the plates, the waveguide is considered non-dispersive, and allows us to use the lumped circuit approximation, where the waveguide is approximated by an RLC circuit. The cutoff frequency where dispersion becomes significant is given by (2.22) and for the LF waveguide is computed to be $f_{c}=24.5 \mathrm{GHz}$. The frequency range of interest during the low frequency experiments was well below this cutoff frequency, therefore the LF setup can be simulated using the lumped circuit approximation.

The capacitance of the waveguide can be approximated with the capacitance of a parallel plate capacitor, and is given by the formula below:

$$
C=K \cdot \varepsilon_{0} \frac{\operatorname{Area}(L \times W)}{\text { Separation }(H)}
$$

where $\varepsilon_{0}=8.854 \times 10^{-12}$, and $\mathrm{K} \approx 1$ for air.

Using the dimensions given in Table D-1, the total capacitance of the waveguide is approximatively $\mathrm{C}=2.06 \mathrm{pF}$. 
Using the definition of the characteristic impedance for the case when the series resistance is negligible,

$$
Z_{C}(0) \triangleq \sqrt{\frac{L}{C}}
$$

the inductance of the waveguide can be calculated to be $\mathrm{L}=7.9 \mathrm{nH}$.

\section{D.3 Waveguide attenuation}

In order to estimate the effect of the waveguide on the signals reaching the spectrum analyzer, two possible configurations for the waveguide equivalent circuit were simulated in LT Spice. The first case assumes negligible waveguide inductance, and the second case assumes a waveguide inductance of $7.9 \mathrm{nH}$ calculated above. In both cases, two values for capacitance were tried: the $2 \mathrm{pF}$ capacitance corresponds to the capacitance of a parallel plate capacitor and the $3 \mathrm{pF}$ capacitance case allows for fringing capacitance, also. For comparison, the case where the waveguide is not present was also simulated. The simulation setup is given in Figure D-1 and the results in Figure D-2.

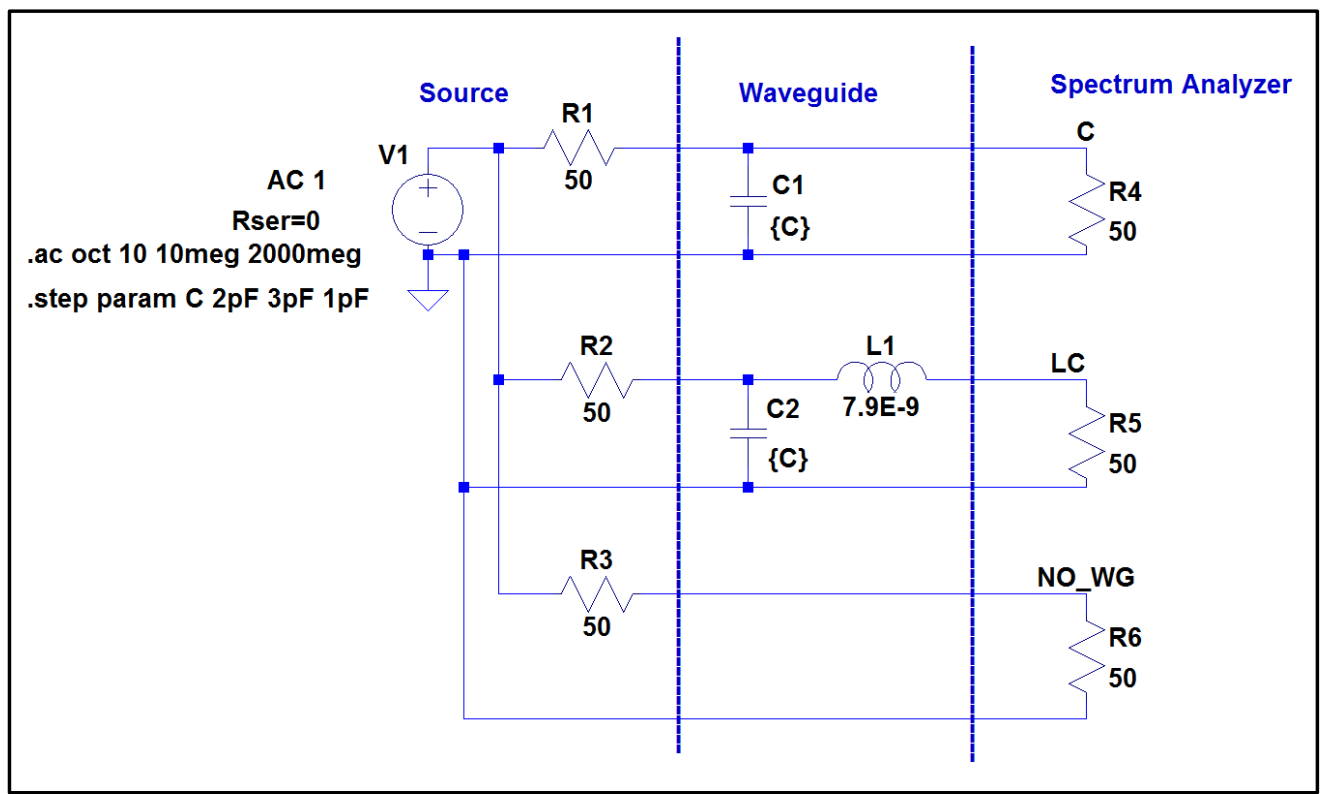

Figure D-1. LF waveguide circuit approximation 


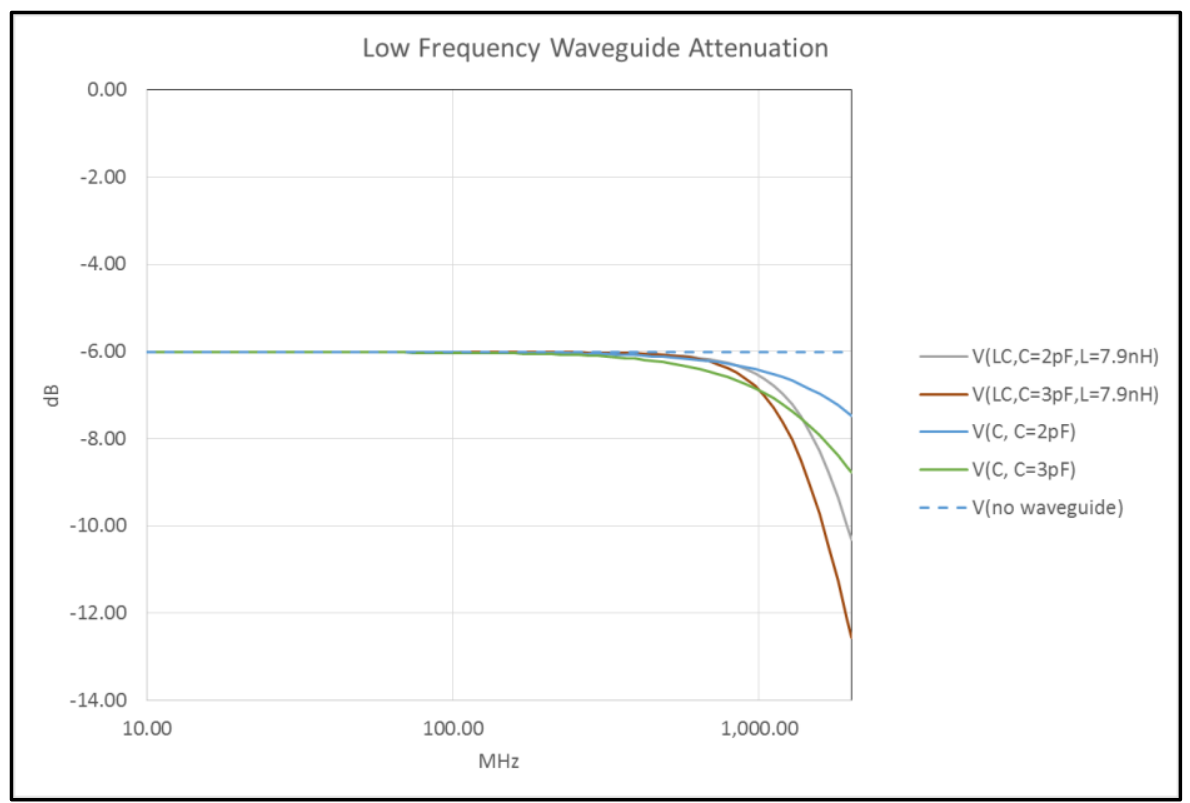

Figure D-2. LF waveguide output

Figure $\mathrm{D}-2$ shows that below $1 \mathrm{GHz}$ the waveguide has a very small effect (less than $1 \mathrm{~dB}$ ) on the amplitude of signals reaching the spectrum analyzer. The simulations show that above $1 \mathrm{GHz}-1.5 \mathrm{GHz}$ the signal attenuation by the waveguide may become significant. In such a case, if a precise estimation of the harmonic amplitudes is required, a thorough characterization of the waveguide using a Vector Network Analyzer should be performed.

Moreover, when various sections of an RF circuit have different characteristic impedances, some of the power is reflected at the interface between sections of dissimilar impedance. The reflection coefficient $(\Gamma)$ is given by the equation below:

$$
\Gamma=\frac{Z_{L}-Z_{0}}{Z_{L}+Z_{0}}
$$

Where $Z_{0}$ is the characteristic impedance of the transmission line and $Z_{L}$ is the impedance of the load.

The forward and backward propagating waves interfere and give rise to a voltage standing wave inside the transmission line. The ratio of the maximum to minimum voltage of the standing wave (SWR or VSWR) varies depending on the size of the mismatch and is given by: 


$$
V S W R=\frac{V_{\max }}{V_{\min }}=\frac{1+|\Gamma|}{1-|\Gamma|}
$$

Using $Z_{0}=50 \Omega$ and $Z_{L}=61.9 \Omega$, we obtain $\Gamma=-0.107$ and $V S W R=1.24$. This means that depending on the precise position of the probe and nanowire sample inside the waveguide, the signal across the sample could be $20 \cdot \log (1.24) \approx 1.87 \mathrm{~dB}$ lower than the maximum amplitude generated by the source.

\section{D.4 Conclusion}

Two effects that can decrease the amplitude of the harmonics generated by the samples were identified and their magnitude was estimated. The magnitude of the attenuation is less than $10 \mathrm{~dB}$ below $2 \mathrm{GHz}$, which was consistent with the fact that harmonics up to $2 \mathrm{GHz}$ were easily detected by the test setup. 


\section{E.1 Purpose}

The purpose of this investigation is to determine the effect of the biasing circuit on the high frequency signal $(50 \mathrm{GHz})$ coupled in the nanowire diode. The effect of a chip inductor placed very close to the probe tip was investigated in order to determine whether it limits the leakage into the biasing circuit of the high frequencies coupled from the field into the diode.

\section{E.2 Voltage Potential Inside the microwave waveguide.}

The output power of the $50 \mathrm{GHz}$ source is $17 \mathrm{dBm}$. The units of $\mathrm{dBm}$ are used for specifying power referenced to $1 \mathrm{~mW}$.

The following formulas can be used to convert between power in Watts and $\mathrm{dBm}$ :

$$
\begin{gathered}
P_{d B m} \equiv 10 \log \frac{P_{W}}{1 m W}=30+10 \log \frac{P_{W}}{1 W} \\
P_{W}=1 W 10^{\frac{P_{d B m}-30}{10}}
\end{gathered}
$$

Given $\mathrm{P}_{\mathrm{dBm}}=17 \mathrm{dBm}$ and using the above formula we find the power in watts is $\mathrm{P}_{\mathrm{W}}=10^{-1.3 \mathrm{~W}} \approx 0.05 \mathrm{~W}$

Then, using the formulas in Balanis

$$
\begin{aligned}
& P_{m n}^{T E}=\left|A_{m n}\right|^{2} \frac{\beta_{c}^{2}}{2 \eta \varepsilon^{2}}\left(\frac{a}{\varepsilon_{0 m}}\right)\left(\frac{b}{\varepsilon_{0 n}}\right) \sqrt{1-\left(\frac{f_{c, m n}}{f}\right)^{2}}, \varepsilon_{0 q}=\left\{\begin{array}{l}
1, q=0 \\
2, q \neq 0
\end{array}\right. \\
& (\text { Balanis, } 8-57, p .373)
\end{aligned}
$$


Then, for the WR19 waveguide used $(a=9.4 \mathrm{~mm}, b=4.7 \mathrm{~mm})$ we obtain

$\beta_{\mathrm{c}}=661$

$f_{c, m n}=31,558,764,337 \mathrm{~Hz}$

$$
\begin{aligned}
& 17 \mathrm{dBm}=\left|A_{10}\right|^{2} \frac{(661)^{2}}{2 \times 377 \times\left(8.854^{-12}\right)^{2}}\left(\frac{0.094}{1}\right)\left(\frac{0.047}{2}\right) \sqrt{1-\left(\frac{31,558,764,337}{50,000,000,000}\right)^{2}} \\
& \quad 17 \mathrm{dBm}=\left|A_{10}\right|^{2} \times 3.2897 \times 10^{19}=>A_{10}=3.89856 \times 10^{-11} \\
& \left|E_{y}^{+}\right|_{\text {max }}=2,912 \mathrm{~V} / \mathrm{m}
\end{aligned}
$$

Using the Electric Field strength computed above, the voltage potential difference across various dimensions/features can be computed:

Table E-1. Microwave waveguide and field parameters

\begin{tabular}{|l|l|c|}
\hline Feature & Value & Units \\
\hline Sample thickness & 0.00127 & $\mathrm{~m}$ \\
\hline a (WR19 cross-section) & 0.0047 & $\mathrm{~m}$ \\
\hline $\mathrm{b}$ (WR19 cross-section) & 0.0024 & $\mathrm{~m}$ \\
\hline $\mathrm{E}_{\mathrm{y}, \max }$ & 2,912 & $\mathrm{~V} / \mathrm{m}$ \\
\hline$\Delta \mathrm{V}_{\text {waveguide,a }}$ & 13.83 & $\mathrm{~V}$ \\
\hline$\Delta \mathrm{V}_{\text {waveguide, }}$ & 7.03 & $\mathrm{~V}$ \\
\hline$\Delta \mathrm{V}_{\text {sample }}$ & 3.70 & $\mathrm{~V}$ \\
\hline
\end{tabular}

Therefore, the voltage potential difference inside the WR19 waveguide for the $17 \mathrm{dBm}$ source used is in the range $3.7 \mathrm{~V}-13.8 \mathrm{~V}$.

\section{E.3 Field coupling to the sample}

The biasing probe and the nanowires are axially aligned. The longitudinal direction of the probe/nanowire setup is parallel with the electric field propagating through the WR19 waveguide (1). The probe/nanowire setup do not form any loops that are normal to the magnetic fields inside the WR19 waveguide (2). There are no charge carriers provided by the field to the probe/nanowire setup (3). Because of (1)-(3), the coupling between the field and the probe/nanowire setup is capacitive. It is assumed that the field coupling can be modeled by a circuit consisting of a $50 \mathrm{GHz}$ AC Voltage Source in 
series with a capacitor. A further assumption is that value of the series capacitor is such that $Z_{\text {capacitor }}(50 \mathrm{GHz})=Z_{\text {waveguide }}(50 \mathrm{GHz})$.

The waveguide impedance is calculated as outlined in Balanis:

$$
\begin{gathered}
Z_{w}^{+z}\left(T E_{m n}^{z}\right)=+j \frac{\eta}{\sqrt{\left(\frac{f_{c}}{f}\right)^{2}-1}}, \text { Balanis } 8-20 c \\
=>Z_{w}^{+z}\left(T E_{10}^{z}\right)=+j \frac{377 \Omega}{\sqrt{\left(\frac{31,558,764,337}{50,000,000,000}\right)^{2}-1}}=486 \Omega
\end{gathered}
$$

Estimation of the capacitance:

$$
\left.\begin{array}{c}
Z_{C}=\frac{1}{j \omega C}=\frac{1}{j \times 2 \times \pi \times f \times C} \\
Z_{C}=\text { assumption }=Z_{w}^{+Z}\left(T E_{10}^{z}\right)=486 \Omega
\end{array}\right\}
$$

\section{E.4 Model parameters for probe and wires}

\section{E.4.1 Probe dimensions}

The probe used was Micromanipulator 7A. The physical parameters from the specification sheet are given in the table and figure below: 
Table E-2. Probetip specifications

\begin{tabular}{|l|l|l|l|l|l|l|l|l|l|}
\hline Style & $\begin{array}{c}\text { Model } \\
\text { Number }\end{array}$ & \multicolumn{1}{|c|}{$\begin{array}{c}\text { Tip } \\
\text { Diameter }\end{array}$} & $\begin{array}{c}\text { Point } \\
\text { Radius } \\
(\mu \mathrm{m})\end{array}$ & $\begin{array}{c}\text { Point } \\
\text { Taper } \\
\text { Length }\end{array}$ & $\begin{array}{c}\text { Included } \\
\text { Angle }\end{array}$ & $\begin{array}{l}\text { Overall } \\
\text { Length }\end{array}$ & $\begin{array}{c}\text { Shank } \\
\text { Diameter }\end{array}$ & Material & Attributes \\
\hline $\begin{array}{l}\text { Fine } \\
\text {-tip }\end{array}$ & $7 \mathrm{~A}$ & $\begin{array}{l}0.005^{\prime \prime} \\
0.127 \mathrm{~mm}\end{array}$ & 0.35 & $\begin{array}{l}0.020^{\prime \prime} \\
0.508 \mathrm{~mm}\end{array}$ & 14 & $\begin{array}{l}1.4^{\prime \prime} \\
35.56 \mathrm{~mm}\end{array}$ & $\begin{array}{l}0.020^{\prime \prime} \\
0.508 \mathrm{~mm}\end{array}$ & $\begin{array}{l}\text { Shank: } \\
\text { Nickel }\end{array}$ & $\begin{array}{l}\text { Bendable } \\
\text { shank, } \\
\text { cat-whisker }\end{array}$ \\
\hline
\end{tabular}

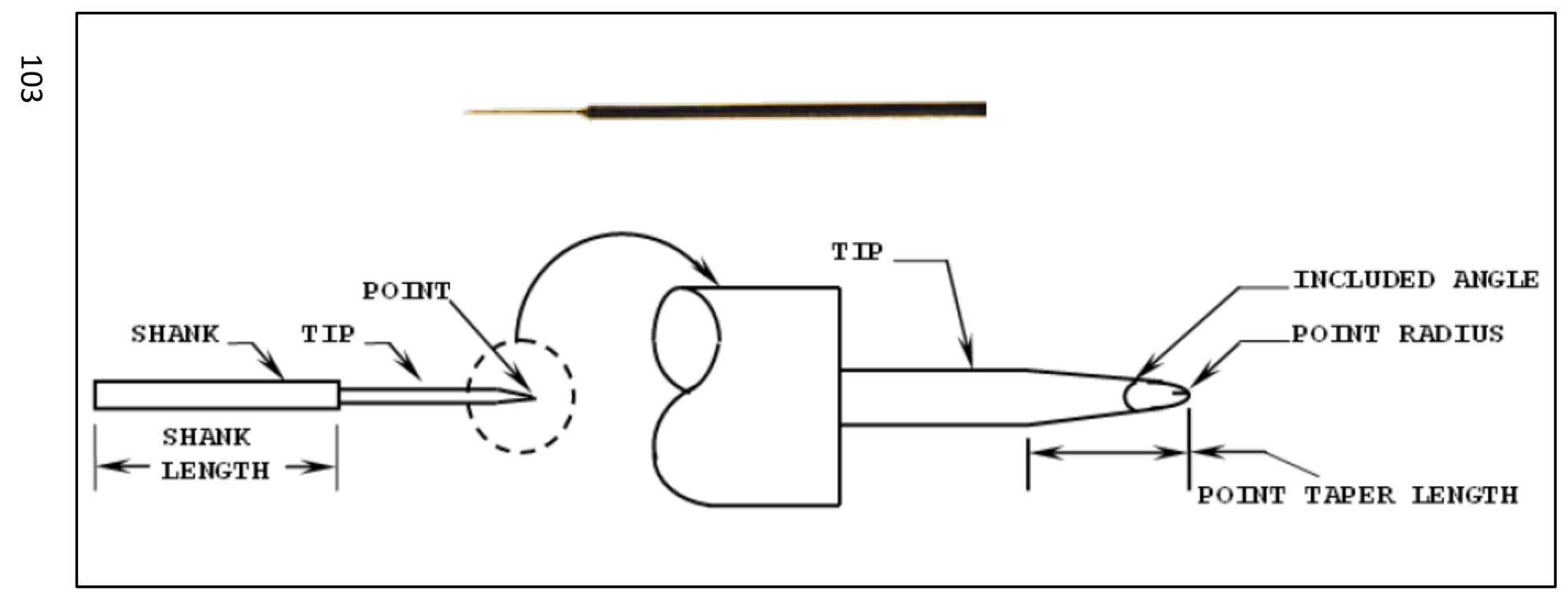

Figure E-3. Probetip diagram 
Using the probetip picture from the figure above, the following probe component dimensions can be estimated:

- probe length $\approx 8 \mathrm{~mm}$

- shank length $\approx 28 \mathrm{~mm}$

The formula for resistance is $R=\frac{\rho \times L}{A}$, where $\rho$ is resistivity, $L$ is the length of the conductor, and $\mathrm{A}$ is the cross-section area.

\section{E.4.2 Circuit component parameters}

The computed circuit component parameters for the microwave setup are summarized in the table below. Details pertaining to the parameter computation are given in the following subsections.

Table E-3. Circuit component parameters

\begin{tabular}{|c|c|c|c|c|c|c|c|c|}
\hline $\begin{array}{c}\text { Descrip- } \\
\text { tion }\end{array}$ & Material & $\begin{array}{c}\text { Length } \\
(\mathrm{mm})\end{array}$ & $\begin{array}{c}\text { Diame- } \\
\text { ter } \\
(\mathrm{mm})\end{array}$ & $\begin{array}{c}\text { Resis- } \\
\text { tivity } \\
\times 10^{\wedge}-8 \\
(\Omega \mathrm{m})\end{array}$ & $\begin{array}{c}\text { Resis- } \\
\text { tance( } \\
\Omega)\end{array}$ & $\begin{array}{c}\text { Self- } \\
\text { Induc- } \\
\text { tance } \\
(\mathrm{nH})\end{array}$ & $\begin{array}{c}\text { Self- } \\
\text { Capaci- } \\
\text { tance } \\
(\mathrm{pF})\end{array}$ & Note \\
\hline Probe Tip & Tungsten & 8 & 0.127 & 5.6 & 0.035 & 7.66 & 0.0955 & $\begin{array}{c}\text { Contacts } \\
\text { sample }\end{array}$ \\
\hline $\begin{array}{c}\text { Probe } \\
\text { Shank }\end{array}$ & Nickel & 28 & 0.508 & 100 & 0.138 & 26.1 & 0.3468 & $\begin{array}{c}\text { Holds } \\
\text { probe tip }\end{array}$ \\
\hline $\begin{array}{c}\text { Wire } \\
\text { (AWG 24) }\end{array}$ & Copper & 500 & 0.511 & 1.68 & 0.041 & 752 & 2.961 & $\begin{array}{c}\text { Sample } \\
\text { bias }\end{array}$ \\
\hline $\begin{array}{c}\text { Wire } \\
\text { (AWG 22) }\end{array}$ & Copper & 500 & 0.644 & 1.68 & 0.026 & 729 & 3.135 & $\begin{array}{c}\text { Sample } \\
\text { bias }\end{array}$ \\
\hline
\end{tabular}

from CRC Handbook of Chemistry and Physics, 64th edition.

$$
f_{S R}=\frac{1}{2 \pi \sqrt{L C_{P}}}=>C_{P}=\frac{1}{f_{S R}^{2} 4 \pi L}
$$

\section{E.5 Investigation of the effects of circuit inductance through SPICE simulations}

LT Spice software package was used to perform circuit analysis on the microwave circuit. The figure below shows the circuit simulated. 


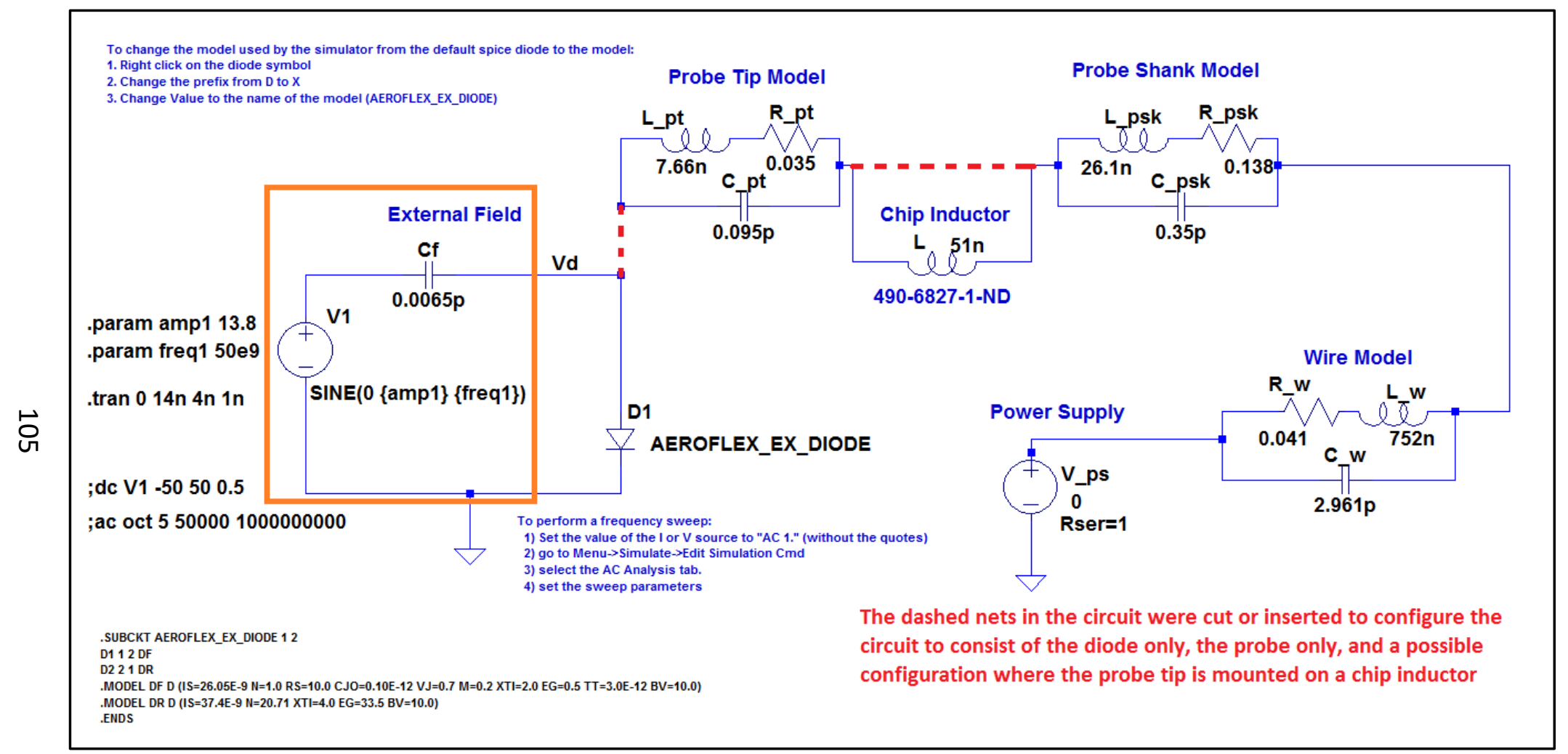

Figure E-4. SPICE simulation details 
The results of the simulations are summarized in Figure E-5 below:

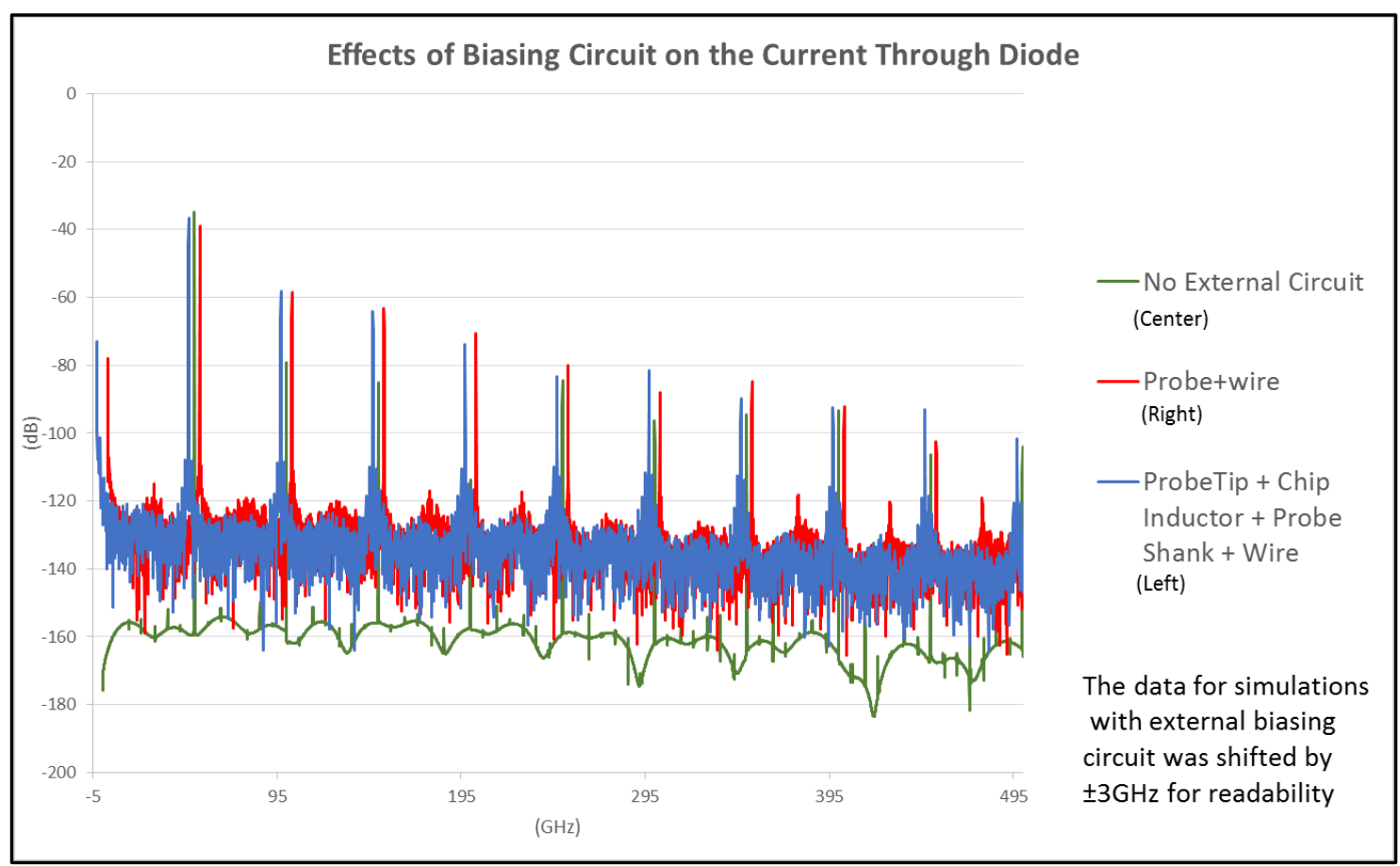

Figure E-5. LT SPICE Simulation results

\section{E.6 Conclusion}

The LTSpice simulations show two main things about the behavior of high frequency diodes inside the waveguide:

(1) The external circuit has a substantial effect on the current through the diode. For the case of this simulation, the second harmonic amplitude from the configuration without the biasing circuit is about $21 \mathrm{~dB}(-75 \mathrm{~dB}-(-54 \mathrm{~dB}))$ below the amplitude with an external biasing circuit. Therefore, the addition of the external circuit is beneficial to the operation of the diode as a frequency multiplier in the waveguide.

(2) Adding an extra inductor after the probe tip does not significantly affect the current through the diode. In the case of the second harmonic, the difference between the simulation of the bias through [probe + wire] and the simulation of the bias through a [short tip + chip inductor + wire] is less than $1 \mathrm{~dB}(-54.2 \mathrm{~dB}-(-53.7 \mathrm{~dB}))$. 


\section{E.7 Device parameter calculators details}

The following sub-sections contain details about the online calculators used to compute device parameters in Table E-3.

\section{E.7.1 Self-Capacitance Calculator for solid cylinder}

The self-capacitance was estimated with the online calculator from Wolfram Alpha.

\begin{tabular}{|l|l|}
\hline electric capacitance & $\begin{array}{l}3.135 \mathrm{pF} \text { (picofarads) } \\
=0.003135 \mathrm{nF} \text { (nanofarads) } \\
=3.135 \times 10^{-12} \mathrm{~F} \text { (farads) }\end{array}$ \\
\hline$C=\left(8+4.1\left(\frac{l}{r}\right)^{0.76}\right) \varepsilon_{0} r$ \\
\hline$C$ & electric capacitance \\
\hline$l$ & length \\
\hline$r$ & radius \\
\hline$\varepsilon_{0}$ & electric constant $\left(\approx 8.854 \times 10^{-12} \mathrm{~F} / \mathrm{m}\right)$ \\
\hline
\end{tabular}

Figure E-6. Self-capacitance calculator at www.wolframalpha.com

\section{E.7.2 Self-Inductance calculator}

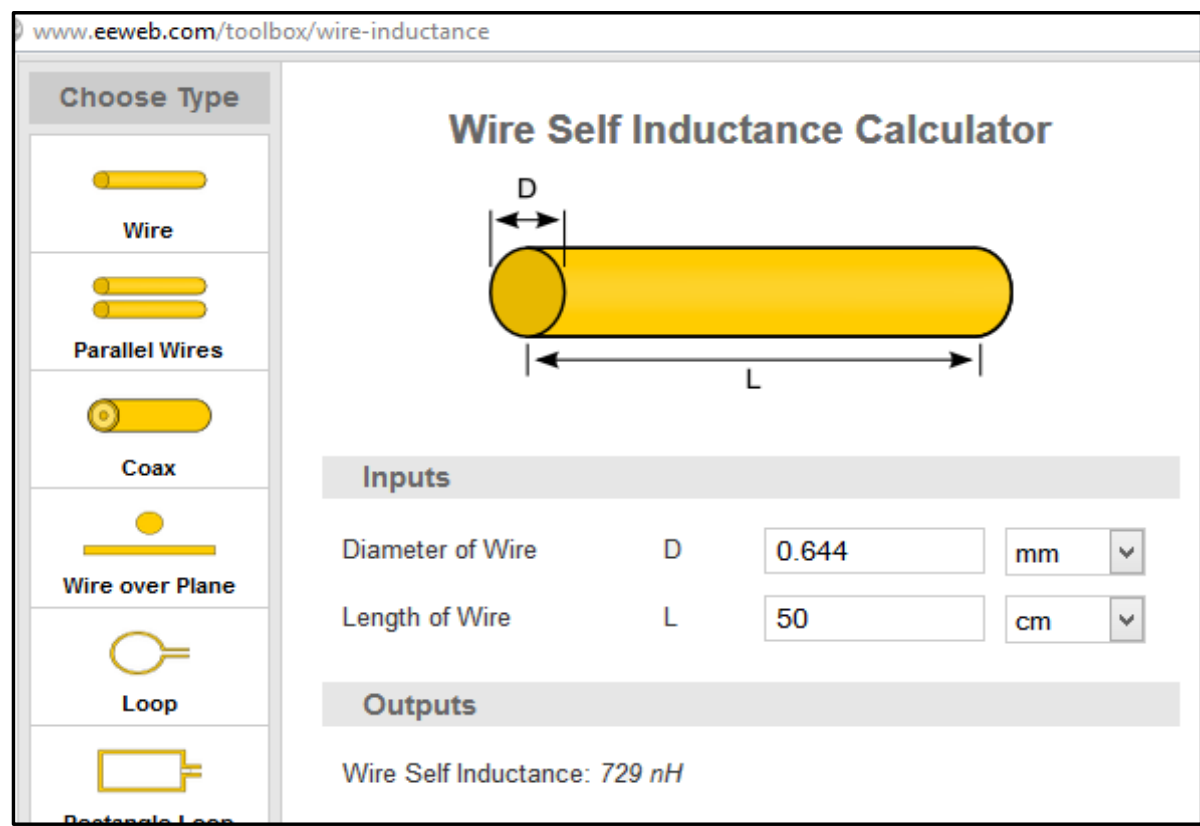

Figure E-7. Self-inductance calculator from www.eeweb.com/toolbox/wire-inductance 


\section{Self-Inductance Details}

The inductance of a single conductor is called self-inductance. Self-inductance is not typically measured, since it is only part of a complete circuit loop.

The inductance calculated by the tool above is the self-inductance. The self-inductance is used in some simulations and is part of the total loop inductance. In this tool, the variables required are the wire length and the wire diameter. Notice that there is not a return path referenced in this inductance estimator. When calculating a loop inductance, the self-inductance as well as the mutual inductance to the return path and the return paths self-inductance is accounted for. It is assumed that the mutual inductance between different portions of the circuit is negligible. 


\section{APPENDIX F. $\quad$ DATA ACQUISITION PROGRAM SOURCE CODE}

Program Tek492;

//const

filename='D: \marius $\backslash S C H O O L \backslash T H z \backslash$ Measurements $\backslash 2013 \_04 \_20 \backslash$ shp800+dc_block_fin=5 $00 \mathrm{MHz}$ fc $=1 \mathrm{GHz} . \mathrm{csv}^{\prime}$;

$/ /$ const comment $=$ 'test_date $=04 / 20 / 2013$

shp800+dc_block_fin $=500 \mathrm{MHz} f \mathrm{fc}=1.003 \_\mathrm{GHz}, \mathrm{SA} \_$RF_Atten=20dB, Rev=-10dB.

RF_out=0dBm';

//const

filename='D:\marius $\backslash S C H O O L \backslash T H z \backslash M e a s u r e m e n t s \backslash 2013$ 04_20 $\backslash G$ raphene_on_Cu_LF_

WaveGuide_contact_fin $=500 \mathrm{MHz} f \mathrm{fc}=1 \mathrm{GHz}$ _VBias $=0.1 \mathrm{~V}$ _run5.csv';

$/ /$ const comment $=$ 'test_date $=04 / 20 / 2013$

Graphene_on_Cu_LF_WaveGuide_contact_fin $=500 \mathrm{MHz} f \mathrm{fc}=1 \mathrm{GHz} V$ Bias $=0.1 \mathrm{~V}$ run5';

//const

filename='D:\marius $\backslash S C H O O L \backslash T H z \backslash M e a s u r e m e n t s \backslash 2013 \_04 \_20 \backslash$ sample152n+p+_conta

ct_fin $=500 \mathrm{MHz} \_\mathrm{fc}=1 \mathrm{GHz}$ VBias $=0.0 \mathrm{~V} \_$run5.csv';

$/ /$ const comment $=$ 'test_date $=04 / 20 / 2013$

sample152n+p+_LF_WaveGuide_contact_fin $=500 \mathrm{MHz} f \mathrm{fc}=1 \mathrm{GHz}$ VBias $=0.0 \mathrm{~V}$ run5';

const

filename='D:\marius \SCHOOL\THz \Measurements \2013_05_15\LF_Waveguide_LPFilter s+BiasT_unattenuated_fin $=500 \mathrm{MHz} 200 \mathrm{MHzPer}$.fc $=2.5 \mathrm{GHz}$ RefLevel $=-10 \mathrm{dbm}$ tweaked.csv';

const comment $=$ 'test_date $=05 / 26 / 2013$

LF_Waveguide_LPFilters+BiasT_unattenuated_fin $=500 \mathrm{MHz} 200 \mathrm{MHzPer} f \mathrm{fc}=2.5 \mathrm{GHz}$.Ref Level=-10dbm tweaked';

type

TPoint $=$ record

fr : double;

Iv : double;

end;

type

TTek49xSet $=$ record

valid_data : Boolean;

FINE : Boolean;

DELFR : Boolean; 


$$
\begin{aligned}
& \text { FRQRNG : integer; } \\
& \text { EXMXR : Boolean; } \\
& \text { MINATT : integer; } \\
& \text { RLMODE : String; } \\
& \text { REFLVL : integer; } \\
& \text { VRTDSP : String; } \\
& \text { FREQ : Double; } \\
& \text { SPAN : Integer; } \\
& \text { PHSLK : Boolean; } \\
& \text { IDENT : Boolean; } \\
& \text { RESBW : String; } \\
& \{\ldots . . .\} \\
& \text { ENCDG : String; } \\
& \text { POINT : Integer; } \\
& \text { RQS : Boolean; } \\
& \text { EOS : Boolean; } \\
& \text { end; } \\
& \text { TTek49xDpre }=\text { record } \\
& \text { valid_data : Boolean; } \\
& \text { XGRAT : Double; } \\
& \text { XCENT : Double; } \\
& \text { DXZERO : Double; } \\
& \text { DXMULT : Double; } \\
& \text { XDIV : Double; } \\
& \text { YGRAT : Double; } \\
& \text { YCENT : Double; } \\
& \text { DYZERO : Double; } \\
& \text { DYMULT : Double; } \\
& \text { YDIV : DOUBLE; } \\
& \text { end; } \\
& \text { TTek49xWFMPRE = record } \\
& \text { valid_data : Boolean; } \\
& \text { WFID : String; } \\
& \text { ENCDG : String; } \\
& \text { NRPT : Integer; } \\
& \text { XINCR : Double; } \\
& \text { XZERO : Double; } \\
& \text { XUNIT : String; } \\
& \text { YOFF : Double; } \\
& \text { YMULT : Double; }
\end{aligned}
$$




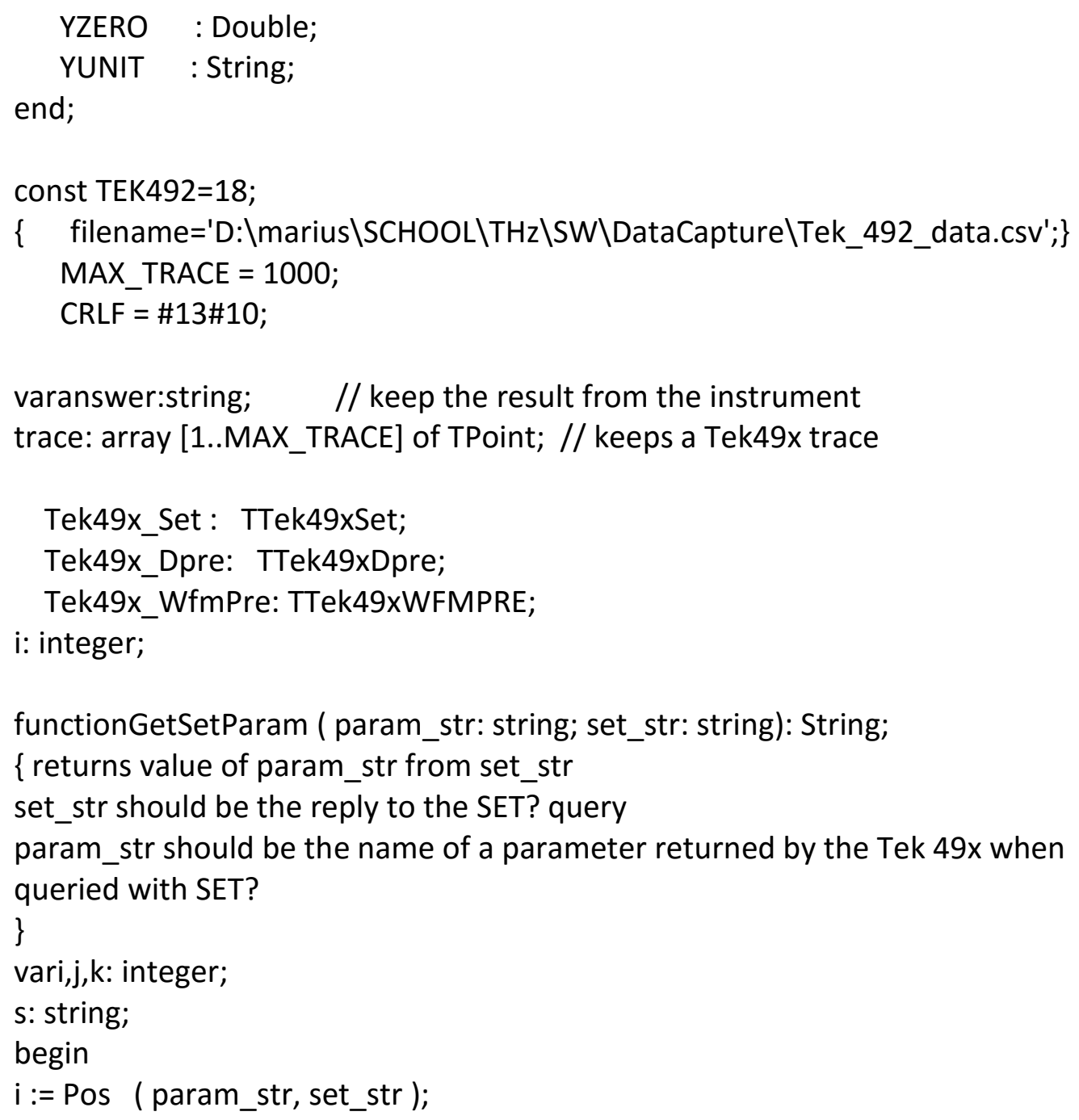




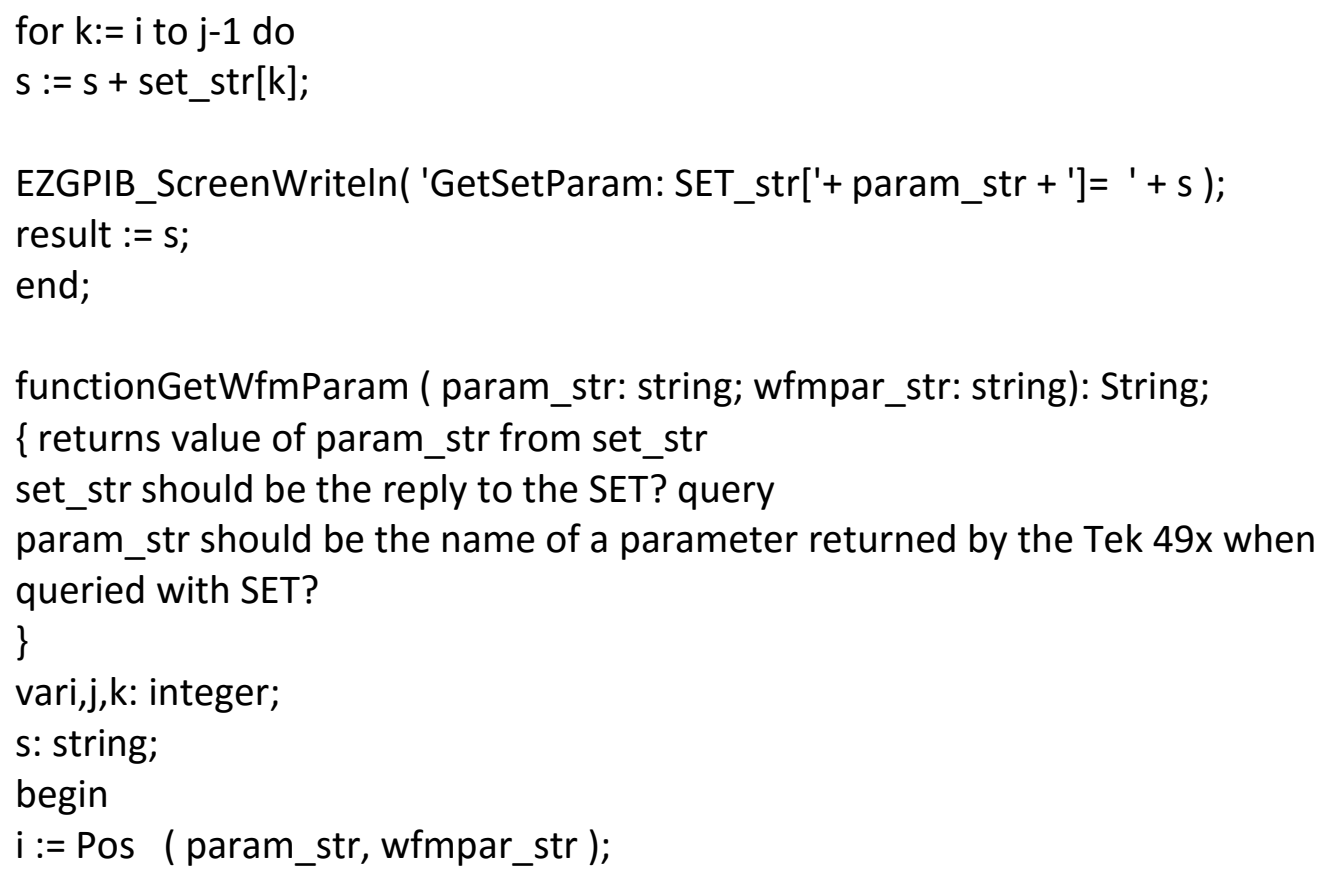




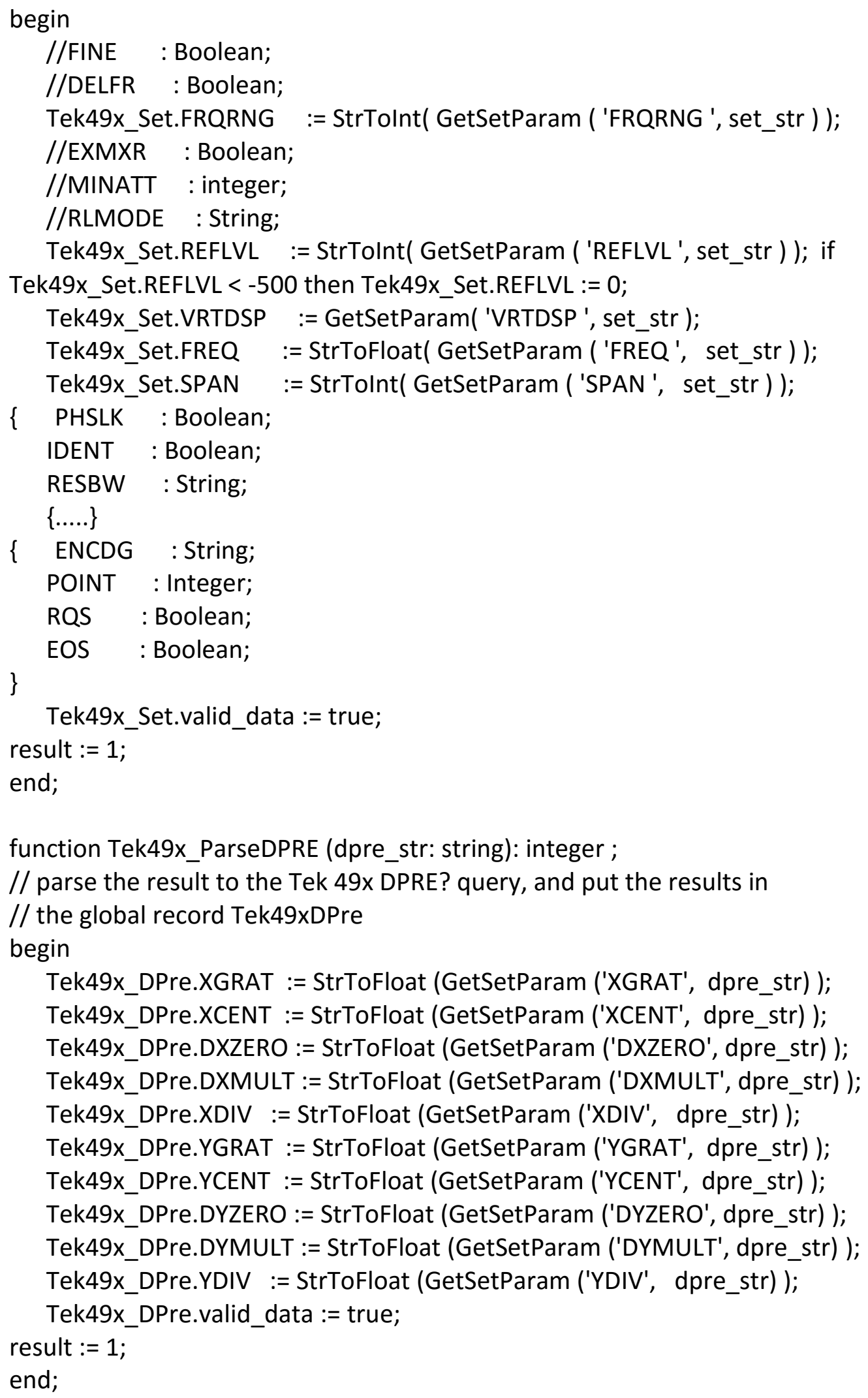


function Tek49x_ParseWFMPRE (dpre_str: string): integer ;

// parse the result to the Tek 49x DPRE? query, and put the results in

// the global record Tek49xDPre

begin

Tek49x_WfmPre.XINCR := StrToFloat (GetWfmParam ('XINCR', dpre_str) );

Tek49x_WfmPre.XZERO :=StrToFloat (GetWfmParam ('XZERO', dpre_str));

Tek49x_WfmPre.YOFF := StrToFloat (GetWfmParam ('YOFF', dpre_str));

Tek49x_WfmPre.YMULT :=StrToFloat (GetWfmParam ('YMULT', dpre_str) );

Tek49x_WfmPre.YOFF := StrToFloat (GetWfmParam ('YOFF', dpre_str));

Tek49x_WfmPre.YZERO :=StrToFloat (GetWfmParam ('YZERO', dpre_str));

Tek49x_WfmPre.YUNIT := (GetWfmParam ('YUNIT', dpre_str));

Tek49x_WfmPre.valid_data := true;

result := 1;

end;

functionnext_token (var s: string): string ;

// pops and returns the next token from the beginning of $s$, and shrinks $s$

// delimiters are , ; or space

var i: integer;

delimiter_found: boolean;

rs: string;

d: string;

begin

$\mathrm{d}:=$ ',; ';

rs := ";

$\mathrm{i}:=1$;

delimiter_found := false;

while $(i<=$ length (s) ) do

begin

//EZGPIB_ScreenWrite $\left(d+{ }^{\prime}\right.$ "'+s[i] + d[1] + '"');

if $s[i]<>d[1]$ then

begin

$r s:=r s+s[i] ;$

//EZGPIB_ScreenWrite ('+');

end else

begin

delimiter_found := True;

//EZGPIB_ScreenWrite ('-');

break;

end;

inc (i); 
end;

if ( delimiter_found) then

$\mathrm{s}:=\operatorname{copy}(\mathrm{s}, \mathrm{i}+1$, length $(\mathrm{s}))$;

result :=rs;

end;

function Tek49x_CurveParse (curve_str: string): integer ;

// parses the result to the CURVE? query without scaling it.

// one should call Tek49x_CurveScale () to scale the result to the appropriate

// freq/vert range

vari,j: integer;

s, s2: string;

begin

$\mathrm{i}:=\operatorname{Pos}($ ', ', curve_str );

$s:=$ copy (curve_str, i+1, length (curve_str) );

//EZGPIB_ScreenWriteln( CRLF + CRLF + s + CRLF + CRLF );

$\mathrm{j}:=1$;

while ( length (s) $>0$ ) do

begin

//EZGPIB_ScreenWrite( Length (s) );

s2 := next_token (s) ;

trace[j].Iv := StrTolnt ( s2);

//EZGPIB_ScreenWrite( s2 + '=' + EZGPIB_ConvertStripToNumber(trace[j].Iv) + '\%' );

$\operatorname{inc}(j)$;

if $\mathrm{j}>$ MAX_TRACE then break; // safety

end ;

result := j-1;

end;

procedure Tek49x_CurveClear ();

// must be used before Tek49x_CurveParse to reset values

var i:integer;

begin

for $\mathrm{i}:=1$ to MAX_TRACE do

begin

trace[i].fr := i; 


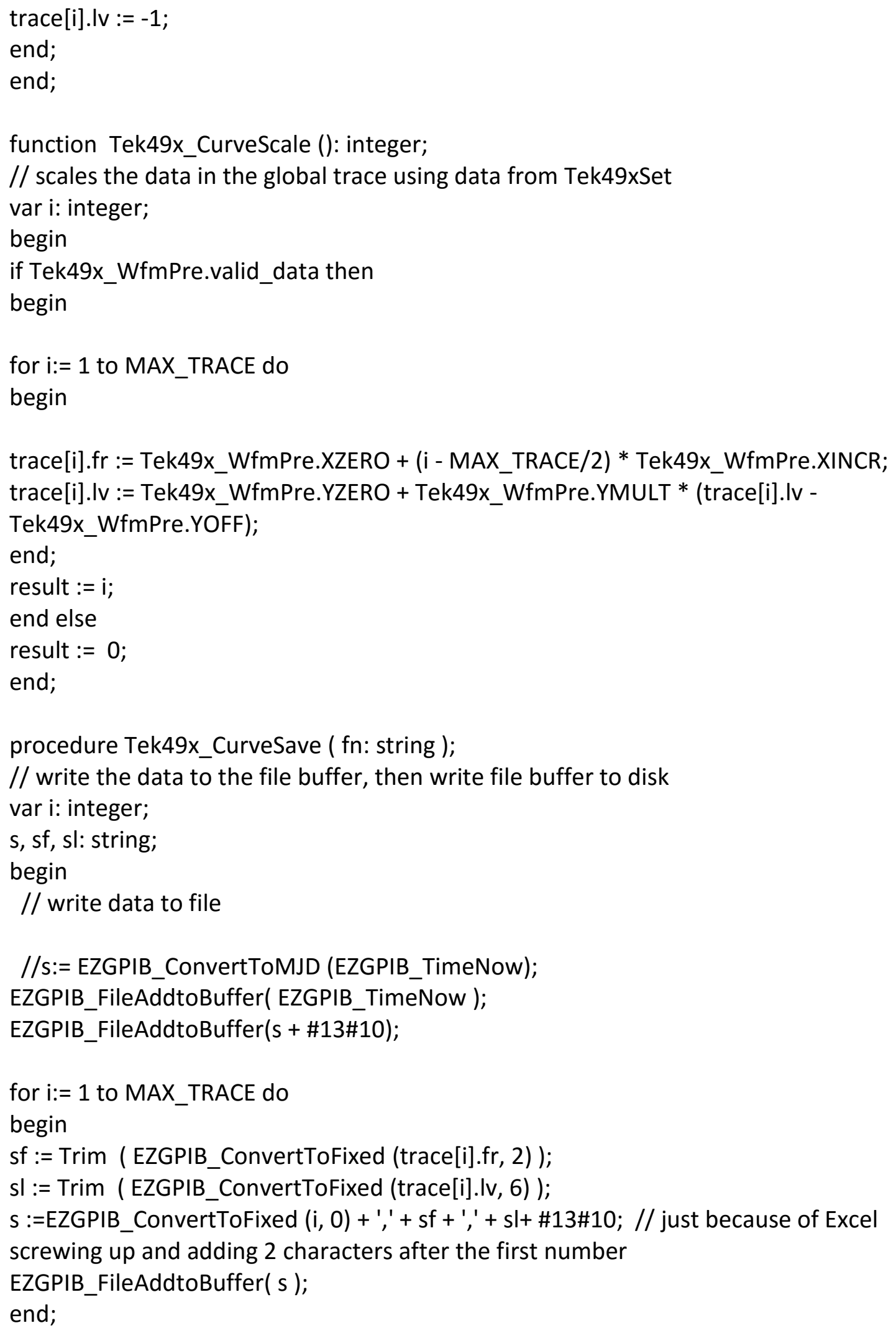




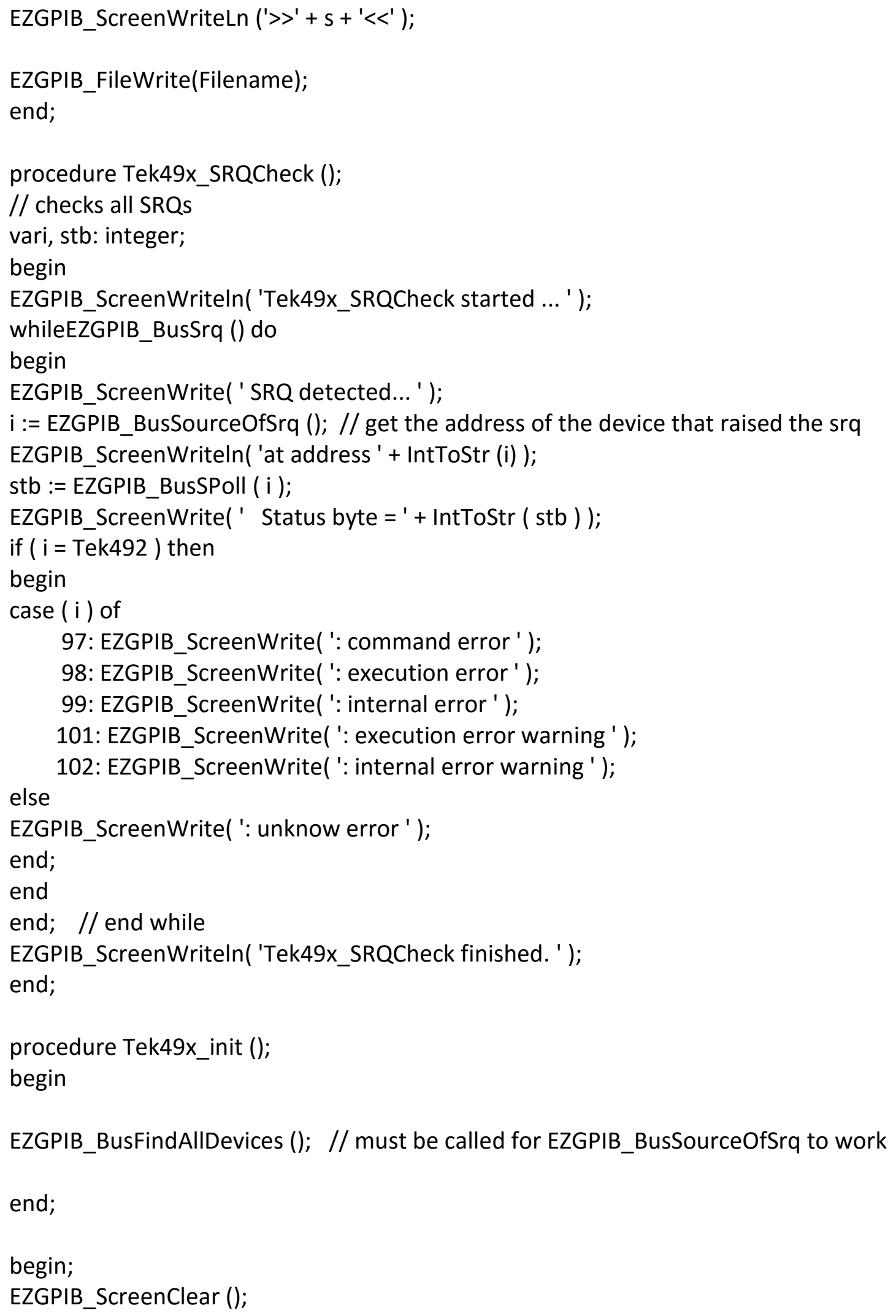


Tek49x_Set.valid_data := False;

Tek49x_DPre.valid_data := False;

Tek49x_WfmPre.valid_data := False;

Tek49x_init ();

EZGPIB_ScreenClear;

EZGPIB_FileDelete(Filename);

EZGPIB_FileClearBuffer;

EZGPIB_FileAddtoBuffer (comment +\#13\#10);

EZGPIB_buswritedata(TEK492,'ID?');

EZGPIB_buswaitfordata(TEK492,answer,20.0);

EZGPIB_ScreenWriteln (Answer);

if ( Pos ('TEK/49', answer) < 1 ) then

begin

EZGPIB_ScreenWriteln ('Tek 49x not found. Program cannot continue.');

exit;

end else

EZGPIB_ScreenWriteln( 'Tek 49x found');

// acquire settings

EZGPIB_buswritedata( TEK492, 'SET?');

EZGPIB_buswaitfordata( TEK492, answer, 20.0);

EZGPIB_ScreenWriteln ('sent: "SET?"; received: ' + Answer );

Tek49x_ParseSet (Answer);

EZGPIB_FileAddtoBuffer( Answer + \#13\#10);

//EZGPIB_buswritedata( TEK492, 'STSTOP' );

EZGPIB_TimeSleep( 2 );

// execute a sweep

EZGPIB_buswritedata ( Tek492, 'SIGSWP' );

EZGPIB_TimeSleep ( 3 ); // allow 3 seconds for the sweep to take place

// acquire a curve

EZGPIB_buswritedata ( TEK492, 'WAIT;CURVE?');

EZGPIB_buswaitfordata(TEK492,answer,20.0);

Tek49x_SRQCheck (); 


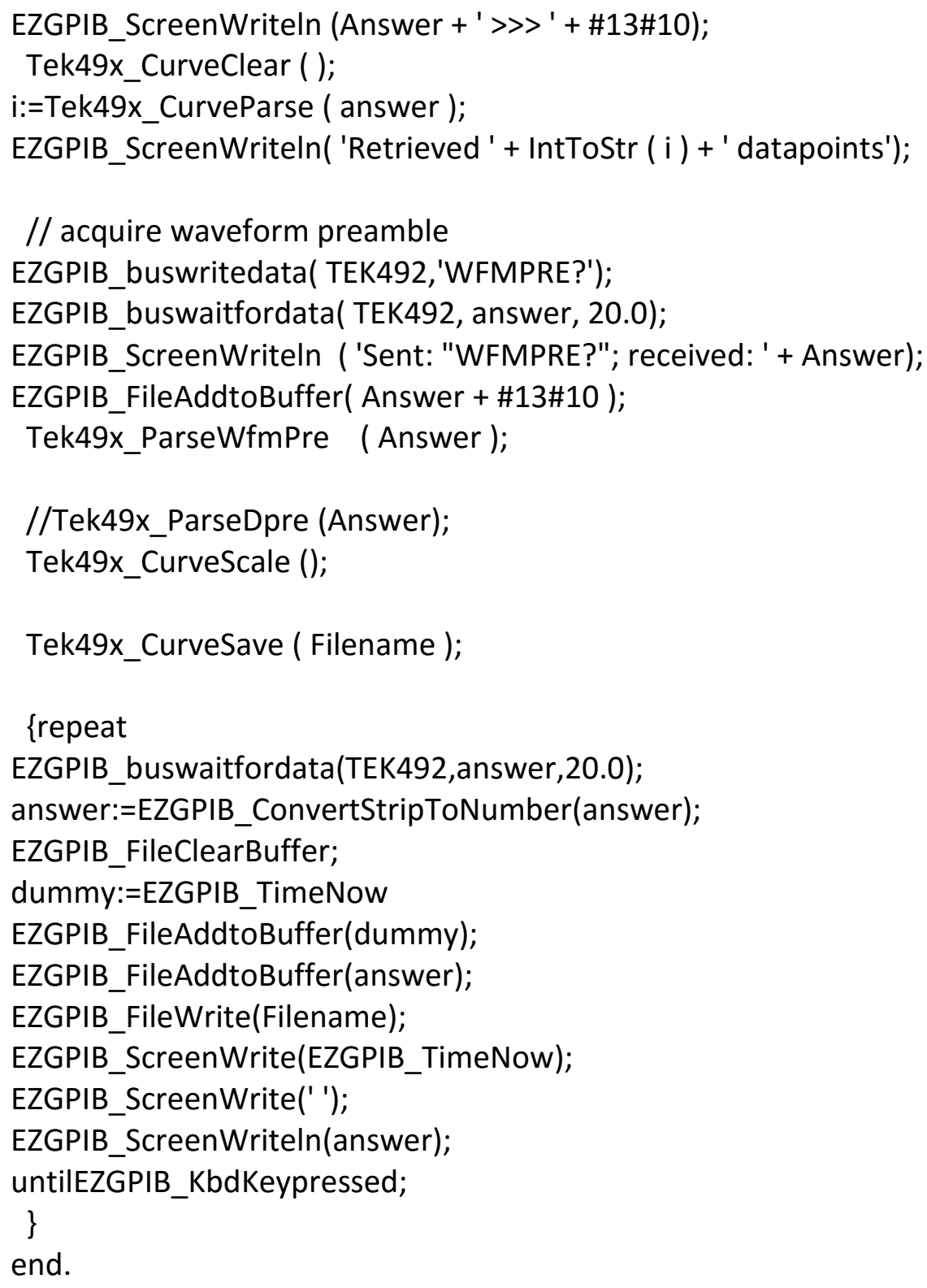

